\title{
Growing knowledge
}

Citation for published version (APA):

Rovers, S. F. E. (2020). Growing knowledge: supporting students' self-regulation in problem-based learning. [Doctoral Thesis, Maastricht University]. Maastricht University. https://doi.org/10.26481/dis.20200916sr

Document status and date:

Published: 01/01/2020

DOI:

10.26481/dis.20200916sr

Document Version:

Publisher's PDF, also known as Version of record

\section{Please check the document version of this publication:}

- A submitted manuscript is the version of the article upon submission and before peer-review. There can be important differences between the submitted version and the official published version of record.

People interested in the research are advised to contact the author for the final version of the publication, or visit the DOI to the publisher's website.

- The final author version and the galley proof are versions of the publication after peer review.

- The final published version features the final layout of the paper including the volume, issue and page numbers.

Link to publication

\footnotetext{
General rights rights.

- You may freely distribute the URL identifying the publication in the public portal. please follow below link for the End User Agreement:

www.umlib.nl/taverne-license

Take down policy

If you believe that this document breaches copyright please contact us at:

repository@maastrichtuniversity.nl

providing details and we will investigate your claim.
}

Copyright and moral rights for the publications made accessible in the public portal are retained by the authors and/or other copyright owners and it is a condition of accessing publications that users recognise and abide by the legal requirements associated with these

- Users may download and print one copy of any publication from the public portal for the purpose of private study or research.

- You may not further distribute the material or use it for any profit-making activity or commercial gain

If the publication is distributed under the terms of Article $25 \mathrm{fa}$ of the Dutch Copyright Act, indicated by the "Taverne" license above, 


\section{GROWING KNOWLEDGE}

Supporting students' self-regulation in

problem-based learning

Sanne F.E. Rovers 
The research reported here was carried out at

Maastricht University 4 Maastricht UMC+

in the School of Health Professions Education

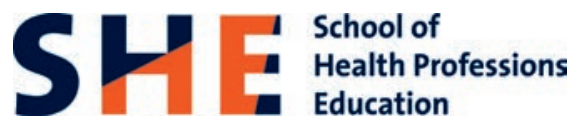

in the context of the research school

\section{ico}

(Interuniversity Center for Educational Research)

Sanne F. E. Rovers

Growing knowledge: Supporting students' self-regulation in problem-based learning

Book design \& illustrations: Ilse Schrauwers, isontwerp.nl

Printing: Ipskamp Printing Maastricht

ISBN: 9789492303356

Copyright (c) Sanne Rovers, 2020 Maastricht.

The copyright of articles that have been published has been transferred to the respective journals. No other parts of this publication may be reproduced, distributed, or transmitted in any form or by any means, including photocopying, recording, or other electronic or mechanical methods, without the prior written permission of the author. 


\section{GROWING KNOWLEDGE}

Supporting students' self-regulation in

problem-based learning

\section{Proefschrift}

ter verkrijging van de graad van doctor aan de Universiteit Maastricht, op gezag van de Rector Magnificus, Prof. dr. Rianne M. Letschert, volgens het besluit van het College van Decanen,

in het openbaar te verdedigen

op woensdag 16 september 2020 om 16:00 uur

door

Sanne Francisca Else Rovers 


\section{Promotores}

Prof. dr. J.J.G. van Merriënboer

Prof. dr. A.B.H. de Bruin

Prof. dr. H.H.C.M. Savelberg

\section{Beoordelingscommissie}

Prof. dr. S. Heeneman (voorzitter)

Prof. dr. S.E. Köhler

Prof. dr. M.C.A. oude Egbrink

Prof. dr. A. Renkl (Albert-Ludwigs-Universität Freiburg)

Prof. dr. M.F. van der Schaaf (Universiteit Utrecht) 


\section{Table of Contents}

Chapter 1

General Introduction

Chapter 2

How and why do students use learning strategies?

A mixed methods study on learning strategies and desirable difficulties

with effective strategy users

Chapter 3

50

Granularity matters: Comparing different ways of measuring self-regulated learning

Chapter 4

Improving student expectations of learning in a problem-based environment

Chapter 5

The effects of a Biomedical Sciences curriculum reform on students'

perceived competency development

Chapter 6

General Discussion

Summaries

English summary

Nederlandse samenvatting

Appendix

Valorization

Acknowledgements

About the author

SHE dissertation series

ICO dissertation series 


\section{GHAPTERI}

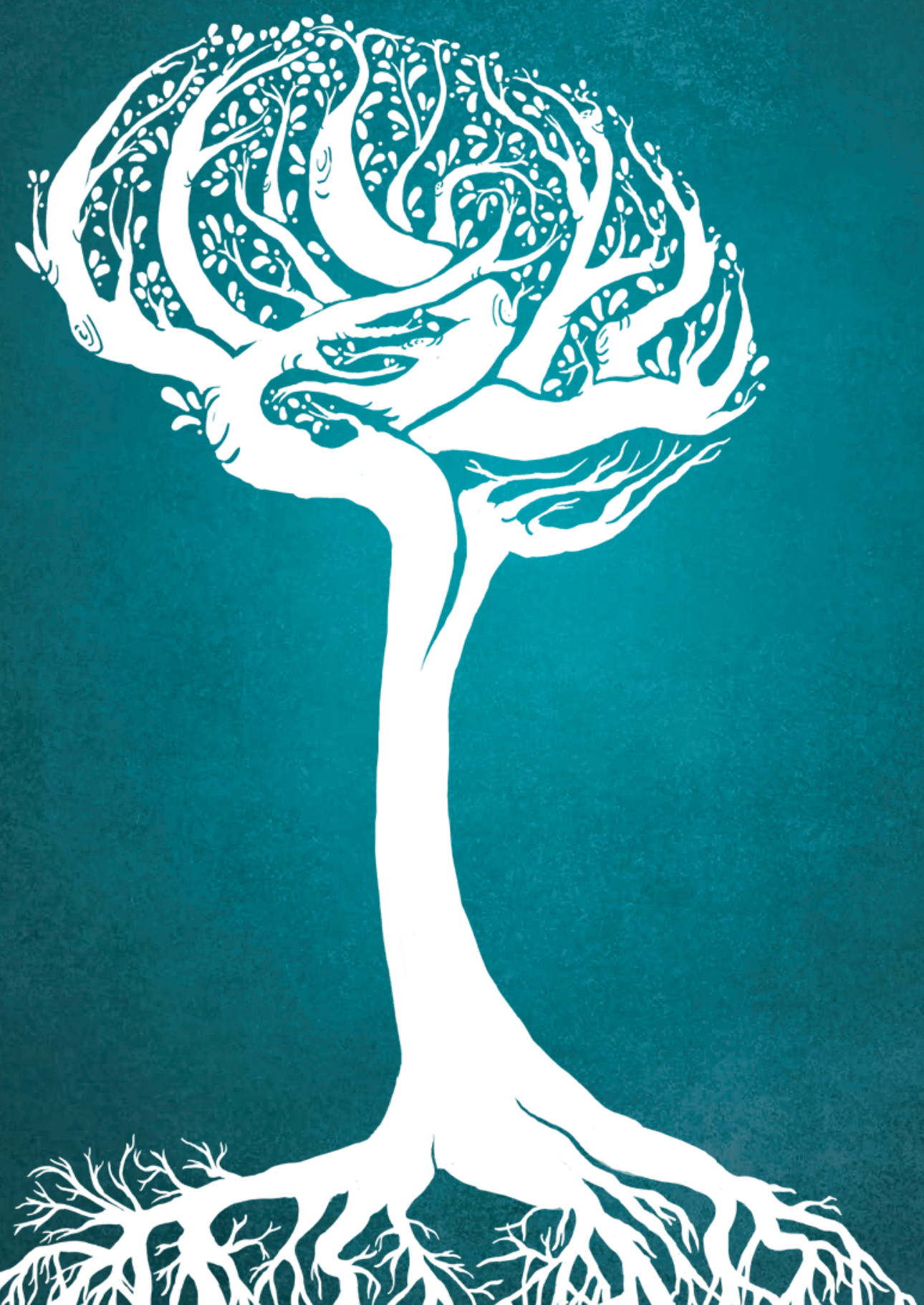




\section{Ceneral Introduction}

Lifelong learning has become an important hallmark of higher medical education (Skinner et al., 2015). Cenerally, it has been promoted as a way to prepare people for a rapidly changing world, in which it is not possible to provide students in school with all the knowledge and skills that will be required from them throughout their working lives (Sharples, 2000). Also specific to health professions education, researchers have emphasized the importance of lifelong learning for medical professionals in order to stay up to date in their profession (Frankford, Patterson, \& Konrad, 2000; Murdoch-Eaton \& Whittle, 2012; Teunissen \& Dornan, 2008). Developing lifelong learning skills places a heavy demand on students' self-regulated learning $(\mathrm{SRL})$ abilities, as it requires them to take the initiative to instigate this learning and to use appropriate strategies in order to be effective, and therefore requires students' self-regulated learning abilities to be appropriately developed during their formal education (Skinner et al., 2015). However, this is often neglected in problem-based learning (PBL) curricula (Silén \& Uhlin, 2008), which is the dominant educational approach at Maastricht University.

In this dissertation, we aim to investigate how self-regulation can be improved in (bio)medical students in a problem-based curriculum. This introduction first provides a description of the PBL approach and the research that has been conducted regarding its effects on student learning. After this, we describe the considerations around promotion and measurement of SRL in a PBL context. We conclude by specifying the research questions for the respective studies in the dissertation, followed by a description of the different chapters.

\section{What is problem-based learning?}

Problem-based learning (PBL) is an educational approach that is characterized by contextual, collaborative, constructive, and self-directed or self-regulated learning (Dolmans, De Grave, Wolfhagen, \& Van Der Vleuten, 2005). In order for learning to be contextual, real-world professional cases are presented to students as the basis for learning. Due to the contextspecific nature of learning (Pintrich, 1999), the alignment of the learning context to realworld professional practice is assumed to enhance students' transfer of knowledge from the academic learning context to their future careers (Könings, Brand-Gruwel, \& Van Merriënboer, 2005). Students work on these problems in small groups called tutorials, ideally consisting of roughly 8 to 10 students (although in practice, groups often consist of 12 students or even more). This constitutes the collaborative nature of learning in $\mathrm{PBL}$, in which students learn from each other by jointly creating explanations for the problem at hand (Hmelo-Silver, 
2004). The constructivist theory of learning states that learning is enhanced when students can embed the newly offered information to their own experiences and already existing prior knowledge (Ertmer \& Newby, 1993). The tutorial group process is instrumental in this regard, as it activates students' prior knowledge and promotes elaboration on the learning content (Dolmans, Wolfhagen, Van der Vleuten, \& Wijnen, 2001). Finally, learning in PBL is assumed to be self-regulated, as students themselves are made responsible for their own learning goals and strategies to solve the problem presented (Hmelo-Silver, 2004).

Although theoretically, many different ways could be contrived to make learning in PBL contextual, collaborative, constructive and self-regulated, at Maastricht University the PBL process traditionally consists of seven steps, often referred to as the "Seven-Jump" (Schmidt, 1983). In the first step, unknown terms and concepts referred to in the problem are clarified. After this, a problem definition is constructed (step two). As a third step, students engage in a collaborative brainstorm, using their prior knowledge to analyze what they already know about the problem, and come up with potential explanations, which are clustered into a coherent model based on underlying themes. During this process, students are expected to find elements in the problem that they cannot yet explain, i.e. gaps in their knowledge (step four). In the fifth step, students use these gaps in their knowledge to formulate explicit questions about the problem that they will study further, which are called learning issues. After this, the tutorial group disbands and students proceed to study learning resources that are relevant to the learning issues individually (step six), attempting to come up with explanations. After a few days, the tutorial group reconvenes for students to present their findings to each other (step seven). Based on all individual students' explanations, students attempt to come up with a joint solution to the problem by attempting to integrate their different findings and resolve potential conflicts in information (Moust, Van Berkel, \& Schmidt, 2005; Schmidt, 1983; Schmidt, Van der Arend, Kokx, \& Boon, 1993).

In their recent review on meta-analyses and reviews of PBL research from 1992 onwards, Hung, Dolmans and Van Merriënboer (2019) identified three waves of research on PBL. The first wave of research focused on the basic question of whether or not PBL works. In other words, does it have a positive effect on students' learning outcomes? In the second wave, researchers started focusing on the process of PBL, investigating how the approach influences the learning outcomes. Finally, the third wave was characterized by an increased focus on the contexts in which PBL takes place, and how this influences the process and effects (Hung et al., 2019).

Research has shown positive effects of PBL on students' learning processes and outcomes. For example, Strobel and Van Barneveld (2009) found in their meta-synthesis, consisting of eight meta-analyses and systematic reviews, that PBL had a positive influence on students' long-term retention of learning content and development of skills, when compared to more traditional approaches to teaching. Furthermore, student satisfaction was higher in PBL curricula (Colliver, 2000; Newman, 2003; Strobel \& Van Barneveld, 2009). Other authors have 
reported positive effects on deep learning and conceptual understanding of topics (Berkson, 1993; Gijbels, Dochy, Van den Bossche, \& Segers, 2005).

Despite these promising findings, other reports have warned that the PBL approach has lost a large part of its effectiveness over the years (Dolmans et al., 2001; Moust et al., 2005; Woltering, Herrler, Spitzer, \& Spreckelsen, 2009). Students seem to grow tired of PBL and the associated steps after having been exposed to the approach for a while (Czabanowska, Moust, Meijer, Schröder-Bäck, \& Roebertsen, 2012), and as a result tend to skip important aspects of the PBL cycle. As these steps reflect the underlying principles of contextual, collaborative, constructive and self-regulated learning, this tendency can have detrimental effects on students' learning (Moust et al., 2005).

\section{Promoting and measuring SRL in PBL}

First and foremost, an important distinction to make is that between self-directed learning $(\mathrm{SDL})$ and self-regulated learning (SRL). The definitions of these terms are not always clear, and they are often used interchangeably in the literature (Loyens, Magda, \& Rikers, 2008; Saks \& Leijen, 2014). For the purpose of this dissertation, it is important to start out by making this distinction more transparent. Loyens et al. (2008) state that the range of processes covered by SDL is broader than that implicated in SRL. SDL entails students' independent pursuit of learning over the span of different courses and programs, whereas SRL is limited to independent learning within a specific learning task (Jossberger, Brand-Gruwel, Boshuizen, \& Van de Wiel, 2010; Loyens et al., 2008). Although PBL places a high demand on students' independent learning, it primarily does so within the context of set courses in a set curriculum. As such, we will be referring to this process of independent learning as SRL, rather than SDL.

The self-study phase (i.e., step 6 in the Seven-Jump) has been a particularly troublesome aspect of the PBL cycle (Moust et al., 2005), which in addition has been difficult to study, as it mostly takes place individually, outside of the tutorial group. The amount of time students spend on self-study is not necessarily related to their academic achievement (Kamp, Dolmans, Van Berkel, \& Schmidt, 2012; Van den Hurk, Wolfhagen, Dolmans, \& Van der Vleuten, 1998), indicating that during this time spent on self-study, students might be using an ineffective approach to learning. Therefore, rather than putting emphasis on the time students spend studying, it might be more important to focus on the use of effective learning strategies. An important aspect of this problem is self-regulated learning, which includes both motivational as well as cognitive processes (Boekaerts, 1997; Pintrich, Wolters, \& Baxter, 2000).

Research indicates that students' identified learning issues do not always reflect how much time they spend on the corresponding topics, even when these learning issues were in fact the ones that were intended by the faculty members. In other words, students' actual behavior during self-study does not always conform with their intentions, as operationalized by the 
learning issues (Dolmans, Schmidt, \& Gijselaers, 1995). Apparently, students get distracted by other, possibly irrelevant information. A possible reason for this divergence could be an initial discrepancy between the way of teaching and learning students know from schooling thus far, and the problem-based learning approach, which places a lot of emphasis on students' active, self-regulated behavior. In high school, students have been exposed to a teacher-based approach (Könings, Brand-Gruwel, \& Van Merriënboer, 2007), and as such, they are not used to this new, problem-based way of learning (Raidal \& Volet, 2009). Research shows that students have a preference to work according to their own learning habits (Vermetten, Vermunt, \& Lodewijks, 2002). Therefore, the incongruence between their preferred way of working and the learning environment they find themselves in may cause them to revert to a non-problembased way of working during the self-study phase. For example, studies indicate that students in a PBL environment can feel uncertainty about what to study and as a result, rely on externally provided resources (Dolmans \& Schmidt, 1994; Lloyd-Jones \& Hak, 2004). In other words, instead of displaying behaviors appropriate for PBL (following self-defined learning issues, independently searching for literature to share with fellow students in the tutorial group, and using learning strategies that facilitate deep learning such as elaboration), students might rely solely on faculty-provided literature and use ineffective learning strategies like memorizing. Rather than employing easy-to-use, surface-level strategies that are only effective for the short term, students should be motivated to use more effortful strategies, which lead to better results in the long term, incorporating so-called 'desirable difficulties' into their learning (Bjork, 1994). When these suboptimal behaviors are turned into habits, it will be difficult to change them later on in the curriculum. In the remainder of this section, we will discuss the issues associated with SRL in PBL which are relevant to the studies reported on in this dissertation.

Throughout the years, several SRL models have been put forward (e.g., Pintrich, 2004; Winne \& Hadwin, 1998; Zimmerman, 2002). According to the framework of Zimmerman (2002), self-regulated learning consists of three cyclical phases: forethought, performance and reflection. The forethought phase involves activities before learning and consists of task analysis and self-motivation beliefs. The performance phase, occurring during the learning process itself, consists of self-control and self-observation. After learning, students go through the self-reflection phase, which consists of self-judgment and self-reaction. In terms of PBL, the forethought phase is related to the first five steps of the Seven-Jump. In the performance phase, PBL students should be monitoring whether they are achieving their learning issues, and adjust their study behavior when necessary. The reflection phase is related to the final stages of the PBL process, in which students compare and synthesize their acquired information, and decide whether they have successfully accomplished the learning issues.

As mentioned above, one of the reasons for ineffective self-regulation in students might be a mismatch between the expectations they have about their learning environment when entering university on the one hand, and the expectations set forth by the university on the 
other. One approach to improving students' self-regulated learning could therefore be to align students' expectations to those set forth by the university. When students know what is expected of them in a PBL environment and why, they may have an increased willingness to work with these expectations, and show increased efforts and subsequent performance in self-regulating their learning.

The curriculum can be another way to address students' self-regulation and learning experiences. Recent years have seen a shift in medical education towards competency-based curricula (Frank et al., 2010). As competency-based curricula tend to offer students a large degree of autonomy over their learning process and the monitoring of their progress, they have been indicated to foster students' development of lifelong learning abilities, as lifelong learning requires students to learn how to identify and address learning needs throughout their entire professional lives (Harris, Snell, Talbot, Harden, \& for the International CBME Collaborators, 2010).

Self-regulated learning, in PBL specifically and in education more generally, has proven difficult to measure. This is an important issue, as we need reliable and valid measurement instruments in order to measure potential effects of any interventions aimed at improving students' SRL. Traditionally, questionnaires have been employed to assess students' self-reported use of SRL strategies (Panadero, Klug, \& ]ärvelä, 2016; Schellings \& Van Hout-Wolters, 2011), with common assessment instruments being the Motivated Strategies for Learning Questionnaire (MSLQ; Pintrich, Smith, Garcia, \& McKeachie, 1993), the Metacognitive Awareness Inventory (MAl; Schraw \& Dennison, 1994), and the Learning and Study Strategies Inventory (LASSI; Weinstein \& Palmer, 2002). However, the use of self-report questionnaires has been criticized for a variety of reasons (e.g., Veenman, Van Hout-Wolters, \& Afflerbach, 2006; Winne, Jamieson-Noel, \& Muis, 2002; Winne \& Perry, 2000). These criticisms tend to focus around two themes.

First and foremost, researchers have expressed concern about whether or not students are actually able to provide accurate self-report regarding their own self-regulatory strategy use. A first problem concerns social desirability: students might report the use of strategies they think will be considered as 'good', in order to make a favorable impression on others (Bråten \& Samuelstuen, 2007). Related to this, students might unintentionally conflate the value they ascribe to a certain strategy with how much they actually use it (Bernacki, Byrnes, \& Cromley, 2012; Bråten \& Samuelstuen, 2007), or might incorrectly label their learning strategies in selfreport questionnaires due to a lack of metacognitive knowledge (Veenman, 2011). Finally, students' self-reports could be influenced simply by memory deficits. For example, researchers have indicated that students might have better memory for strategies they commonly use, while undervaluing the occurrence of the ones used infrequently (Perry \& Winne, 2006; Tourangeau, Rips, \& Rasinski, 2000).

Secondly, concerns have been raised regarding the tendency for self-report questionnaires to treat SRL as a stable, static attribute, whereas SRL should actually be conceptualized as a context-dependent, dynamic process of learning. For example, students' motivation and their 
corresponding use of strategies will not be constant, but rather will vary during their learning process (Moos \& Azevedo, 2008). Most self-report questionnaires are not able to capture these fluctuations. Furthermore, on a broader level, students will need different strategies for different contexts and learning tasks (Bråten \& Samuelstuen, 2007; McCardle \& Hadwin, 2015; Winne \& Hadwin, 1998). As the context from which students are required to report their strategies is often unclear in self-report questionnaires (Perry \& Winne, 2006), results from self-report questionnaires may be muddled.

\section{Research questions}

The central research question in this dissertation is as follows: How can we support (bio)medical students' self-regulated learning in a problem-based curriculum? We aimed to answer this general research question by focusing on three aspects. First, in order to serve as a basis for the development of effective interventions to support SRL, it is important to consider what effective self-regulation in a PBL curriculum actually is and ideally looks like. Second, in order to properly assess potential effects of any interventions, it is important to have a clear overview of the different forms of measurement available, and the methodological considerations associated with these different approaches. The final step then becomes the design of interventions in order to actually improve students' SRL strategy use. In this dissertation we focused on two facets of students' learning experience. First, we designed an intervention for students themselves, aimed at improving their expectations of learning in a PBL environment. When students know what is expected of them in a PBL environment and why, they may have an increased willingness to work with these expectations, and show increased efforts and subsequent performance in self-regulating their learning. Second, we focused on the level of the curriculum. Specifically, we looked into the effects of a curriculum redesign within the Biomedical Sciences bachelor program, and investigated whether this redesign had the expected effects on students' competence development. In summary, four sub-questions were identified:

- RQ1: How do highly effective self-regulating students in a PBL curriculum approach their learning? How do they incorporate desirable difficulties into this process?

- RQ2: How do offline self-report questionnaires compare to online forms of measurement in terms of calibration of students' self-report of strategy use, versus their actual strategy use? Does the degree of calibration vary as a function of the granularity at which SRL is measured?

- RQ3: Can students' SRL strategies be enhanced by means of a workshop aimed at aligning their perceptions and expectations about their learning environment to those of the university? Do students with different prior levels of SRL and realistic perceptions and expectations benefit differentially from this intervention? 
- RQ4: What are the effects of a curriculum reform toward competency-based education within the Biomedical Sciences bachelor program on students' selfperceived competency development?

\section{Outline of dissertation}

In this dissertation, we aim to answer the research questions outlined above by means of four different studies. In the first study (Chapter 2) we attempt to answer RQ1 by means of focus group interviews with medical students who had been identified by their mentors as effective in self-regulated learning. After having filled out a questionnaire inquiring about their use of different learning strategies, which was adapted from Hartwig and Dunlosky (2012), students took part in a focus group discussion aiming at gaining an understanding of how they used these strategies when learning. Four months after the first focus group, students participated in a second session in order to further discuss results and interpretations.

Chapter 3 describes the results of the second study, in which we conducted a narrative literature review aimed at answering RQ2. In this study, we compared different forms of measurement for SRL in terms of their calibration with students' behavioral measures of strategy use.

The third study aimed at answering RQ3, and is described in Chapter 4. In this study, firstyear medical students were randomly assigned to either a workshop focused at aligning their perceptions and expectations about their learning environment to those of the university with the aim of enhancing their use of effective SRL strategies, or to a control condition in which no workshop was provided. In a pretest-posttest control group design, we investigated the effects of the workshop on students' perceptions and expectations about their learning environment, and on their self-reported use of learning strategies.

In Chapter 5, we describe the results of a study conducted to answer RQ4. In order to answer this research question, two cohorts of Biomedical Sciences bachelor students were compared: one cohort of students who started their bachelor's program before the introduction of a new competency-based curriculum (implicated in the development of students' lifelong learning), and one cohort of students who started their bachelor's program after the new curriculum had been implemented. At the end of each of the three years of their bachelor's program, students were asked to fill out questionnaires aimed at measuring their self-perceived development of general academic competencies, as well as their self-efficacy for studying Biomedical Sciences. In order to gain a deeper insight into the results of the questionnaire, focus groups were organized at two points in this longitudinal study.

Chapter 6 provides the Ceneral Discussion of this dissertation, in which we discuss the findings from the different studies described above. Theoretical, practical and methodological considerations, implications and limitations are discussed. 


\section{References}

Berkson, L. (1993). Problem-based learning: Have the expectations been met? Academic Medicine, 68(10), S79-88. doi:10.1097/00001888-199310000-00053

Bernacki, M. L., Byrnes, J. P., \& Cromley, ]. G. (2012). The effects of achievement goals and self-regulated learning behaviors on reading comprehension in technology-enhanced learning environments. Contemporary Educational Psychology, 37(2), 148161. doi:10.1016/j.cedpsych.2011.12.001

Bjork, R. A. (1994). Memory and metamemory considerations in the training of human beings. In ]. Metcalfe \& A. Shimamura (Eds.), Metacognition: Knowing about knowing (pp. 185-205). Cambridge, MA: MIT Press.

Boekaerts, M. (1997). Self-regulated learning: A new concept embraced by researchers, policy makers, educators, teachers and students. Learning and Instruction, 7(2), 161-186. doi:10.1016/S0959-4752(96)00015-1

Bråten, I., \& Samuelstuen, M. S. (2007). Measuring strategic processing: Comparing task-specific self-reports to traces. Metacognition and Learning, 2(1), 1-20. doi:10.1007/s11409-007-9004-y

Colliver, J. A. (2000). Effectiveness of problem based learning curricula - Research and theory. Academic Medicine, 75(3), 259266.

Czabanowska, K., Moust, ]. H. C., Meijer, A. W. M., Schröder-Bäck, P., \& Roebertsen, H. (2012). Problem-based learning revisited, introduction of active and self-directed learning to reduce fatigue among students. Journal of University Teaching ELearning Practice, 9(1), 1-13.

Dolmans, D. H. J. M., De Grave, W., Wolfhagen, I. H. A. P., \& Van Der Vleuten, C. P. M. (2005). Problem-based learning: Future challenges for educational practice and research. Medical Education, 39, 732-741. doi:10.1111/j.1365-2929.2005.02205.X

Dolmans, D. H. J. M., \& Schmidt, H. G. (1994). What drives the student in problem-based learning? Medical Education, 28(5), 372-380. doi:10.1111/j.1365-2923.1994.tb02547.x

Dolmans, D. H. J. M., Schmidt, H. G., \& Gijselaers, W. H. (1995). The relationship between student-generated learning issues and self-study in problem-based learning. Instructional Science, 22, 251-267. doi:10.1007/BFoo891779

Dolmans, D. H. J. M., Wolfhagen, I. H. A. P., Van der Vleuten, C. P. M., \& Wijnen, W. H. F. W. (2001). Solving problems with group work in problem based learning - hold on to the philosophy. Medical Education, 35, 884-889. doi:10.1046/j.13652923.2001.00915.x

Ertmer, P. A., \& Newby, T. J. (1993). Behaviorism, cognitivism, constructivism: Comparing critical features from an instructional design perspective. Performance Improvement Quarterly, 6(4), 50-72. doi:10.1111/j.1937-8327.1993.tbo0605.x

Frank, J. R., Mungroo, R., Ahmad, Y., Wang, M., De Rossi, S., \& Horsley, T. (2010). Toward a definition of competency-based education in medicine: a systematic review of published definitions. Medical Teacher, 32(8), 631-637. doi:10.3109/014215 9X.2010.500898

Frankford, D. M., Patterson, M. A., \& Konrad, T. R. (2000). Transforming practice organizations to foster lifelong learning and commitment to medical professionalism. Academic Medicine, 75(7), 708-717.

Gijbels, D., Dochy, F., Van den Bossche, P., \& Segers, M. (2005). Effects of problem-based learning: A meta-analysis from the angle of assessment. Review of Educational Research, 75(1), 27-61. doi:10.3102/00346543075001027

Harris, P., Snell, L., Talbot, M., Harden, R. M., \& for the International CBME Collaborators. (2010). Competency-based medical education: implications for undergraduate programs. Medical Teacher, 32(8), 646-650. doi:10.3109/0142159X.2010.500703

Hartwig, M. K., \& Dunlosky, J. (2012). Study strategies of college students: Are self-testing and scheduling related to achievement? Psychonomic Bulletin \& Review, 19(1), 126-134. doi:10.3758/s13423-011-0181-y

Hmelo-Silver, C. E. (2004). Problem-based learning: What and how do students learn? Educational Psychology Review, 16(3), 235-266. doi:10.1023/B:EDPR.0000034022.16470.f3

Hung, W., Dolmans, D. H. J. M., \& Van Merriënboer, J. J. G. (2019). A review to identify key perspectives in PBL meta-analyses and reviews: trends, gaps and future research directions. Advances in Health Sciences Education, 24, 943-957. doi:10.1007/ s10459-019-09945-X 
Jossberger, H., Brand-Cruwel, S., Boshuizen, H., \& Van de Wiel, M. (2010). The challenge of self-directed and self-regulated learning in vocational education: A theoretical analysis and synthesis of requirements. Journal of Vocational Education and Training, 62(4), 415-440. doi:10.1080/13636820.2010.523479

Kamp, R. J. A., Dolmans, D. H. J. M., Van Berkel, H. J. M., \& Schmidt, H. G. (2012). The relationship between students' small group activities, time spent on self-study, and achievement. HigherEducation, 64(3), 385-397. doi:10.1007/s10734-011-9500-5

Könings, K. D., Brand-Cruwel, S., \& Van Merriënboer, J. J. C. (2005). Towards more powerful learning environments through combining the perspectives of designers, teachers, and students. British Journal of Educational Psychology, 75(Pt 4), 645-660. doi:10.1348/000709905X43616

Könings, K. D., Brand-Cruwel, S., \& Van Merriënboer, J. J. G. (2007). Teachers' perspectives on innovations: Implications for educational design. Teaching and Teacher Education, 23(6), 985-997. doi:10.1016/j.tate.2006.06.004

Lloyd-Jones, G., \& Hak, T. (2004). Self-directed learning and student pragmatism. Advances in Health Sciences Education, 9, 61-73. doi:10.1023/B:AHSE.0000012228.72071.1e

Loyens, S. M. M., Magda, J., \& Rikers, R. M. J. P. (2008). Self-directed learning in problem-based learning and its relationships with self-regulated learning. Educational Psychology Review, 20(4), 411-427. doi:10.1007/s10648-008-9082-7

McCardle, L., \& Hadwin, A. F. (2015). Using multiple, contextualized data sources to measure learners' perceptions of their self-regulated learning. Metacognition and Learning, 10, 43-75. doi:10.1007/s11409-014-9132-0

Moos, D. C., \& Azevedo, R. (2008). Monitoring, planning, and self-efficacy during learning with hypermedia: The impact of conceptual scaffolds. Computers in Human Behavior, 24(4), 1686-1706. doi:10.1016/j.chb.2007.07.001

Moust, J. H. C., Van Berkel, H. J. M., \& Schmidt, H. G. (2005). Signs of erosion: reflections on three decades of problem-based learning at Maastricht University. Higher Education, 50, 665-683. doi:10.1007/s10734-004-6371-z

Murdoch-Eaton, D., \& Whittle, S. (2012). Ceneric skills in medical education: developing the tools for successful lifelong learning. Medical Education, 46, 120-128. doi:10.1111/j.1365-2923.2011.04065.x

Newman, M. (2003). A pilot systematic review and meta-analysis on the effectiveness of Problem Based Learning. Middlesex University, UK: ITSN Learning and Teaching Support Network.

Panadero, E., Klug, J., \& ]ärvelä, S. (2016). Third wave of measurement in the self-regulated learning field: when measurement and intervention come hand in hand. Scandinavian Journal of Educational Research, 60(6), 723-735. doi:10.1080/00313831.201 5.1066436

Perry, N. E., \& Winne, P. H. (2006). Learning from learning kits: gStudy traces of students' self-regulated engagements with computerized content. Educational Psychology Review, 18, 211-228. doi:10.1007/s10648-006-9014-3

Pintrich, P. R. (1999). The role of motivation in promoting and sustaining self-regulated learning. International Journal of Educational Research, 31(6), 459-470. doi:10.1016/S0883-0355(99)00015-4

Pintrich, P. R. (2004). A conceptual framework for assessing motivation and self-regulated learning in college students. Educational Psychology Review, 16(4), 385-407. doi:10.1007/s10648-004-0006-x

Pintrich, P. R., Smith, D. A. F., Garcia, T., \& McKeachie, W. J. (1993). Reliability and predictive validity of the Motivated Strategies for Learning Questionnaire (MSLQ). Educational and Psychological Measurement, 53(3), 801-813.

doi:10.1177/0013164493053003024

Pintrich, P. R., Wolters, C. A., \& Baxter, G. P. (2000). Assessing metacognition and self-regulated learning. In G. Schraw \& ]. Impara (Eds.), Issues in the measurement of metacognition (pp. 43-97). Lincoln, NE: Buros Institute of Mental Measurements.

Raidal, S. L., \& Volet, S. E. (2009). Preclinical students' predispositions towards social forms of instruction and self-directed learning: a challenge for the development of autonomous and collaborative learners. HigherEducation, 57, 577-596. doi:10.1007/s10734-008-9163-z

Saks, K., \& Leijen, Ä. (2014). Distinguishing self-directed and self-regulated learning and measuring them in the e-learning context. Procedia-Social and Behavioral Sciences, 112, 190-198. doi:10.1016/j.sbspro.2014.01.1155

Schellings, G., \& Van Hout-Wolters, B. (2011). Measuring strategy use with self-report instruments: theoretical and empirical considerations. Metacognition and Learning, 6(2), 83-90. doi:10.1007/s11409-011-9081-9 
Schmidt, H. G. (1983). Problem-based learning: rationaleand description. Medical Education, 17, 11-16. doi:10.1111/j.1365-2923.1983. tbo1086.x

Schmidt, H. G., Van der Arend, A., Moust, J. H. C., Kokx, I., \& Boon, L. (1993). Influence of tutors' subject-matter expertise on student effort and achievement in problem-based learning. Academic Medicine, 68(10), 784-791. doi:10.1097/00001888199310000-00018

Schraw, G., \& Dennison, R. S. (1994). Assessing metacognitive awareness. Contemporary Educational Psychology, 19(4), 460-475 doi:10.1006/ceps.1994.1033

Sharples, M. (2000). The design of personal mobile technologies for lifelong learning. Computers \& Education, 34(3-4), 177-193. doi:10.1016/S0360-1315(99)00044-5

Silén, C., \& Uhlin, L. (2008). Self-directed learning-a learning issue for students and faculty! Teaching in Higher Education, 13(4), 461-475. doi:10.1080/13562510802169756

Skinner, D. E., Saylors, C. P., Boone, E. L., Rye, K. J., Berry, K. S., \& Kennedy, R. L. (2015). Becoming lifelong learners: A study in self-regulated learning. Journal of Allied Health, 44(3), 177-182.

Strobel, J., \& Van Barneveld, A. (2009). When is PBL more effective? A meta-synthesis of meta-analyses comparing PBL to conventional classrooms. Interdisciplinary Journal of Problem-Based Learning, 3(1). doi:10.7771/1541-5015.1046

Teunissen, P., \& Dornan, T. (2008). Lifelong learning at work. BM], 336(7645), 667-669. doi:10.1136/bmj.39434.601690.AD

Tourangeau, R., Rips, L. J., \& Rasinski, K. (2000). The psychology of survey response. Cambridge, UK: Cambridge University Press. Van den Hurk, M. M., Wolfhagen, H. A. P., Dolmans, D. H. J. M., \& Van der Vleuten, C. P. M. (1998). The relation between time spent on individual study and academic achievement in a problem-based curriculum. Advances in Health Sciences Education, 3, 43-49. doi:10.1023/A:1009732511707

Veenman, M. V. J. (2011). Alternative assessment of strategy use with self-report instruments: A discussion. Metacognition and Learning, 6, 205-211. doi:10.1007/s11409-011-9080-x

Veenman, M. V. J., Van Hout-Wolters, B. H. A. M., \& Afflerbach, P. (2006). Metacognition and learning: conceptual and methodological considerations. Metacognition and Learning, 1(1), 3-14. doi:10.1007/s11409-006-6893-0

Vermetten, Y. J., Vermunt, J. D., \& Lodewijks, H. G. (2002). Powerful learning environments? How university students differ in their response to instructional measures. Learning and Instruction, 12(3), 263-284. doi:10.1016/s0959-4752(01)00013-5

Weinstein, C. E., \& Palmer, D. R. (2002). Learning and Study Strategies Inventory (LASSI): Users Manual (2nd ed.). Clearwater, FL: H\&H Publishing

Winne, P. H., \& Hadwin, A. F. (1998). Studying as self-regulated learning. In D. J. Hacker, J. Dunlosky, \& A. C. Graesser (Eds.) Metacognition in educational theory and practice (pp. 277-304). Mahwah: Lawrence Erlbaum.

Winne, P. H., Jamieson-Noel, D. L., \& Muis, K. (2002). Methodological issues and advances in researching tactics, strategies, and self-regulated learning. In P. R. Pintrich \& M. L. Maehr (Eds.), Advances in Motivation and Achievement: New Directions in Measured and Methods (Vol. 12, pp. 121-155). Greenwich, Connecticut: JAI.

Winne, P. H., \& Perry, N. E. (2000). Measuring self-regulated learning. In M. Boekaerts, P. R. Pintrich, \& M. Zeidner (Eds.), Handbookofself-regulation (pp. 531-566). Orlando, FL: Academic Press.

Woltering, V., Herrler, A., Spitzer, K., \& Spreckelsen, C. (2009). Blended learning positively affects students' satisfaction and the role of the tutor in the problem-based learning process: results of a mixed-method evaluation. Advances in Health Sciences Education: Theory and Practice, 14(5), 725-738. doi:10.1007/s10459-009-9154-6

Zimmerman, B. J. (2002). Becoming a self-regulated learner: An overview. Theory into Practice, 41(2), 64-70. doi:10.1207/ S15430421tip4102_2 
Chapter 1

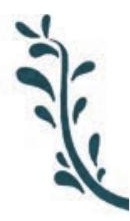




\section{GHAPTER2}

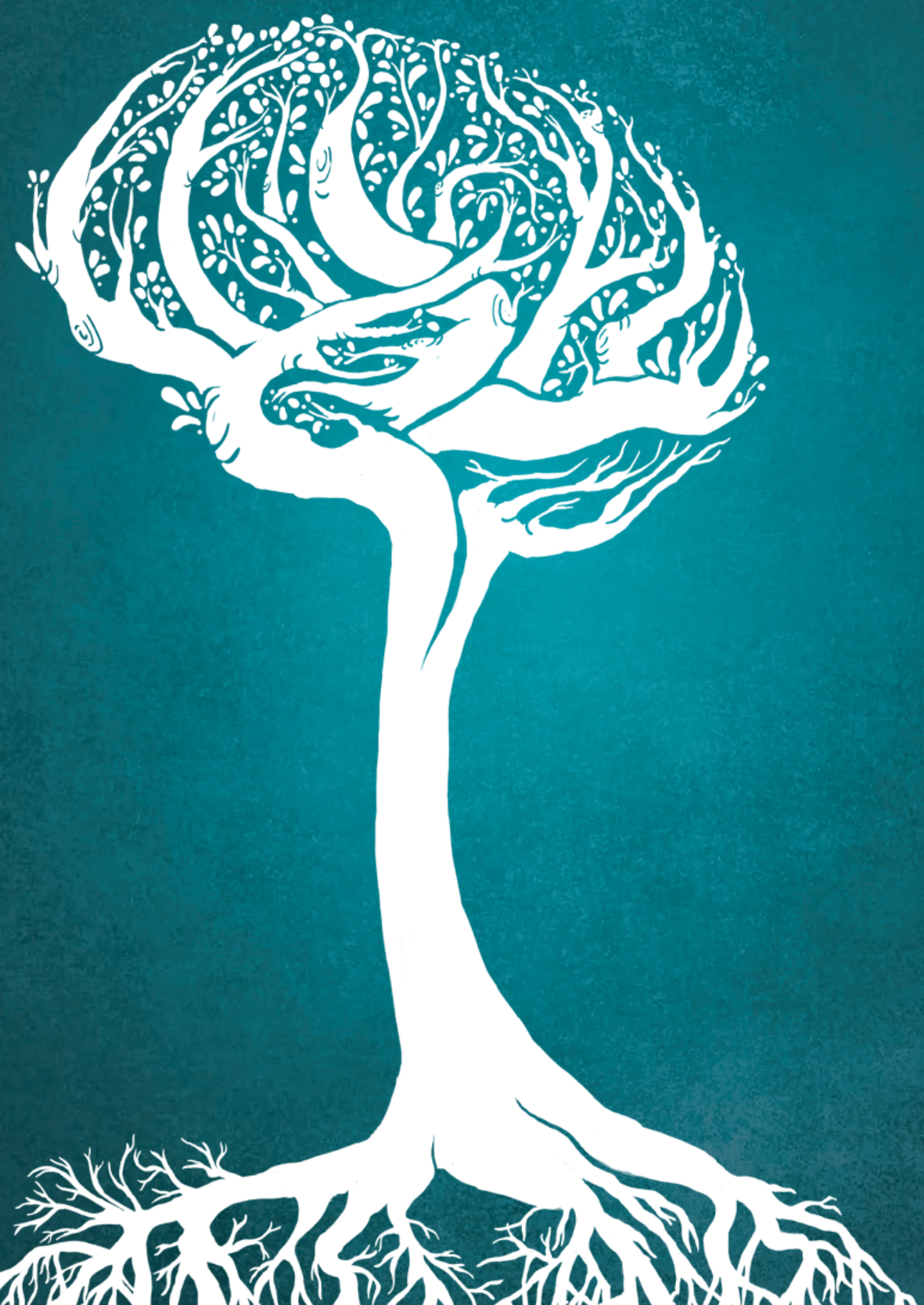




\title{
How and why do students use learning strategies?
}

\author{
A mixed methods study on learning strategies \\ and desirable difficulties with effective strategy users
}

Rovers, S. F. E., Stalmeijer, R. E., van Merriënboer, J. J. G.,

Savelberg, H. H. C. M., \& De Bruin, A. B. H. (2018).

Frontiers in Psychology, 9, 2501.

\begin{abstract}
In order to ensure long-term retention of information, students must move from relying on surface-level approaches that are seemingly effective in the short term to 'building in' so called 'desirable difficulties', with the aim of achieving understanding and long-term retention of the subject matter. But how can this level of self-regulation be achieved by students when learning?
\end{abstract}

Traditionally, research on learning strategy use is performed using self-report questionnaires. As this method is accompanied by several drawbacks, we chose a qualitative, in-depth approach to inquire about students' strategies and to investigate how students successfully self-regulate their learning. In order to paint a picture of effective learning strategy use, focus groups were organized in which previously identified, effectively self-regulating students $(\mathrm{N}=$ 26) were asked to explain how they approach their learning.

Using a constructivist grounded theory methodology, a model was constructed describing how effective strategy users manage their learning. In this model, students are driven by a personal learning goal, adopting a predominantly qualitative or quantitative approach to learning. While learning, students are continually engaged in active processing and selfmonitoring. This process is guided by a constant balancing between adhering to established study habits, while maintaining a sufficient degree of flexibility to adapt to changes in the learning environment, assessment demands and time limitations. Indeed, students reported using several strategies, some of which are traditionally regarded as 'ineffective' (highlighting, rereading etc.). However, they used them in a way that fit their learning situation. Implications are discussed for the incorporation of desirable difficulties in higher education. 


\section{Introduction}

Self-regulated learning (SRL) refers to the "process whereby students activate and sustain cognitions, behaviors and affects, which are systematically oriented towards the attainment of their goals" (Schunk \& Zimmerman, 1994, p. 309). With the enormous increase in available information since the emergence of the Internet (Arbesman, 2013), SRL is becoming increasingly important in modern education. This can be especially daunting for students in a problem-based curriculum, as this approach places high demands on students' independent self-study and individual search for information (e.g., Kirschner, Sweller, \& Clark, 2006). Students will need effective self-regulatory strategies in order to successfully navigate this educational landscape. As students often rely on ineffective, surface-level study strategies (Kornell \& Bjork, 2007), it is important to understand what constitutes effective strategy use in a problem-based curriculum, and how to improve SRL in students not skilled in self-regulation.

An important concept in this regard is that of 'desirable difficulties'. What constitutes as 'desirable' when introducing difficulties into the learning process, at least from the students' perspective, will likely depend on the goals they set for learning. Learning goals can include long-term understanding and transfer, or simply a desire to pass an exam. When the aim is simply to pass the test, different learning strategies apply than when the focus is on longterm understanding and transfer. In fact, strategies which have a positive effect on long-term understanding and transfer, may even have a negative effect on learning in the short term and vice versa (Helsdingen, Van Cog, \& Van Merriënboer, 2011; Van Merriënboer, De Croock, \& Jelsma, 1997; Van Merriënboer \& Kirschner, 2018). However, this short-term achievement will not prepare students for long-term, professional practice (Boud \& Falchikov, 2006). From an educational perspective, the focus should therefore be on long-term retention and transfer. Indeed, as defined by Bjork (1994), creating desirable difficulties when learning refers to the process in which students use effortful learning strategies, with the aim of achieving long-term learning benefits, rather than surface-level strategies which are only effective in the short term.

The traditional way of measuring students' strategy use is through self-report surveys (Panadero, Klug, \& Järvelä, 2016). These studies often reveal that students rely on ineffective strategies when studying. For example, Blasiman, Dunlosky, and Rawson (2017) found that over the course of a semester, students often relied on ineffective strategies such as reading notes and rereading text. Similarly, Karpicke, Butler, and Roediger (2009) found that while students often rely on rereading strategies, few students use more effective strategies like retrieval practice. One of the drawbacks of this form of measurement is that students are usually confronted with a set of predefined strategy categories to choose from. Authors have raised questions about whether self-report questionnaires are able to gauge students' use of different learning strategies across different contexts and tasks (McCardle \& Hadwin, 2015; Perry \& Winne, 2006; Schellings, 2011; Winne \& Hadwin, 1998), students' ability to recover 
the required information from their memory (Perry \& Winne, 2006), the possibility of socially desirable answers (Bråten \& Samuelstuen, 2007), and a potential tendency for students to rate the value they attach to a certain strategy rather than their actual use (Bernacki, Byrnes, \& Cromley, 2012; Bråten \& Samuelstuen, 2007). Another possibility is that students use certain strategies to regulate their learning which they do not recognize as belonging to a particular category (Veenman, 2011). Furthermore, it is possible that strategies which are traditionally treated as ineffective by these self-report questionnaires are in fact adapted by students to fit their learning situation and goals in an effective way. These expectations were the basis for exploration in the current study.

In order to overcome these difficulties, a more qualitative, in-depth approach to inquiring about students' use of learning strategies can be worthwhile in order to investigate how students successfully self-regulate their learning. Specifically, this rich form of data collection allows for the description of different contexts and learning tasks, allowing students to distinguish between different learning strategies used in different situations and for different goals, as well as how they potentially use seemingly 'ineffective' strategies to adapt to a learning situation or goal. A qualitative approach to inquiry enables students to give more elaborate explanations for as to how and why they use particular strategies, as well as potential variations with regard to varying circumstances. By carefully constructing the questions, it should also be possible to distinguish between the value students attach to different strategies versus their actual use. Furthermore, students' rich descriptions of their approaches to learning allow the researcher to identify strategies that students would be unable to correctly label in a questionnaire.

As a qualitative approach to data collection, the focus group method can have several advantages over traditional interviews. When using focus groups, participants' interactions with each other can yield insights that would not be possible to obtain with individual interviews (Kitzinger, 1995). In addition to being able to complement each other, participants have the opportunity to respond to each other's answers, making it easier to identify differences between their views. These differences can further be used to clarify the reasons behind participants' views (Kitzinger, 1994). Finally, with regard to social desirability, research has also found that focus groups, when compared to individual interviews, can actually induce participants to take a more critical stance (Kitzinger, 1995; Watts \& Ebbutt, 1987). What matters here is to create a safe atmosphere for participants in which to express their views (Kitzinger, 1995).

For this study, we chose to focus on effective self-regulators, rather than making a comparison between effective versus less effective students. Rather than focusing on the factors that influence effective self-regulation and the incorporation of desirable difficulties, the aim of this study was to take a step back and come to a comprehensive picture of what this 
effectiveness actually looks like.

In summary, in order to acquire more in-depth insight into the variation of students'strategy use and the reasons behind it, these considerations led us to choose a focus group approach to study students' self-regulation and incorporation of desirable difficulties into their learning. We complemented the focus group approach with a traditional learning strategy survey (cf., Hartwig \& Dunlosky, 2012) to compare and contrast results between approaches and analyze the value of each. The research questions guiding this study were: How do highly effective self-regulating students in a PBL higher-education curriculum approach their learning? How do they incorporate desirable difficulties into this process?

\section{Methods}

\section{Context}

This study took place in the context of the first and second year of the 6-year undergraduate medical program at Maastricht University. This university uses a problem-based learning (PBL) format, in which learning takes place starting from authentic, real-world cases (Schmidt, 1983). Students work on these problems in small tutorial groups, typically consisting of approximately10-12 students. These tutorial sessions are moderated by a tutor, who is expected to act as a facilitator, rather than as a knowledge transmitter. To structure the PBL process, Maastricht University uses a seven-step model called the Seven-Jump (Moust, Van Berkel, \& Schmidt, 2005), consisting of clarification of terms, problem definition, brainstorming about possible explanations to the problem, structuring and analysis of the identified explanations, identification of learning questions, self-study, and post-discussion aimed at integrating individual students' findings. The first five steps take place in one tutorial group session, after which students individually study the literature to answer the learning questions outside the tutorial group. A few days later, the tutorial group gets together again to discuss their findings in the post-discussion, after which the cycle repeats for a new problem. In this curriculum, the academic year is divided into six courses, ranging between four to eight weeks, each focusing on a specific multidisciplinary topic. At the end of a course, students are tested with an exam focused on the contents of this course (mostly multiple-choice).

Given its emphasis on students' independent literature search and self-study, the PBL format provides a fruitful context for the study of students' use of learning strategies and incorporation of desirable difficulties. Specifically, as students are required to find their own literature and use it to independently answer their learning questions, they will need a range of strategies to manage this process and monitor their understanding, leading to a large pool of potential strategies for students to report on. This situation offers a unique potential to gain insight into what constitutes an effective approach. 


\section{Participants}

In order to come to a picture of effective strategy use and the incorporation of desirable difficulties for students in a PBL curriculum, we used a purposive sampling strategy (Ritchie, Lewis, Nicholls, \& Ormston, 2013). At the end of the first year (academic year 2013-2014), mentors of first-year undergraduate medical students were asked to identify students who they perceived to use effective learning strategies (the instructions for the mentors can be found in Appendix 2A). Sixteen mentors identified 42 students for the study. These students were approached by e-mail to invite them for our study, to be held at the beginning of their second year (academic year 2014-2015). Thirty students (71\%) indicated willingness to participate. Two students indicated it would not be possible to be present at the times the focus groups were held. Two students filled out the learning strategy questionnaire (see below) but did not attend the focus groups, and were therefore excluded from further analysis. The final number of students participating in the focus groups was therefore $N=26$, of which 20 students were female, ages ranging between 18-23 years old (one student did not provide an age). The total number of students enrolled for the tutorial groups at the beginning of Year 2 was 298. Written informed consent was obtained from all participants prior to the start of the study. The study was approved by the ethical review board of the Netherlands Association for Medical Education (file number 402). Students were offered a small monetary gift voucher as a reward for their participation in the study.

\section{Learning strategy questionnaire}

At least one week prior to the focus groups, students were asked to fill out a learning strategy questionnaire. We adapted the questionnaire used by Hartwig and Dunlosky (2012) to fit our PBL learning situation. Specifically, we adapted the wording of the questionnaire to refer to the tutorial group meetings that students encounter in the PBL setting. Furthermore, rather than asking students whether they do or do not use a specific strategy regularly (using a binary yes/no format), we used a Likert scale asking students how often they use these strategies while studying, ranging from 1 (never) to 5 (every study session). This was also applied to the question of whether students go back to course material after a course has ended, and whether students read study sources more than once. For the questions asking students on what parts of the day they study most and on what parts of the day they study most effectively, "evening" and "late night" were combined into one category ("evening"). Furthermore, the strategy questions were adapted to reflect the ones most relevant for the current educational context.

We dropped the question asking students whether they study more for open questions or multiple-choice questions, as the tests that medical students encounter in the program are mostly multiple-choice. The question of how students decide what to study next was posed as an open question. Finally, in order to reflect the focus of our study, we added four questions: (1) How did you develop the study strategies you are using now (open question, replacing the 
question of whether students' study strategies were taught to them by a teacher), (2) If you had the time and somebody would explain it to you, would you want to change your study strategies (yes/no), (3) What and why would you then want to change (open question), and (4) What kind of education would you most appreciate to change your study strategies? Think about: lectures, videos, practice with a trainer, etc. (open question). Finally, we added a question asking students for any further comments they may have. All questions not rated on a Likert scale (open questions and study times) were thematically coded by two raters. Inconsistencies were discussed until consensus was reached.

With this questionnaire we attempted to obtain a baseline measure of students' strategy use (what are the strategies that are used), to later complement this with the in-depth focus groups (how are the strategies used). In summary, the adapted questionnaire consisted of 10 questions assessing students' strategy use, using a Likert scale ranging from 1 (never) to 5 (every study session), as well as one question allowing students to list other strategies they use during studying. Furthermore, there were 12 questions inquiring about additional aspects of students' study behavior, for example, preferred study time (with five questions being open ended). Appendix 2B provides an overview of the questionnaire.

\section{Focus groups}

Students were divided into four separate focus groups. Each focus group lasted approximately 1 to 1.5 hours. Each focus group was moderated by the second author and observed by the last author and a student assistant. The second author is an educational scientist by background and specializes in qualitative methodology. The last author specializes in effective study strategies. She served as an observer, in order to avoid influencing the results or "leading" the participants. The student assistant observed as well and organized the focus groups. Based on a vignette approach, students were asked how they prepare for different educational activities in the PBL medical curriculum. A total of six vignettes was used (see Appendix $2 \mathrm{C}$ for the interview protocol, including the vignettes used). These vignettes concerned the postdiscussion, exam, progress test, skills lab, Pscribe (written assignments assessing students' pharmacotherapeutic reasoning) and extracurricular activities. To answer our research question related to students' learning strategies during self-study, we focused our analysis on the first two vignettes (post-discussion and exam). After four months, students were invited back for a second focus group meeting, in which we discussed preliminary results, in order to check our interpretation of the findings (member checking), and to see whether students were consistent in their reports. Two students did not attend the second meeting because the interview dates did not fit their schedule.

The interview protocol used for the focus groups can be found in Appendix $2 \mathrm{C}$. 


\section{Analysis}

All focus groups were audio recorded and transcribed verbatim. A constructivist grounded theory methodology (Charmaz, 2014) was taken when analyzing the data. In grounded theory, the aim is to generate a theory or understanding of a certain process (Creswell, 2007). In a process of iterative data analysis, the researchers go through the different steps of open coding (generating initial codes for data categories), axial coding (identifying a core phenomenon and its surrounding categories), and selective coding (connecting categories and developing the theory). We chose this approach due to our focus on understanding the process of effective strategy use and incorporation of desirable difficulties, with a strong interest in the conditions that support or hinder this process (Creswell, 2007).

Initial, open coding was done by the first author. This was done in a line-by-line fashion, in which representative codes were assigned to the participants' utterances. During this process, several meetings were held with the second and last author to discuss the codes. After arriving at an initial codebook, codes were related to each other in a process of axial coding. During this process, codes were compared and contrasted with each other, looking for connections in order to create themes from overlapping codes. This step was initially done by the first author, with the second and last author each coding a non-overlapping $25 \%$ of the codebook to ensure rigor. Findings from this step were discussed until consensus was reached. Results from the analysis were discussed with the third and fourth author. Finally, in a process of selective coding by the first, second and last author, themes were related to each other in order to come to an overarching model of the data.

\section{Findings}

\section{Learning strategy questionnaire}

Tables 1 and 2 show the results from the survey on students' strategy use and the additional aspects of students' study behavior, respectively.

Interestingly, the students in our sample indicate a frequent use of the strategies regarded in the literature as effective, such as self-testing, questioning and self-explanation (Dunlosky, Rawson, Marsh, Nathan, \& Willingham, 2013; Hartwig \& Dunlosky, 2012), indicating that our purposeful sampling strategy was effective. Furthermore, as indicated in Table 2, students report spacing their tutorial preparations over multiple sessions, indicating use of distributed practice (Dunlosky et al., 2013). However, as indicated by Table 2, students also report using some of the strategies that are typically viewed as ineffective for reaching long-term retention and transfer, particularly summarizing, mental imagery and underlining/marking (Dunlosky et al., 2013).

When responding to the question about which other strategies they use, strategies students reported (restricted to the ones not covered by the questionnaire) were: preparing 
their case on their laptop and shortly summarizing it before the tutorial group, writing out practical activities and going over this information during the exam week, drawing or writing out difficult things, making practice tests and correcting incorrectly answered items, watching videos, making diagrams after studying a case to summarize as much as possible, making concrete and compact cases, working in a disciplined manner, creating mind maps and drawings, drawing figures or pictures, rereading summaries, writing down and rereading difficult parts, printing out all cases and information from practicals and putting them together in one folder to create an overview of the entire course, rehearsing lectures, and attentively working out learning materials in the case.

When responding to the question asking students whether they had any further comments, students emphasized the importance of lectures, active processing of learning materials through the creation of summaries, the added value of problem-based learning and discussions during tutorial groups, and the importance of keeping order in the learning materials to avoid missing information.

In the focus groups, students were asked about their study approaches, in order to gain more insight into the ways in which they use their learning strategies.

\section{Focus groups}

Using the constructivist grounded theory methodology, a model was constructed describing how highly effective strategy users approach their learning. The results of this process are depicted in Figure 1. In this model, students are driven by a personal learning goal, adopting either a qualitative or quantitative approach to learning. When learning, these highly effective strategy users are continually engaged in active processing of subject matter, while monitoring their understanding of the content and adjusting their approach when necessary. This process is guided by a constant balance between adhering to established study habits, while maintaining a sufficient degree of flexibility to adapt to changes in the learning environment, assessment demands and time limitations. Although students demonstrated metacognitive knowledge of the effectiveness of their strategies and the reasons for using them, this was not the case for all aspects of their strategy use. Indeed, students reported using several strategies which are traditionally regarded as 'ineffective' (highlighting, rereading etc.), but used them in a way that helped them adjust to their learning situation and goal.

In the following, we will describe the different components of this model, the implications for students' self-regulation, and the incorporation of desirable difficulties into their learning. 
Table 1. Means and standard deviations for students' responses on the learning strategy questions, from highest to lowest mean.

\begin{tabular}{lccc}
\hline Strategy & N & Mean & Standard deviation \\
\hline Self-testing & 26 & 4.0 & 1.1 \\
Summarizing & 26 & 3.9 & 1.2 \\
Mental imagery & 26 & 3.9 & .8 \\
Underlining/marking & 25 & 3.5 & 1.3 \\
Questioning & 26 & 3.4 & .9 \\
Self-explanation & 26 & 3.3 & 1.1 \\
Rereading & 26 & 2.9 & 1.0 \\
Co-studying & 26 & 2.6 & 1.1 \\
Cramming & 26 & 2.2 & 1.1 \\
Asking someone to test me & 26 & 1.8 & 1.0 \\
\hline
\end{tabular}

Questions were answered on a 5-point Likert scale ranging from 1 (never) to 5 (every study session).

Table 2. Summary of students' responses to questions about additional aspects of their study behavior

\begin{tabular}{|c|c|c|c|c|c|}
\hline Question & $\mathrm{N}$ & Answers & $\begin{array}{l}\text { Number of } \\
\text { responses }\end{array}$ & Mean & $\begin{array}{l}\text { Standard } \\
\text { deviation }\end{array}$ \\
\hline \multirow{11}{*}{$\begin{array}{l}\text { How do you decide what } \\
\text { to study next? [open } \\
\text { question] }\end{array}$} & \multirow{11}{*}{$\begin{array}{l}26 \\
(40 \text { an- } \\
\text { swers })\end{array}$} & I study everything & $1(2.5 \%)$ & & \\
\hline & & I study in a random order & $1(2.5 \%)$ & & \\
\hline & & I use the course's structure & $9(22.5 \%)$ & & \\
\hline & & Making a schedule ahead of time & $11(27.5 \%)$ & & \\
\hline & & $\begin{array}{l}\text { Using the order in which information } \\
\text { is presented in sources }\end{array}$ & $1(2.5 \%)$ & & \\
\hline & & Whatever costs least time & $1(2.5 \%)$ & & \\
\hline & & $\begin{array}{l}\text { Whatever I feel that I don't (fully) } \\
\text { understand/find difficult }\end{array}$ & $6(15.0 \%)$ & & \\
\hline & & Whatever I find interesting & $1(2.5 \%)$ & & \\
\hline & & Whatever is due soonest & $5(12.5 \%)$ & & \\
\hline & & Whatever is most important to me & $3(7.5 \%)$ & & \\
\hline & & Whatever takes most work & $1(2.5 \%)$ & & \\
\hline
\end{tabular}


Table 2. Continued

\begin{tabular}{|c|c|c|c|c|c|}
\hline Question & $N$ & Answers & $\begin{array}{l}\text { Number of } \\
\text { responses }\end{array}$ & Mean & $\begin{array}{l}\text { Standard } \\
\text { deviation }\end{array}$ \\
\hline $\begin{array}{l}\text { Do you usually return } \\
\text { to study material from } \\
\text { an earlier course after a } \\
\text { course has ended? [Please } \\
\text { indicate on a scale from } \\
1-2-3-4-5 \\
\text { (never) - (always) }\end{array}$ & 26 & & & 2.7 & .8 \\
\hline $\begin{array}{l}\text { When you study, do you } \\
\text { usually read the book/ } \\
\text { article/other source more } \\
\text { than once? [Please indi- } \\
\text { cate on a scale from } \\
1-2-3-4-5 \\
\text { (never) - (always) }\end{array}$ & 26 & & & 2.9 & 1.0 \\
\hline $\begin{array}{l}\text { Imagine that in the course } \\
\text { of studying, you notice } \\
\text { that you understand a } \\
\text { certain concept in the text. } \\
\text { What do you do? }\end{array}$ & 24 & $\begin{array}{l}\text { Don't study it again } \\
\text { Study it again later }\end{array}$ & $\begin{array}{l}9(37.5 \%) \\
15(62.5 \%)\end{array}$ & & \\
\hline $\begin{array}{l}\text { What time of the day } \\
\text { do you mostly do your } \\
\text { studying? }\end{array}$ & $\begin{array}{l}26 \\
(39 \text { an- } \\
\text { swers })\end{array}$ & $\begin{array}{l}\text { Morning } \\
\text { Afternoon } \\
\text { Evening } \\
\text { No preference }\end{array}$ & $\begin{array}{l}14(35.9 \%) \\
19(48.7 \%) \\
3(7.7 \%) \\
3(7.7 \%)\end{array}$ & & \\
\hline $\begin{array}{l}\text { During what time of the } \\
\text { day do you believe your } \\
\text { studying is most effec- } \\
\text { tive? }\end{array}$ & $\begin{array}{l}26 \\
(34 \text { an- } \\
\text { swers })\end{array}$ & $\begin{array}{l}\text { Morning } \\
\text { Afternoon } \\
\text { Evening } \\
\text { No preference }\end{array}$ & $\begin{array}{l}17(50.0 \%) \\
14(41.1 \%) \\
1(2.9 \%) \\
2(5.9 \%)\end{array}$ & & \\
\hline $\begin{array}{l}\text { What do you usually do: } \\
\text { Prepare for a tutorial } \\
\text { group in one study session } \\
\text { right before the tutorial } \\
\text { group OR space out tutori- } \\
\text { al group preparation over } \\
\text { multiple study sessions? }\end{array}$ & 26 & $\begin{array}{l}\text { One study session } \\
\text { Multiple study sessions }\end{array}$ & $\begin{array}{l}4(15.4 \%) \\
22(84.6 \%)\end{array}$ & & \\
\hline $\begin{array}{l}\text { How did you develop the } \\
\text { study strategies you are } \\
\text { using now? } \\
\text { [open question] }\end{array}$ & $\begin{array}{l}26 \\
(33 a n- \\
\text { swers) }\end{array}$ & $\begin{array}{l}\text { Adjusting to requirements } \\
\text { Comparing with other students } \\
\text { Experience } \\
\text { Experimenting/trial and error } \\
\text { Tips from staff }\end{array}$ & $\begin{array}{l}5(15.5 \%) \\
2(6.1 \%) \\
15(45.5 \%) \\
10(30.3 \%) \\
1(3.0 \%)\end{array}$ & & \\
\hline
\end{tabular}




\section{Table 2. Continued}

\begin{tabular}{|c|c|c|c|c|c|}
\hline Question & $\mathrm{N}$ & Answers & $\begin{array}{l}\text { Number of } \\
\text { responses }\end{array}$ & Mean & $\begin{array}{l}\text { Standard } \\
\text { deviation }\end{array}$ \\
\hline \multirow{3}{*}{$\begin{array}{l}\text { If you had the time and } \\
\text { somebody would explain } \\
\text { it to you, would you want } \\
\text { to change your study } \\
\text { strategies? [yes/no] }\end{array}$} & \multirow[t]{3}{*}{26} & Yes & $13(50.0 \%)$ & & \\
\hline & & No & $11(42.3 \%)$ & & \\
\hline & & Maybe & $2(7.7 \%)$ & & \\
\hline \multirow{9}{*}{$\begin{array}{l}\text { What and why would you } \\
\text { then want to change? } \\
\text { [open question] }\end{array}$} & \multirow{9}{*}{$\begin{array}{l}17 \\
(20 \text { an- } \\
\text { swers })\end{array}$} & Effective studying/efficiency & $8(40.0 \%)$ & & \\
\hline & & Focus during lectures & $1(5.0 \%)$ & & \\
\hline & & Improve study order & $1(5.0 \%)$ & & \\
\hline & & Integrating/applying knowledge & $2(10.0 \%)$ & & \\
\hline & & Making better summaries & $1(5.0 \%)$ & & \\
\hline & & Making studying more fun & $1(5.0 \%)$ & & \\
\hline & & Planning & $4(20.0 \%)$ & & \\
\hline & & Start studying with other students & $1(5.0 \%)$ & & \\
\hline & & Test taking strategies & $1(5.0 \%)$ & & \\
\hline \multirow{10}{*}{$\begin{array}{l}\text { What kind of education } \\
\text { would you most appreci- } \\
\text { ate to change your study } \\
\text { strategies? Think about: } \\
\text { lectures, videos, practice } \\
\text { with a trainer, etc.' [open } \\
\text { question] }\end{array}$} & \multirow{10}{*}{$\begin{array}{l}22 \\
(29 \text { an- } \\
\text { swers })\end{array}$} & \multicolumn{2}{|c|}{ Creating a mindmap or something visual1 (3.4\%) } & & \\
\hline & & Exercises & $2(6.9 \%)$ & & \\
\hline & & Exercises with trainer & $12(41.4 \%)$ & & \\
\hline & & $\begin{array}{l}\text { Lecture followed by exercises with } \\
\text { trainer }\end{array}$ & $1(3.4 \%)$ & & \\
\hline & & Lectures & $4(13.8 \%)$ & & \\
\hline & & More opportunities to ask questions & $1(3.4 \%)$ & & \\
\hline & & $\begin{array}{l}\text { Talking with fellow students about the } \\
\text { learning materials }\end{array}$ & $1(3.4 \%)$ & & \\
\hline & & $\begin{array}{l}\text { Trying and discussing ideas of others } \\
\text { (possibly of a trainer) }\end{array}$ & $1(3.4 \%)$ & & \\
\hline & & Videos & $5(17.2 \%)$ & & \\
\hline & & $\begin{array}{l}\text { Written explanation with discussion } \\
\text { session led by trainer }\end{array}$ & $1(3.4 \%)$ & & \\
\hline
\end{tabular}

\footnotetext{
${ }^{1}$ Students could provide multiple answers in response to these questions. Percentages therefore reflect proportions of the total number of answers given, rather than the total number of students.
} 


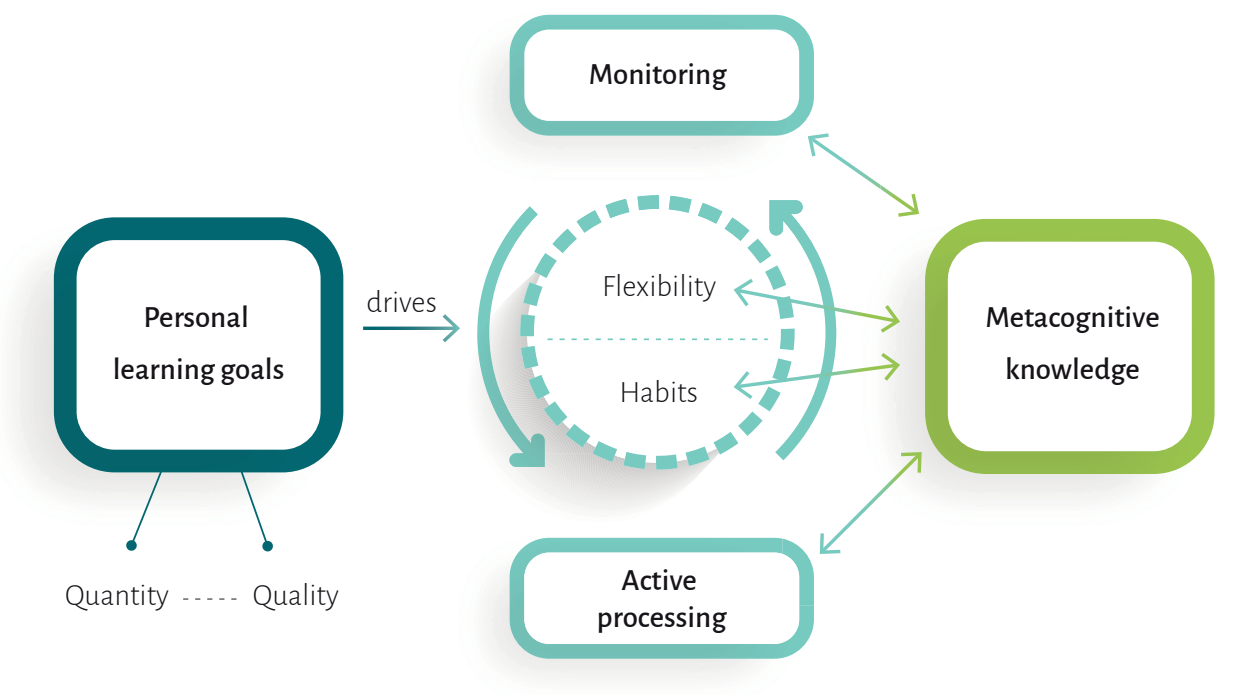

Figure 1. Model describing highly effective strategy users' approach to learning.

Quantity and quality

During the focus groups, many of the students described being driven by a personal learning goal, adopting a quantitative or qualitative approach to learning. Specifically, quantitatively oriented students used numerical indicators as the basis for their learning. For example, when referring to collecting information for the post-discussion, one student stated:

"And then, yeah, just translate it a little bit and write it down in my own words. And uh, yeah, then I just have about fifteen pages usually. And when I have three pages I really feel like I, yeah, have too little."

Focus group 1, session 1, participant A

On the other hand, students adopting a qualitative approach emphasized the quality of their materials and of their understanding. Rather than focusing on how much material they had produced, these students would focus on how well they understood and remembered what they had studied. As one student explained:

"Well, ifyou have 7 pages and you don't understand any of it, you haven't achieved anything in the end. You'll have a lot of material to study and when you study you can brag about having a 50-page case."

Focus group 1, session 1, participant B 


\section{Active processing and monitoring}

During focus group discussions it became clear that students were continually engaged in active processing of the subject matter, while monitoring their understanding of the content and adjusting their approach when necessary. In this sense, students are incorporating desirable difficulties into their learning, as they are not content with passively reading the subject matter, but try to find ways to be actively engaged.

"You should never literally copy an entire text. Or [you should do it] in the way he [other participant] does it, explain it or write it in your own words, but do something that makes it your own."

\section{Focus group 4, session 1, participant A}

In some cases, the PBL system at Maastricht University was indicated as a contributing factor to this active approach, as students are required to be able to discuss their findings in the postdiscussions. This became clear in the words used to describe it:

"I think that is really the key, treat the subject matter in an active way. You're in Maastricht, this is what they ask from you and it also just works."

\section{Focus group 1, session 1, participant C}

"Well I had, yes in [a different city] I really had to learn from books. (...), so I think that that is just, that's not possible here, in Maastricht you also have to be able to tell everything coherently. So then I made a mix from that, that I, because I was good at studying from books, but that I could also reproduce it in the tutorial group."

Focus group 2, session 1, participant A

In addition to this active processing, students reported a continuous monitoring of understanding, and adjusting their learning when necessary. In many cases, this monitoring was achieved by various forms of self-testing. A commonly reported tactic for this was explaining the subject matter to another person, either physically or hypothetically:

"(...) sometimes it is nice when people are like asking questions. Then I hear myselfexplaining it and then I hear whether I understand it, so to speak."

Focus group 3, session 1, participant A

"And, uhm, when I look through my case at the end I should actually be able to explain each component that I discuss to someone else. I don't actually do that, but I should be able to."

Focus group 1, session 1, participant B

Also, students often used externally provided resources such as practice tests to test their knowledge and understanding. Interestingly, the strategies students reported using to 
correct learning when this monitoring revealed knowledge deficits, were mostly surfacelevel strategies such as rereading. However, self-testing is an important strategy to improve learning (Roediger \& Karpicke, 2006) and has to be actively built into the learning process. The fact that students reported using practice tests and testing themselves indicated again students' willingness to incorporate desirable difficulties into their learning.

\section{Habits and flexibility}

Students' learning process, as guided by their learning goal and characterized by active processing of subject matter and continuous monitoring of understanding, is further guided by a constant balance between adhering to established study habits, while maintaining a sufficient degree of flexibility to adapt to changes in the learning environment, assessment demands and time limitations. For example, students often indicated they had fixed times or places for studying, or a fixed order in which to process the materials for studying. At the same time, students also found themselves in situations where they had to adapt to changes in their learning situation and reported several strategies to maintain this flexibility. For example, one student indicated photocopying book sections in advance to be able to study when going home to parents during the weekends, thereby maintaining flexibility in time and location on which to study. This flexibility was also evident in students' strategy use. Students reported that they had experimented with strategies over the years, finding out "what works for them". While some students indicated that they had not experienced the need to change their strategies, because they felt comfortable with their strategies and were happy with the results they produced, others indicated that they had used criteria such as their performance as benchmarks for whether or not they should adjust their strategies. As one student indicated:

"I think this is something in which you are supposed to grow and if you keep telling yourself that your own strategy works and you score 6's [points out of 10, 10 being the highest] then you're actually doing something wrong. But then you're just, I would almost say lazy, you just don't feel like changing it."

Focus group 1, session 1, participant B

Furthermore, several students indicated adapting their strategies according to the demands of the test. Although some students reported using the same studying methods regardless of the way of questioning on the test, others indicated adapting their strategies depending on whether they would have to answer multiple choice questions (focusing on retention and recognition) or open questions (studying more, with a stronger focus on understanding).

\section{Metacognitive knowledge}

Although students demonstrated metacognitive knowledge of the effectiveness of their strategies and the reasons for using them, this was not the case for all aspects of their strategy 
use. Students indicated in the second session that, when given a list of all strategies mentioned in the first session and asked to indicate which strategies they used most often, it was difficult to label these strategies properly. As one student indicated:

"(...) with me mostly with visualizing, that I didn't realize that I was doing it or how I was doing it, until I wrote down that I was doing it. Then I thought, oh yes, I do this quite a lot."

\section{Focus group 1, session 2, participant B}

It was especially difficult for students to indicate how they monitored their understanding, or how they distinguished between important and less important topics and how deep to process the information. Many students indicated this was a "feeling", or something they had learned from experience.

Furthermore, students reported using several strategies which are traditionally regarded as 'ineffective', such as highlighting and rereading of text (Dunlosky et al., 2013). However, students used them in a way that helped them adjust to their learning situation, by using the strategies in an active way. Although there were some exceptions (e.g., highlighting text in order to reread it afterwards), examples include repeating subject matter using different sources and media, making handwritten summaries to be actively engaged with the subject matter, paraphrasing in order to monitor understanding, or rereading text to check whether it still makes sense in the context of clinical practice.

In fact, in one of the focus groups students indicated the need to incorporate desirable difficulties into their learning process, emphasizing the wish to attain long-term retention, rather than short-term storage, in order to become a competent doctor after graduation. Students often recognized the need to invest effort in learning, as opposed to relying on loweffort surface-level strategies (for example, purposefully using English rather than Dutch books, as the additional effort required prevents a shallow reading of the text). An overarching theme in this regard was a focus on creating understanding, finding the logic in the educational material and making connections between different topics and educational activities, as opposed to for example rote learning or memorizing symptoms. One student explained:

"I always do that [check if you can apply the case to medical practice], I always try to make the case explainable. Just because I like that, then I know that I understand and when it is written down on sheets everywhere then I think oh, why is this value high or that value low. Or, because that lab test, oh yes, that makes sense too. It is not that I will think about what it is [come up with a diagnosis], but I do check to see if it makes sense or not"

Focus group 2, session 1, participant B 
In summary, the participants in our study use a variety of strategies to regulate their learning and to incorporate desirable difficulties into this process. In addition to active processing of subject matter and a continuous monitoring of understanding, participants understand the need to obtain long-term storage and understanding, rather than short-term results, in some cases prompted by the perspective of having to become a capable doctor.

\section{Discussion}

This paper outlines the results of a study investigating highly effective strategy users' approaches to learning. As a starting point, a survey was administered to students asking about their study strategies and how they approach their learning. Results from this survey indicated students' adherence to some highly effective strategies (e.g., self-testing), but also the use of some of the less effective strategies (e.g., highlighting). Afterwards, focus groups were organized in order to gain insight into how students use these learning strategies. Specifically, as survey data can provide insight into which strategies students use and how often they use them, the qualitative approach can clarify why students use these strategies, under which circumstances, and how flexible they are regarding their use.

Based on the focus groups, a model was constructed which describes how these students prepare for different learning activities. The first element in our model, as emanating from the focus groups was the distinction between quantitatively versus qualitatively oriented students. The students who mentioned having a learning goal, expressed this in a way that suggests a sharp distinction between these two opposites: students are either quantitatively or qualitatively oriented. However, from a motivational or self-regulatory perspective, one would expect this variable to fall along a continuum (Ryan \& Deci, 2000), with students leaning more towards either side of the spectrum depending on varying contexts and conditions. For example, it is conceivable that students who have a predominantly qualitative orientation might become more quantitatively oriented in the face of insecurities or time constraints. Conversely, generally quantitatively oriented students might adopt a more qualitative orientation when studying topics they are highly interested in. Possibly, students who did not express a learning goal might fall somewhere along this spectrum (a point we have tried to emphasize by adding the dotted line connecting the two opposites). Validating the polarized versus continuous nature of this distinction, as well as determining the factors that influence students' respective orientations, could be an interesting avenue for future research.

The second theme concerned students maintaining a continuous balance between established habits versus a flexibility to meet changing demands. Indeed, this would make sense from a desirable difficulties perspective, as these students do not 'give up' in the face of changing demands, but rather persist and adapt to the situation in order to reach their goals. Earlier research also correlated flexibility (termed adaptive control) with self-regulated 
learning, deep processing, and a propensity to undertake effortful cognitive activities (Evans, Kirby, \& Fabrigar, 2003). In terms of implications, several follow-up questions can be asked. First, what is the optimal combination between habits and flexibility? Will this balance be different in less effective students? What are students' core habits? What should be flexible, and what should be stable? What can be taught? Interventions should focus on optimizing this balance. Monitoring of understanding could be at the core of these interventions. When students have an accurate insight into which aspects they do and do not understand, and which strategies lead to a better understanding, it can be easier to make decisions about which strategies need to remain stable, and which should be adapted.

The third theme arising from the data, which characterized students' learning process, was students' continuous engagement in active processing of the learning material and monitoring of understanding. In addition to being aspects of effective (self-regulated) strategy use (Dunlosky et al., 2013; Zimmerman, 1990), it is also possible that this result can (at least partly) be attributed to the problem-based learning curriculum in which this study took place, as these learning methods are hallmarks of this instructional approach (HmeloSilver, 2004; Loyens, Magda, \& Rikers, 2008). Indeed, one of the students in the focus group even indicated the problem-based curriculum as a reason for adopting an active approach to learning. Given the fact that this study has only been carried out in a problem-based learning context, it is difficult to disentangle these influences. Future studies could seek to unravel these factors further.

The final theme emerging from the focus groups concerned students' metacognitive knowledge. Interestingly, students reported using several strategies which traditional selfreport questionnaires tend to treat as 'ineffective', but used them in an active way to help cope with the demands of their specific learning situation. This indicates that what matters most is not which strategies students use, but rather how they use them. In other words, students adapted strategies to fit their particular learning situation. Indeed, students' adaptability in their strategy use has been identified by other authors as an important feature of effective self-regulation in students (Broekkamp \& Van Hout-Wolters, 2007). This sense of flexibility was also evident in other parts of the model, where students maintained a continuous balance between established study habits on the one hand, and a sense of flexibility to deal with changes on the other.

Another reason for students' use of surface-level learning strategies could be the form of assessment. Students are often assessed with multiple-choice question tests or open question tests focused solely on short-term retention of information. Several studies have found that students will adapt their strategies based on what they perceive will be expected of them on the examination (Broekkamp \& Van Hout-Wolters, 2007; Thomas \& Rohwer, 1986). Indeed, students in our study indicated changing their strategies according to whether questions would be asked in a multiple choice versus an open question format. In this sense, 
rather than being 'ineffective', these surface-level strategies could be interpreted as being highly efficient in terms of the (short-term) goal students are aiming to achieve, if this goal is to obtain a good grade on the retention-based exam (Morris, Bransford, \& Franks, 1977). If the goal of the curriculum is for students to strive for deep-level processing and understanding, the test demands need to be aligned with this objective (Broekkamp \& Van Hout-Wolters, 2007), asking questions that will require this approach from students.

On the other hand, several students indicated an understanding of the need to obtain long-term retention and understanding, an inclination that seemed to be promoted by a desire to become a capable doctor. This can have important implications for interventions aimed at improving self-regulation for students who are less skilled self-regulators. Specifically, if interventions would focus on aiding students in attaining a clear perspective of their goals and long-term profession, this could improve their self-regulatory behavior and intention to build in desirable difficulties into their learning. Although we did not originally set out to investigate the link between students' learning behavior and their future time perspective, previous work has been done to establish this link, with research indicating that students' long-term time perspectives are associated with adaptive self-regulatory strategies and deep cognitive processing (Bembenutty \& Karabenick, 2004; De Bilde, Vansteenkiste, \& Lens, 2011). As these studies are mostly correlational, the direction of these effects is not entirely clear. Future research could try to establish the direction of causality by employing a longitudinal (De Bilde et al., 2011) or experimental approach.

The model identified can elaborate on existing theoretical models of metacognition by explicating the criteria students use to monitor and control their learning and how they adapt their strategies to fit their learning needs. For example, Nelson and Narens (1990) outline a theoretical framework in which students' allocation of study time is determined by their judgments about the difficulty it takes them to master certain information (ease of learning; EOL), their judgments about how well they have mastered certain recallable information (judgments of learning; JOL), and the degree to which they believe they have previously known currently unrecalled information (feeling of knowing; FOK). Their research found that students will allocate extra study time based on their EOL, JOL and FOK judgments, with students studying general information items generally allocating extra study time to information with a lower EOL (meaning they are judged to be harder), higher FOK, and lower JOL. Also when it comes to the allocation of restudy, students will allocate this restudy time to information they judge as poorly learned (Nelson, Dunlosky, Graf, \& Narens, 1994). The current study adds to this literature by shedding light on some of the criteria students may use to make these judgments. Specifically, students seem to focus on qualitative or quantitative criteria for making these judgments. Furthermore, for FOK, Nelson and Narens (1990) indicate that these judgments monitor the recallable aspects of the information a student has in memory (such as whether they have used it to correctly answer a question before). This could potentially 
explain the differences between the qualitative and quantitative orientations found in our study. For some students, the qualitative aspects related to the studied information may be hard to recall. For example, some of the information may never have been tested yet, making it difficult for students to derive these judgments. This may lead them to focus on more easily recallable, quantitative information instead.

Following this line of reasoning, this focus on easily recallable, quantitative aspects of learning may lead students to adopt more surface-level strategies, as these might be sufficient to satisfy the quantitative criteria. Indeed, Koriat (1997) found that extrinsic cues are less informative for students' JOLs than intrinsic cues, and these inaccurate JOLs could in turn lead to inadequate study strategies. Although students in our study seemed to follow the same general path of self-regulation, the qualitative approach might lead to more elaborative learning strategies and incorporation of desirable difficulties. However, a focus on quantitative criteria is apparently sufficient for students to pass their exams and be successful in university (a point which was already elaborated upon above). However, we do not have any information about their long-term retention. Future studies should focus on more elaborative learning outcomes and longer retention intervals, to further unravel the potentially differential effects of the different approaches to learning.

This study has several limitations. First, our focus groups were limited to second-year undergraduate medical students who were effectively self-regulating their learning. Given the PBL context in which these students are learning, this provided a fruitful basis to start from when investigating effective students' approaches to learning, but we cannot be sure about how these findings relate to other student populations. Furthermore, our study was limited to students from the undergraduate medical program. It is possible that there are characteristics in this program, which are not easily transferable to programs focusing on other domains. A specific example of this can be found in the long-term perspective that several students indicated as the basis for their desire to understand the subject matter, as hinted at above. In a study program like Medicine, the end goal of becoming a doctor is quite clear. In many other undergraduate programs, this long-term perspective may be less evident. Future research could look into what constitutes effective self-regulation in other study programs and other, non-PBL oriented universities. Furthermore, although the purpose of this study was to illustrate effective self-regulation rather than to contrast different groups of students, it would be interesting to see what picture will emerge when asking the same questions to low self-regulating students. We have tried to ensure replicability by providing rich descriptions of context, methods, and results, in an attempt to increase opportunities for judgments of transferability.

Related to the distinction between effective versus ineffective strategy users is the question of whether we were able to correctly identify which students were effective strategy users. We used students' mentors as informants for our purposeful sampling strategy. We 
have confidence in this strategy, as mentors are among the few key persons who have a bird's eye view of students' overall performance, for both the entire duration of the program, as well as in comparison to other students. They also discuss students' learning strategies at least two times during the first year in an individual mentor meeting. However, their judgments are inherently subjective, and although they were given instructions on what is meant by effective strategy users, we have no insight into their decision making when they selected these students. Although it was a conscious decision not to include grades as a measure of self-regulation (as students using shallow strategies may very well obtain good test results in the short term), it could be worthwhile to think about other ways to triangulate students' strategy effectiveness.

Finally, we chose to use a learning strategy questionnaire used by Hartwig and Dunlosky (2012) as a starting point for our study, in order to build further on this work and demonstrate the added value of the focus groups in this context. However, as this survey measures each strategy by only one item, it was not possible to compute reliability or internal consistency estimates. This problem is mitigated by the fact that we used the survey as a starting point for our focus groups, rather than conducting analyses analyzing differences between groups or as a result of some intervention. However, the research design could be strengthened by adding more items per strategy, in order to be able to make inferences about the reliability and internal consistency of students' responses.

Overall, this study contributes to the literature by providing an in-depth, qualitative description of how highly self-regulated medical students in a PBL curriculum approach their learning and build in desirable difficulties in their learning process. This model can serve as a framework for further study into the various factors that influence (effective) self-regulation, and as a starting point for designing interventions focused on improving strategy use in less effective students.

\section{Funding information}

This research was funded by the Netherlands Organisation for Scientific Research (Veni grant number 451-10-035) awarded to Anique de Bruin. 


\section{References}

Arbesman, S. (2013). The half-life offacts. Whyeverything we know has an expiration date. New York: Penguin Group.

Bembenutty, H., \& Karabenick, S. A. (2004). Inherent association between academic delay of gratification, future time perspective, and self-regulated learning. Educational Psychology Review, 16, 35-57. doi:10.1023/B:EDPR.0000012344.34008.5C

Bernacki, M. L., Byrnes, J. P., \& Cromley, J. G. (2012). The effects of achievement goals and self-regulated learning behaviors on reading comprehension in technology-enhanced learning environments. Contemporary Educational Psychology, 37(2), 148-161. doi:10.1016/j.cedpsych.2011.12.001

Bjork, R. A. (1994). Memory and metamemory considerations in the training of human beings. In ]. Metcalfe \& A. Shimamura (Eds.), Metacognition: Knowing about knowing (pp. 185-205). Cambridge, MA: MIT Press.

Blasiman, R. N., Dunlosky, J., \& Rawson, K. A. (2017). The what, how much, and when of study strategies: comparing intended versus actual study behaviour. Memory, 25(6), 784-792. doi:10.1080/09658211.2016.1221974

Boud, D., \& Falchikov, N. (2006). Aligning assessment with long-term learning. Assessment \& Evaluation in Higher Education, 31(4), 399-413. doi:0.1080/02602930600679050

Bråten, I., \& Samuelstuen, M. S. (2007). Measuring strategic processing: comparing task-specific self-reports to traces. Metacognition and Learning, 2(1), 1-20. doi:10.1007/s11409-007-9004-y

Broekkamp, H., \&Van Hout-Wolters, B. H. A. M. (2007). Students' adaptation of study strategies when preparing for classroom tests. Educational Psychology Review, 19, 401-428. doi:10.1007/s10648-006-9025-0

Charmaz, K. (2014). Constructing grounded theory. Thousand Oaks, CA: Sage Publications.

Creswell, J. W. (2007). Qualitative inquiry and research design: Choosing among the five approaches (3rd ed.). Thousand Oaks, CA: Sage Publications

De Bilde, J., Vansteenkiste, M., \& Lens, W. (2011). Understanding the association between future time perspective and selfregulated learning through the lens of self-determination theory. Learning and Instruction, 21(3), 332-344. doi:10.1016/j. learninstruc.2010.03.002

Dunlosky, J., Rawson, K. A., Marsh, E. J., Nathan, M. J., \& Willingham, D. T. (2013). Improving students' learning with effective learning techniques: Promising directions from cognitive and educational psychology. Psychological Science in the Public Interest, 14(1), 4-58. doi:10.1177/1529100612453266

Evans, C. J., Kirby, J. R., \& Fabrigar, L. R. (2003). Approaches to learning, need for cognition, and strategic flexibility among university students. British Journal of Educational Psychology, 73(4), 507-528. doi:10.1348/000709903322591217

Hartwig, M. K., \& Dunlosky, J. (2012). Study strategies of college students: Are self-testing and scheduling related to achievement? Psychonomic Bulletin \& Review, 19(1), 126-134. doi:10.3758/s13423-011-0181-y

Helsdingen, A., Van Gog, T., \& Van Merriënboer, J. (2011). The effects of practice schedule and critical thinking prompts on learning and transfer of a complex judgment task. Journal of Educational Psychology, 103(2), 383-398. doi:10.1037/a0022370

Hmelo-Silver, C. E. (2004). Problem-based learning: What and how do students learn? Educational Psychology Review, 16(3), 235266. doi:10.1023/B:EDPR.0000034022.16470.f3

Karpicke, J. D., Butler, A. C., \& Roediger, H. L. (2009). Metacognitive strategies in student learning: do students practise retrieval when they study on their own? Memory, 17(4), 471-479. doi:10.1080/09658210802647009

Kirschner, P. A., Sweller, J., \& Clark, R. E. (2006). Why minimal guidance during instruction does not work: An analysis of the failure of constructivist, discovery, problem-based, experiential, and inquiry-based teaching. Educational Psychologist, 41(2), 75-86. doi:10.1207/s15326985ep4102_1

Kitzinger, ]. (1994). The methodology of focus groups: the importance of interaction between research participants. Sociology of Health and IIIness, 16(1), 103-121. doi:10.1111/1467-9566.ep11347023

Kitzinger, J. (1995). Qualitative research. Introducing focus groups. BM], 311, 299-302. doi:10.1136/bmj.311.7000.299

Koriat, A. (1997). Monitoring one's own knowledge during study: A cue-utilization approach to judgments of learning. Journal of Experimental Psychology: Ceneral, 126(4), 349-370. doi:10.1037/0096-3445.126.4.349 
Kornell, N., \& Bjork, R. A. (2007). The promise and perils of self-regulated study. Psychonomic Bulletin \& Review, 14(2), 219-224. doi:10.3758/BF03194055

Loyens, S. M. M., Magda, J., \& Rikers, R. M. J. P. (2008). Self-directed learning in problem-based learning and its relationships with self-regulated learning. Educational Psychology Review, 20(4), 411-427. doi:10.1007/s10648-008-9082-7

McCardle, L., \& Hadwin, A. F. (2015). Using multiple, contextualized data sources to measure learners' perceptions of their selfregulated learning. Metacognition and Learning, 10(1), 43-75. doi:10.1007/s11409-014-9132-0

Morris, C. D., Bransford, J. D., \& Franks, J. J. (1977). Levels of processing versus transfer appropriate processing. Journal of Verbal Learning and Verbal Behavior, 16(5), 519-533. doi:10.1016/S0022-5371(77)80016-9

Moust, J. H. C., Van Berkel, H. J. M., \& Schmidt, H. G. (2005). Signs of erosion: reflections on three decades of problem-based learning at Maastricht University. Higher Education, 50, 665-683. doi:10.1007/s10734-004-6371-z

Nelson, T. O., Dunlosky, J., Graf, A., \& Narens, L. (1994). Utilization of metacognitive judgments in the allocation of study during multitrial learning. Psychological Science, 5(4), 207-213. doi:10.1111/j.1467-9280.1994.tbo0502.x

Nelson, T. O., \& Narens, L. (1990). Metamemory: A theoretical framework and new findings. In C. H. Bower (Ed.), The psychology oflearning and motivation (Vol. 26, pp. 125-173). San Diego, CA: Academic Press.

Panadero, E., Klug, J., \& Järvelä, S. (2016). Third wave of measurement in the self-regulated learning field: when measurement and intervention come hand in hand. Scandinavian Journal of Educational Research, 60(6), 723-735. doi:10.1080/00313831.2015. 1066436

Perry, N. E., \& Winne, P. H. (2006). Learning from learning kits: gStudy traces of students' self-regulated engagements with computerized content. Educational Psychology Review, 18, 211-228. doi:10.1007/s10648-006-9014-3

Ritchie, J., Lewis, J., Nicholls, C. M., \& Ormston, R. (2013). Qualitative research practice: A guide for social science students and researchers. Thousand Oaks, CA: Sage.

Roediger, H. L., \& Karpicke, J. D. (2006). Test-enhanced learning: Taking memory tests improves long-term retention. Psychological Science, 17(3), 249-255. doi:10.1111/j.1467-9280.2006.01693.x

Ryan, R. M., \& Deci, E. L. (2000). Self-determination theory and the facilitation of intrinsic motivation, social development, and well-being. American Psychologist, 55(1), 68-78. doi:10.1037/0003-066X.55.1.68

Schellings, G. (2011). Applying learning strategy questionnaires: problems and possibilities. Metacognition and Learning, 6(2), 91109. doi:10.1007/s11409-011-9069-5

Schmidt, H. G. (1983). Problem-based learning: Rationale and description. Medical Education, 17, 11-16. doi:10.1111/j.1365-2923.1983 tbo1086.x

Schunk, D. H., \& Zimmerman, B. J. (1994). Self-regulation of learning and performance: Issues and educational applications. Hillsdale, N]: Lawrence Erlbaum Associates, Inc.

Thomas, J. W., \& Rohwer, W. D. (1986). Academic studying: The role of learning strategies. Educational Psychologist, 21(1-2), 19-41. doi:10.1080/00461520.1986.9653022

Van Merriënboer, J. J. G., De Croock, M. B. M., \& Jelsma, O. (1997). The transfer paradox: Effects of contextual interference on retention and transfer performance of a complex cognitive skill. Perceptual and Motor Skills, 84(3), 784-786. doi:10.2466/pms.1997.84.3.784

Van Merriënboer, J. J. G., \& Kirschner, P. A. (2018). Tensteps to complex learning: Asystematic approach to four-component instructional design. New York, NY: Routledge.

Veenman, M. V. J. (2011). Alternative assessment of strategy use with self-report instruments: a discussion. Metacognition and Learning, 6, 205-211. doi:10.1007/s11409-011-9080-x

Watts, M., \& Ebbutt, D. (1987). More than the Sum of the Parts: research methods in group interviewing. British Educational Research Journal, 13(1), 25-34. doi:10.1080/0141192870130103

Winne, P. H., \& Hadwin, A. F. (1998). Studying as self-regulated learning. In D. J. Hacker, J. Dunlosky, \& A. C. Graesser (Eds.), Metacognition in educational theory and practice (pp. 277-304). Mahwah: Lawrence Erlbaum.

Zimmerman, B. J. (1990). Self-regulated learning and academic achievement: An overview. Educational Psychologist, 25(1), 3-17. doi:10.1207/s15326985ep2501_2 


\section{Appendix}

\section{A: Mentor instructions for identification of effective strategy users}

Dear Medicine Year 1 mentors,

With permission of [the coordinator] I am e-mailing you with a question. Do you also notice that some students use very efficient study strategies, while others struggle with planning their study, how to make summaries and how to prepare for the exam? I am an educational researcher at the department of educational development \& research, and I study metacognition and study strategies. I would like to map the effective study strategies of students, because I think other students can learn a lot from the 'best practices' of their fellow students and to see how these strategies correspond with 'evidence-based' strategies.

\section{What do I want to ask from you?}

For this study I would like to interview first-year Medicine students with good study strategies. In order to identify these students, mentors are the best suited. Throughout the entire previous year, they have witnessed the students from a close range. We are referring both to students who study well (have a good way of preparing for the tutorial group and exam), as well as students who are good at planning their study. Would you be able to e-mail me the names of two or three students from your mentor group in this academic year who you think had the best study strategies? At this point, this should be fresh in your memory. I will then contact the students to ask them if they would like to participate in the interview (this is of course voluntary, completely anonymous, and for a monetary reward). We plan to have the interviews in October 2014. This is the only way to reach the right students for the study, so I am looking forward to your responses (preferably as soon as possible, before July $11^{\text {th }}$ at the latest).

Anique de Bruin. 


\section{B: Learning strategy questionnaire administered prior to the focus groups}

Please indicate how often you use these strategies (Please indicate on a scale from 1 [never] - 2 [almost never] -3 [sometimes I do, sometimes I don't] - 4 [almost always] -5 [every study session]).

1. Rereading of books or articles

2. Making a summary

3. Underlining/marking text

4. Explaining to myself what I am reading

5. Trying to form a mental image (an image in my head) of what I am reading

6. Testing myself with practice tests or self-made test questions

7. Asking someone else to test me

8. Asking questions to other students (outside of the tutorial group)

9. 'Cramming' on the night before the test

10. Studying with friends/other students

11. Other (please indicate which ones)

\section{Further questions}

12. How do you decide what to study next? [open question]

13. Do you usually return to study material from an earlier course after a course has ended? Please indicate on a scale from 1 (never) $-2-3-4-5$ (always)

14. When you study, do you usually read the book/article/other source more than once? Please indicate on a scale from 1 (never) $-2-3-4-5$ (always)

15. Imagine that in the course of studying, you notice that you understand a certain concept in the text. What do you do? [Please indicate: Don't study it again OR Study it again later]

16. What time of the day do you mostly do your studying? [Please indicate: morning, afternoon, evening]

17. During what time of the day do you believe your studying is most effective? [Please indicate: morning, afternoon, evening] 
18. What do you usually do: Prepare for a tutorial group in one study session right before the tutorial group OR space out tutorial group preparation over multiple study sessions?

19. How did you develop the study strategies you are using now? [open question]

20. If you had the time and somebody would explain it to you, would you want to change your study strategies? [yes/no]

21. What and why would you then want to change? [open question]

22. What kind of education would you most appreciate to change your study strategies? Think about: lectures, videos, practice with a trainer, etc. [open question]

23. Do you have any other comments? [open question] 
2C: Interview protocol used for the focus groups

Interview guide second year students Medicine - Study strategies

Learning Strategies of Medical Students: Improving Learning Effectiveness

\author{
Meetings:
}

26 November 10:00-12.00,

1 December 16:00-18:00,

3 December 11:00-13:00 \& 16:00-18:00

Leading Research Questions:

- How do undergraduate medical students prepare for educational meetings and exams, and how do they self-regulate their learning?

- To what extent do they use evidence-based strategies as self-testing and spacing?

- What are the different varieties of evidence-based strategies as self-testing and spacing that students use?

- What types of activities do they undertake to regulate their study behavior?

\title{
To do before the start of the interview
}

- Informed consent: To emphasize the research goal again, to declare that the participant is allowed to leave at every moment and that their results will be anonymized. They will receive a copy of the transcripts as a complement.

- NB: Let them sign the form! 
Interview

\section{Introduction}

Research has shown that students in higher education rarely use effective study strategies. This leads to suboptimal learning results. Changing study strategies is often desired, but it is often not self-evident how this can be achieved and which alternatives are available.

In this research we want to interview students with effective study strategies to make an overview which strategies they use, to view how these correspond with scientifically proven strategies and which strategy variants they use. We also want to hear about their ideas and experiences about how they change their strategies and regulate their study behaviour.

\section{Step 0}

To give a global explanation of the goal of this research ("to get an overview on how students prepare for different study activities and which study strategies they use").

\section{Step 1}

To discuss different study strategies and the usage of them by students.

\section{Procedure Step 1:}

- Through strategies mentioned in the questionnaire (filled in by the students) the moderator will ask the students to describe in which extent they know and use these strategies.

- Students receive a sheet with different study strategies.

- After students have read this sheet, the next things will be discussed:

- To which extent students use and know these strategies

- To which extent the students use the strategies, depending on the assignment, education activity or other factors

- To which extent students are aware of how they plan and regulate their study [n.b. to what extent students consciously plan and regulate their study (not planning in the sense of time management. If students tend to move in that direction, guide them in another direction)] 
Step 2

Enhancing different study strategies and preparation on educational activities

\section{Procedure Step 2:}

- Through several vignettes about different educational activities the moderator will ask students to describe how they would prepare for these educational activities, which strategies they use for this and to name concrete examples.

- Students will get a sheet book with one vignette on each page.

- After students have read the vignette, the moderator will ask the questions listed below (questions with step 1) per vignette.

- The pile of vignettes will be worked through one by one.

- After discussing the vignettes, the moderator will ask for a summary:

- Which strategies do you most often use and why?

- How did these strategies develop?

- What is the best tip for other students to improve their study strategies?

\section{Questions according to Step 2 (per vignette):}

1. Approach: how do you prepare for this educational activity?

2. Example approach: can you give an example on how you prepared?

3. Variation in strategies: to what extent do you vary in your approach and which other approaches do you use?

4. [N.B. Questions 1,2 and 3 keep asking about self-testing and spacing]

5. Self-regulation: do you verify if you have prepared enough? How do you do that and what do you to be better prepared? N.B. The use of 'self-testing' can be emphasized here.

6. Feedback: how do you cope with the feedback you received on this educational activity? And with information outside of the regular materials (tutor instructions, summary, information from tutor e.g. Learning goals)?

7. Confidence: are you satisfied about your preparation?

8. Change: if you would change something about your preparation, what would it be? 


\section{Vignettes}

1. Case As usual you will get a new case to prepare before the tutorial meeting next Monday. The subject is a little bit of repetition, but most parts are totally new. How do you prepare your case? How do you look for literature and resources for your case and how do you estimate how much time you need to prepare? Could you explain how you would prepare for the tutorial meeting?

2. Skillslab (excluded from analysis) The OSCE test is coming later in the year. You already heard from several people that the test is going to be hard and everything has to be according to the rules. How would you approach this OSCE test? How did you do that with previous feedback sessions? Do you make use of Teacher-Independenttraining?

3. Exam You are just starting your 8-week course and know that the course is going to be heavy and hard. There are no tests in between, so there is only one chance to pass this course. The cases are very different. A couple of cases are about the same subject while the other cases are about several different subjects. How do you prepare for an exam with only multiple choice questions? And how do you prepare for an exam with open questions? And what do you do when it is a combination of multiple choice and open questions?

4. Progress test (excluded from analysis) In one and a half month the progress test is coming up. Last year it was easy but this year it is different, because you also have to remember the knowledge of the last courses. The knowledge you have to know keeps increasing. How do you prepare now for the progress test? How do you cope with feedback (PROF system)?

5. Pscribe (excluded from analysis) In the beginning of the year you hear about a pharmacology assignment that has to be handed in in three weeks. You are allowed to work together if you wish, but it is not allowed to hand in the same assignment. You already know a little bit about the subject, but this knowledge needs to be refreshed. How do you approach this assignment?

6. Extra-curricular assignment (excluded from analysis) In the beginning of the year you get to know that there is a surgical assignment due in 4 months. This assignment consists a report about a specialized subject. You cannot obtain information as easily as in usual in the commonly known books. Nobody you know has the same assignment. How do you approach this assignment? 
Protocol $2^{\text {nd }}$ round Focus groups Medicine year 2

\section{Coal meeting:}

To obtain a rank of advisable study strategies per educational activity to recommend to students.

Different study strategies used by students in every educational activity in the first meeting are placed together. The question is to rank these study strategies from most to least advisable to other students.

\section{Concrete:}

1. Make, after discussion, a top 5 of most advisable study strategies (from most to least) per educational activity. [this might be not achievable for all educational activities. Do this for at least the tutorial, skillslab, exams and progress test].

2. Also declare why you recommend these 5 strategies and why this order.

Thank students for participating and distribute Iris cheques (vouchers), let students sign the form. 
Chapter 2

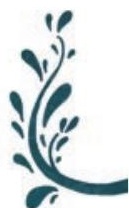


CHAPTER 3 


\title{
Granularity matters:
}

Comparing different ways of measuring

self-regulated learning

Rovers, S. F. E., Clarebout, G., Savelberg, H. H. C. M., de Bruin,

A. B. H., \& van Merriënboer, J. J. G. (2019).

Metacognition and Learning, 14(1), 1-19.

\begin{abstract}
Although self-regulated learning (SRL) is becoming increasingly important in modern educational contexts, disagreements exist regarding its measurement. One particularly important issue is whether self-reports represent valid ways to measure this process. Several researchers have advocated the use of behavioral indicators of SRL instead.

An outstanding research debate concerns the extent to which it is possible to compare behavioral measures of SRL to traditional ways of measuring SRL using self-reportquestionnaire data, and which of these methods provides the most valid and reliable indicator of SRL.

The current review investigates this question. It was found that granularity is an important concept in the comparison of SRL measurements, influencing the degree to which students can accurately report on their use of SRLstrategies. The results show that self-report questionnaires may give a relatively accurate insight into students' global level of self-regulation, giving them their own value in educational research and remediation.

In contrast, when students are asked to report on specific SRL strategies, behavioral measures give a more accurate account. First and foremost, researchers and practitioners must have a clear idea about their research question or problem statement, before choosing or combining either form of measurement.
\end{abstract}




\section{Introduction}

Since the emergence of the Internet, there has been a sharp increase in the amount of information available, and the half-life of information has dramatically shortened (Arbesman, 2013). For students and professionals alike, this 'information jungle' can be hard to navigate. In order to survive, they need to constantly monitor and evaluate their progress towards their own learning goals, and adjust their behavior if necessary. These skills are captured by so-called self-regulated learning skills (Zimmerman \& Schunk, 1989). Within the context of education, self-regulated learning (SRL) concerns the process whereby learners actively take charge of their own learning. They actively monitor their learning process and outcomes, and are able to regulate and adapt their behavior, cognition and motivation when necessary to optimize their learning outcomes (Zimmerman, 2000). Due to the enormous increase in available information, SRL has become much more important for students in order to complete their education, but its measurement has been a problematic aspect (Winne, 2010; Veenman, Van Hout-Wolters, \& Afflerbach, 2006).

In order for students to develop effective SRL strategies and to be appropriately supported in this development, researchers and educators need accurate, reliable measures for this construct. In this way, researchers and educators can come to an accurate account of students' self-regulation and students' points for improvement. In 2008, Zimmerman published an article on innovative ways of measuring SRL (Zimmerman, 2008). In this work, several outstanding questions regarding the measurement of SRL were highlighted. One of these questions was the extent to which it is possible to compare trace data (computerized log files of students' online behaviors) to traditional ways of measuring SRL using self-report questionnaire data. As Veenman (2005) pointed out, convergence between self-report statements and concurrent behavior tends to be low, however many new approaches have emerged since this publication that warrant closer investigation. This narrative review will discuss the progress that has been made in this area and extend the question to the comparison of self-report questionnaires to several online measures of SRL.

To provide the background for this study, this section will first introduce some of the most influential models describing the SRL process. Ideally, measurement of SRL is informed by a theoretical model, with the model serving as the underlying framework. After introducing the models, we will describe some important considerations in the measurement of SRL (online versus offline measuring, calibration and granularity), after which we will describe the common methods used for measurement. Being the traditional way to measureSRL (Schellings \& Van Hout-Wolters, 2011), we will first introduce the use of self-report questionnaires. We will then address the concerns associated with this form of measurement, before describing alternative, online forms of measurement (e.g. think-aloud protocols, systematic observations and computerized log data). 
Influential models of SRL have been put forth by Zimmerman (2000), Pintrich (2004) and Winne and Hadwin (1998). Social-cognitive models were developed by Zimmerman (2000) and Pintrich (2004). Another SRL model was developed by Winne and Hadwin (1998) and focuses on the specific cognitive processes that occur during learning, such as memory processes and operations (Greene \& Azevedo, 2007).

A common theme in most SRL models is that SRL is viewed as a loosely sequenced process of cyclical phases. The social-cognitive model postulated by Zimmerman (2000) describes a cyclical feedback loop of three phases constituting SRL: forethought, performance and reflection. The cyclical nature of these phases postulates that the outcome of each phase provides input for and influences processes in the other phases.

Pintrich (2004) put forth a social-cognitive model of SRL that posits motivation, selfefficacy and goal orientation as the discerning aspects of SRL. His model consists of four phases similar to those put forth by Zimmerman (2000), including forethought, monitoring, control and reflection. As an addition to Zimmerman's model, the model postulates four areas for regulation of learning. Specifically, students can regulate their cognition, motivation, behavior and learning environment.

The SRL model by Winne and Hadwin (1998) consists of four phases: task definition, setting learning goals and plans, enactment of learning strategies, and adapting. In each of these phases, SRL is influenced by a set of processes involving interaction between the conditions, operations, products, evaluations and standards (COPES) that students find themselves in. The learning cycle within this model is again loosely sequenced: learners are expected to go through all of the phases, but may return to earlier phases when they feel this will help improve their products in a later phase. Throughout the process, learners apply a range of choices based on their motivation to execute the task at hand (Winne, 2018).

When it comes to the measurement of SRL, several considerations are reflected in the different forms of measurement. First of all, a distinction can be made between online and offline measures (Schellings, 2011; Veenman, 2005), depending on the timing of the measurement. Online measures (sometimes called process measures) take place during the performance of the actual learning task. Examples include think-aloud protocols, systematic observations or computerized traces with log data. Offline measures are collected either before or after task performance. Self-report questionnaires usually fall into this category. It is important to note that, although this terminology can be somewhat misleading, the distinction between online and offline measurements does not refer to the mode of administration (i.e., whether or not the Internet is used), but to the timing of measurement (before/after or during task performance). For example, a questionnaire that is administered electronically after task performance will still be considered an offline measurement, while a micro-analytic question administered on paper during task performance is an online measurement.

Another important construct in the context of this review is the concept of calibration, 
which can be defined as the degree of correspondence between an individual's self-report of a certain cognitive construct versus the actual, online value of this construct (Winne \& Jamieson-Noel, 2002). This calibration can focus on process variables, for example on the degree of overlap between students' self-reports of cognitive strategy use and their actual strategy use, or on outcome variables, such as the level of correspondence between students' estimated achievement and their actual achievement (e.g. judgments of learning; Schneider, 2008). The focus of this review is on calibration in terms of process variables.

Finally, SRL can be measured at different levels of granularity. Granularity refers to level of detail at which self-regulatory processes are measured. SRL can be measured on a coarse grained level when looking at global SRL process phases, as opposed to fine grained SRL measurements that focus on students' micro-level SRL processes (Azevedo, 2009).

Reflecting these different considerations at varying levels, different methods have been applied to measure SRL. The traditional way to measure SRL is through self-report questionnaires. Examples include the Motivated Strategies for Learning Questionnaire (MSLQ: Pintrich, Smith, Garcia, \& McKeachie, 1991), the Learning and Study Strategies Inventory (LASSI; Weinstein \& Palmer, 2002) and the Metacognitive Awareness Inventory (MAI; Schraw \& Dennison, 1994). Self-report questionnaires tend to treat SRL as a stable aptitude or trait belonging to an individual, giving an indication of how an individual usually approaches learning tasks, thereby aggregating these approaches to studying across studying contexts, episodes and tasks (Schellings, 2011; Schellings, Van Hout-Wolters, Veenman, \& Meijer, 2013; McCardle \& Hadwin, 2015). A main reason for the popularity of self-report questionnaires is the ease with which they can be administered and analyzed, making it possible to examine large samples of learners (Schellings \& Van Hout-Wolters, 2011). However, increasingly large numbers of researchers in the field have stated objections to this approach to measuring SRL (Veenman, 2005; Winne, Jamieson-Noel, \& Muis, 2002; Winne \& Perry, 2000). These criticisms can be roughly divided into two concerns.

The first concern regards the treatment of SRL as a dynamic and context-dependent process versus a static and stable trait. SRL is considered to be a context-dependent process, and SRL strategies employed by students may vary both across and within learning tasks and contexts (McCardle \& Hadwin, 2015; Winne \& Hadwin, 1998; Bråten \& Samuelstuen, 2007). For example, students may employ different strategies when preparing for an exam, as opposed to reading for a class assignment (Bråten \& Samuelstuen, 2007). In a similar vein, students may need to employ different strategies for a mathematics course, as opposed to a humanities course. Furthermore, as described above, most SRL models view SRL as a dynamic, adaptive process. Students' motivation and use of learning strategies may fluctuate over the course of learning (Moos \& Azevedo, 2008). Although it is possible to account for this by applying short micro-analytic questionnaires at various points during the learning process (Cleary, Callan, Malatesta, \& Adams, 2015), most common self-report questionnaires are not suited for this 
purpose. Measurement methods that treat SRL as a static trait, despite the dynamic nature of the underlying models, are considered to be not sensitive enough to these subtle changes in students' SRL. Important information may be lost as a result, making it impossible to answer research questions involving fluctuations in students' SRL strategies within and across learning tasks, and interactions with learner and context characteristics (McCardle \& Hadwin, 2015).

The second concern regards the issue of whether students have the capacity to self-report their use of self-regulatory strategies. Traditional self-report measures of SRL require students to retrieve information about their strategy use from their long-term memory. This can be problematic for four reasons. Firstly, students are likely to have imperfect memory and these memory deficits may cause them to incorrectly report their strategy use. They may overrate the incidence of common events, while underrating the incidence of rare events (Perry \& Winne, 2006; Tourangeau, Rips, \& Rasinski, 2000). Additionally, it is possible that some SRL processes occur subconsciously, leaving students unaware of using them (Perry \& Winne, 2006). Secondly, the general nature of most self-report questionnaires may leave students uncertain about the context from which to draw the report of their strategy use. This may lead different students to use different contexts when answering the same questionnaire, or individual students to confuse several contexts in which they applied different strategies (Perry \&Winne, 2006; Schellings, 2011). Thirdly, the structured nature of self-report questionnaire items may lead to a situation where students indicate their perceived value of a strategy reflected in a questionnaire item, rather than their actual use of this strategy (Bernacki, Byrnes, \& Cromley, 2012; Bråten \& Samuelstuen, 2007). The fourth problem is that students may be inclined to provide socially desirable answers, reporting strategies that they think will please their parents, teachers or the researcher (Bråten \& Samuelstuen, 2007). In addition to this social desirability, students' ability to report their own use of strategies may also be influenced by how familiar they are with the strategies in the questionnaire. Specifically, learners who have insufficient declarative knowledge about self-regulatory strategies may incorrectly label the strategies they report using (Veenman, 2011).

As a result of these issues, researchers have increasingly advocated the use of other, online measures of SRL, in order to adopt a multi-method approach (Veenman, 2005; Winne, 2010). Examples include systematic observations in which the researcher observes students' outward behavior using a systematic, structured observation instrument (Perry, 1998), think-aloud protocols which require students to verbalize their thoughts while working on a task (Ericsson, 2006), and trace data in which time-stamped log files are created displaying students' actions in an online learning environment (Winne, 2010).

The theoretical background outlined above led us to formulate the following two research questions: 1) How do offline self-report questionnaires compare to online forms of measurement in terms of calibration of students' self-report of strategy use, versus their actual strategy use? 2) Does the degree of calibration vary as a function of the granularity at which 
SRL is measured? Although SRL is important for students at all educational levels, this review focuses on studies conducted with students in higher education. This decision was made based on two reasons. First, research has shown that the nature and development of SRL is very different for individuals of different age groups (e.g. Schneider, 2008). Second, as already hinted at above, the nature of learning in higher education is different than in earlier levels of education, with more demands being placed on students in terms of information seeking and independence. As a result, it would be ill-suited to make the comparison over different age groups at this point. We chose to do a narrative review rather than a meta-analysis for two related reasons. First, very few studies have addressed the measurement of SRL in such a manner that a comparison can be made between students' offline self-reports versus an online form of measurement. Second, in several cases where this comparison was possible, it was not the explicit goal of the research, but rather a byproduct of careful triangulation, thereby giving no statistics or effect sizes for the actual calibration. As a result of these factors, a proper meta-analysis with appropriate effect sizes and sufficient power (Pigott, 2012) may not be possible, and a more narrative approach is warranted.

\section{Methods}

\section{Search strategy}

We conducted a search for English, peer-reviewed articles in the following databases: BioMed Central, ERIC, Medline, Psyclnfo, Web of Science and PubMed using the search terms selfregulated learning calibration, (self-regulated learning) AND measur*, and metacognit* AND measur* AND higher education. Different combinations of these search terms yielded similar results. Furthermore, the reference lists from the included articles were screened for other relevant publications. We limited our search to include articles between January 2000-May 2016.

The initial search was conducted by the first author, yielding a total of 2059 hits. Based on initial title screening, 580 unique studies were included for abstract screening. After this, fifty-one studies were selected for potential inclusion. These studies were screened by two independent raters. Disagreements regarding inclusion versus exclusion of a study were resolved through discussion. We only included articles which focused on original research with students from higher education, which used and/or compared both offline self-report and an online SRL assessment tool to make a comparison between these different measurements. This resulted in the final inclusion of 14 studies.

\section{Quality assessment}

Buckley and colleagues (2009) recommend the following quality criteria on which to base judgments about whether or not to include studies in a review: (1) Does the article provide a clear indication of the research questions and hypotheses of the study? (2) Are the study 
participants suitable for the specific study in terms of sample size, selection method, participant characteristics and homogeneity? (3) Have the researchers used valid and reliable data collection methods? (4) Judgment regarding completeness of data. How many participants have dropped out of the study? Specifically, the study should have less than $50 \%$ attrition, or a response rate of at least $60 \%$ in case of survey-based studies. (5) Have the authors applied an appropriate control for confounding, accounting for or removing confounding variables if possible? (6) Is the analysis of results (statistical or otherwise) appropriate? (7) Do the data provide support for the conclusions drawn by the researchers? (8) Is sufficient information provided in the article to enable reproducibility of the study? (9) Does the article concern a prospective rather than a retrospective study? (10) Did the authors attend to all the ethical issues relevant to the study? (11) Was triangulation applied, supporting the results with data from multiple sources? In order for a study to be considered of high quality, Buckley et al. (2009) suggest that at least 7 of the 11 quality criteria must be met.

The first and second author independently judged the quality of the studies that were included. A three-point scale was used to judge quality on each of the criteria (+, +/-, -). Disagreements were resolved through discussion. On the basis of these quality criteria, all studies were retained in the review. Table 1 summarizes these quality criteria.

\section{Results}

When reviewing the literature, we found that in terms of granularity, a general distinction can be made between studies that measure and compare the use of specific self-regulatory strategies, such as highlighting, note creation (fine grained), for at least one of the measures, versus studies measuring a global degree of self-regulatory strategy use (coarse grained), using total scores for self-regulatory activity or scales. Making this distinction led to different conclusions in terms of calibration, as described further below. We will first describe the studies comparing specific strategies, followed by a description of the studies comparing students' global level of self-regulation. Table 2 and Table 3 provide an overview of the findings of this review, separated by method of comparison.

\section{Comparison of specific strategies}

Ten studies were retrieved that made a comparison between self-reports and online measurements in terms of students' use of specific SRL strategies. These studies can be clustered according to the form of online measurement that was used. We will discuss seven studies using trace data (with four studies focusing on specific learning strategies, and three other studies using goal theory as a starting point), one study using think-aloud protocols, one study using eye movements, and one study online forms of self-report, respectively.

One of the first studies since 2000 to compare offline self-report data with an online 
measure was conducted by Winne and Jamieson-Noel (2002). These researchers used traces of students' behavior in a software program called PrepMate as an online measure to study the degree of calibration in terms of students' achievement (alignment between students' prediction of achievement and their actual achievement) and self-report of study tactics (alignment between self-reports and traces of study tactics). Students studied a chapter on lightning formation, with achievement being measured using six items addressing all levels of Bloom's taxonomy (Bloom, Engelhart, Furst, Hill, \& Krathwohl, 1956). Questions were worth either five or ten points. After answering a question, students were asked how many of these points they would give themselves, based on the answer they provided to this question. The self-report questionnaire asked students in how many of the seven paragraphs of the text they had used the respective study strategies (for a full list of strategies, see Winne \& Jamieson-Noel, 2002). Two items on planning were measured dichotomously and scored as no-planning $=0$ or planning $=7$. Calibration in study tactics was measured by comparing students' responses on the questionnaire to their behavior in PrepMate, making a comparison between the number of paragraphs in which students reported using the specific study strategies, versus the number of paragraphs in which they were shown to have used these strategies in PrepMate. It was found that despite a consistent general tendency for overconfidence, students were quite well calibrated in terms of their achievement, with a median calibration of $r=.88$ (although quite some variability among different items was found). More importantly however, there was a higher degree of bias and low calibration in students' reporting of their use of study tactics, with a median calibration of $r=34$. Lowest calibration was found for students' reports of setting objectives and planning a method for the learning task. Furthermore, calibration of study tactics was not related to achievement, while prior knowledge and calibration of achievement were in fact related to achievement. In other words, the degree to which students were able to accurately report their use of study tactics was not related to achievement, but students with higher achievement scores were better able to predict their achievement, when compared to lower achieving students. This indicates that these two forms of calibration tap into different constructs. Prior knowledge was not related to either form of calibration.

In a follow-up analysis, Jamieson-Noel and Winne (2003) again found significant differences between students' self-reports of their study tactics and traces of their actual studying behavior. To investigate the predictive value of traces and self-reports on achievement, separate regression analyses were run for both measurement types. Interestingly, when constructing a measure of traces and self-reported overall SRL intensity by averaging the trace scores and responses to the self-report items respectively, results showed that self-reported SRL intensity (i.e. perceived effort spent with the application of study tactics) significantly predicted achievement (explaining $16 \%$ of the variance in achievement), while no contribution was found for traces. After clustering strategies to reflect the planning and learning phases in Winne and Hadwin's (1998) model of SRL (planning, learning, reviewing and monitoring), traces again did 
not predict students' achievement. For self-reported strategies, the monitoring phase did emerge as a significant predictor of achievement, explaining $23 \%$ of the variance in achievement. It is however important to note that there was no trace for the phase of monitoring, making it impossible for this phase to emerge as a traced predictor. When examining individual tactics, amount of note taking (operationalized as the number of paragraphs in which a student created at least one note) was the only tactic that was a significant predictor when using trace data (23\% of variance in achievement explained). In the analysis of self-reports, the significant predictors were reviewing text and review of pictures. In a final analysis, the authors entered both the traces and the self-report items in one blocked regression analysis. In this analysis, the trace for amount of note taking remained a significant predictor of achievement, as well as the self-report items for reviewing text and reviewing pictures, explaining $17 \%$ and $26 \%$ of the variance in achievement, respectively. Principal component analyses also indicated that traces reveal different forms of SRL than self-reports, with trace data indicating a more active way of studying.

Another study that analyzed students' online traces was conducted by Hadwin, Nesbit, Jamieson-Noel, Code, \& Winne (2007). Hadwin et al. (2007) used a similar software program called gStudy to compare eight students' self-reports of self-regulated learning strategies on the MSLQ to their actual use of specific self-regulatory strategies as measured by the traces. Students studied a chapter in a course on introductory educational psychology, which would later be tested on a final exam (no information is given about the content of this exam or students' achievement on this). They clustered students based on their responses to the MSLQ into High, Medium and Low self-regulators. They then tried to identify similarities within clusters in terms of traced study activities. It was found that there were few similarities between students within the same clusters (with even the most highly calibrated students showing good calibration on only $40 \%$ of studying activities), indicating that there may be a low calibration between students' self-reports and their actual use of self-regulated learning strategies.

Finally, a study using online traces was conducted by Hadwin, Boutara, Knoetzke, \& Thompson (2004), who clustered eight students into the categories of High, Average, Low and Improved performers on the basis of their progression in test performance achievement from pretest to posttest. A software program called CoNoteS2 was used to collect traces of students' studying activities while studying three chapters on sex differences in the context of an instructional psychology course. These trace data were compared with weekly self-report reflections that students wrote regarding their studying tactics. Achievement was measured by students' recall at three levels (unistructural, multistructural and relational), thereby essentially covering text recall and comprehension. They found that High performers were better calibrated than Low performers. However, they also found that studying activities as identified by traces could not independently explain the students' performance developments, indicating the need for additional measures to come to a complete picture.

Zhou and Winne (2012) investigated calibration of a different aspect of SRL, focusing on the 
comparison of specific achievement goals as measured by self-reports versus trace data. Selfreport data were collected with the Achievement Coal Questionnaire (ACQ; Elliot \& McGregor, 2001). Trace data were collected in gStudy (Winne et al., 2006). In gStudy, participants studied an article about hypnosis, in which they were presented with a predefined set of hyperlinks and tags related to each of the four goal orientations (e.g. "I want to learn more about this" as an indicator of a mastery-approach goal). Coal orientations were inferred by counting the number of hyperlinks students clicked and the number of tags they used. Achievement was operationalized as text recall and text comprehension. For all goal orientations, there were significant differences between students' self-reports of their goal orientations and the traces collected in gStudy, with effect sizes ranging between $d=1.39$ and $d=3.94$. A significant correlation with reading achievement posttest performance was found for traced goal orientations (correlation coefficients ranging between $r_{\tau}=.17$ and $r_{\tau}=.23$ ), but not for self-reports.

Also focusing on goal theory, Adesope, Zhou, \& Nesbit (2015) investigated whether achievement goals could influence the use of learning strategies, and whether these learning strategies could in turn influence students' online learning behavior. The authors used the Goal Orientation Questionnaire (COQ; Nesbit, Zhou, Mahasneh, \& Yeung, 2008) to measure students' goal orientation. Learning strategies were measured using the MSLQ. Students' learning behavior was measured while studying an electronic chapter in gStudy (Winne et al., 2006). Although trace data were used in addition to the self-report questionnaire rather than the two measures being explicitly compared, it is interesting to note that there was a predictive relationship between the questionnaire subscales and learning behavior. Specifically, effort regulation and task value, as measured by the MSLQ, showed a positive predictive relationship with the number of notes and tags that were created in gStudy, as well as with duration of study and the total number of actions completed in gStudy. Furthermore, except for rehearsal, the different learning strategies measured by the MSLQ (elaboration, organization, and metacognitive self-regulation) showed positive correlations with learning behavior, with elaboration showing positive correlation with study duration, the total number of actions, and the total number of notes and tags created, organization showing positive correlations with the total number of actions and the total number of notes and tags created, and metacognitive self-regulation showing a positive correlation with the total number of actions and the number of tags created. Correlation coefficients ranged between $r=.21$ and $r=.42$. This predictive relationship between self-reported learning strategies and students' actual behavior indicates that the MSLQ does in fact tap into an important construct and that students might actually be relatively successful in reporting their use or the importance they assign to these strategies.

Finally, Bernacki et al. (2012) used a trace methodology to examine possible relationships between students' achievement goals, strategy use and comprehension performance. Although they did not make an explicit comparison between traces and self-reports in this study, a comparison was made to earlier studies answering the same research questions using 
self-report questionnaires. Students used nStudy to study texts on human development and ADHD, with achievement being operationalized as text comprehension. Coal orientation was measured with the Achievement Goals Questionnaire-Revised (Elliot \& Murayama, 2008). Trace data only replicated a portion of the relationships between goal orientations and learning strategies that were previously reported in self-report studies. Specifically, performance approach goals did not predict any learning strategies, while mastery goals predicted strategies associated with organization and elaboration (specifically note taking and information seeking), and marginally predicted metacognitive monitoring (specifically monitoring of progress), with effect sizes ranging between .13 and 2.75, leaving a general pathway from mastery goals to strategies. Performance avoidance orientation showed a negative relationship with note taking and information seeking behavior, with effect sizes of -1.34 and -.31 , respectively. The results indicate incongruence between self-reports and trace data for goal orientations, calling into question the validity of self-reports for the measurement of this metacognitive construct. Situation model comprehension (but not text based comprehension) was predicted by traces of highlighting and progress evaluation, with effect sizes of .05 and .06, respectively.

Furthermore, self-reports of SRL were compared with think-aloud protocols. De Backer, Van Keer, \& Valcke (2012) used the prospective Metacognitive Awareness Inventory (MAl; Schraw \& Dennison, 1994) and a think-aloud protocol to investigate the effect of a reciprocal peer tutoring intervention on students' metacognitive knowledge and strategy use. Students worked on authentic assignments in the context of instructional sciences, requiring critical thinking, problem solving, negotiating and decision making. The questionnaire data and think-aloud protocols showed diverging results. While MAl scores revealed no difference in metacognitive knowledge and regulation between pretest and posttest, think-aloud data showed an increase in the frequency of use of metacognitive skills, with effect sizes ranging between $d=.45$ and $d=3.12$, as well as an increase in the variation of metacognitive skills.

Furthermore, we found one study that used eye movements as the online measure when making the comparison with offline self-reports. Susac, Bubic, Kaponja, Planinic, \& Palmovic (2014) used eye-tracking data to study students' strategies when rearranging algebraic equations. Eye-tracking data were compared to a self-report questionnaire in which students had to indicate which strategies they had used during the task. Results indicated incongruence between students' self-reports and eye-tracking data. Eye-tracking scan paths revealed several strategies that students did not report in the self-report questionnaire. For example, of the 15 students who indicated that they never checked the provided answers, 51.5\% of trials in fact showed a return in eye movements to the answers. In other words, students' metacognitive calibration appeared to be limited, although considerable individual variability was found. Participants who showed higher accuracy in their metacognitive judgments were more successful in efficient equation solving, when compared to students with lower metacognitive accuracy. Furthermore, the eye-tracking data provided a more reliable prediction of equation 
difficulty, when compared with students' self-reported difficulty rankings. Finally, these eyetracking measures predicted students' performance in terms of inverse efficiency. Inverse efficiency was operationalized as the ratio between response time and accuracy. Low efficient students showing a higher number returns from answers back to equations than high efficient students, a result which the authors explained by suggesting that high efficient students had better insight into where they should looking, thereby requiring fewer returns. However, the authors did not compare this result to the questionnaire data.

Finally, some studies have compared the use of offline self-report questionnaires to online forms of self-report. Cleary et al. (2015) compared students' responses to the MSLQ to their responses to self-report micro-analytic questions delivered to the students by the examiner, assessing exam preparation. The relationship between students' MSLQ scores and their responses to the micro-analytic strategy questions was not significant. Furthermore, the micro-analytic strategy questions were a better predictor of students' academic performance than the MSLQ. Specifically, there were no significant correlations between exam scores and MSLQ scales, while the weighted micro-analytic strategy measure significantly predicted students' grade on the final exam, with a correlation coefficient of $r=.29$.

Overall, studies that focus on the use of specific strategies when comparing self-report questionnaires with behavioral measures indicate low calibration between the two forms of measurement (Adesope et al., 2015; Bernacki et al., 2012; Cleary et al., 2015; De Backer et al., 2012; Hadwin et al., 2004; Hadwin et al., 2007; Jamieson-Noel \&Winne, 2003; Susac et al., 2014; Winne \& Jamieson-Noel, 2002; Zhou \& Winne, 2012). Traces tend to have a higher predictive value in terms of achievement than self-reports.

\section{Comparison of global use of self-regulatory strategies}

As opposed to the 10 studies comparing different types of measurement for specific selfregulatory strategies, four other studies have focused on a global measure of self-regulation, using total or subscale scores that aggregate different self-regulatory strategies. Three studies focused on problem-solving, while one study used an electronic portfolio system.

Cooper, Sandi-Urena, \& Stevens (2008) developed a multi-method instrument to measure students' metacognition in chemistry problem-solving across time. In order to do so, they compared students' answers on the prospective self-report Metacognitive Activities Inventory (MCA-I; Cooper \& Sandi-Urena, 2009) to their study strategies in an online problem-solving environment called IMMEX. In IMMEX, students work on ill-defined chemistry problems while their problem-solving activities are recorded. For example, the number of relevant information pieces considered before trying to solve a problem is used as an indicator of planning. The researchers found convergence between their self-report instrument and students' behavior in the online environment, in the sense that students who performed more metacognitive strategies in the online environment also had higher scores on the questionnaire, as compared 
to students who executed fewer metacognitive strategies. Furthermore, there was a significant correlation between students' problem-solving performance and their strategy use in the online environment, as well as with their scores in the self-report questionnaire.

In a later study on problem-solving, Sandi-Urena, Cooper, \& Stevens (2011) used the MCA-I and the IMMEX environment to assess the effects of a cooperative intervention on students' metacognitive awareness and strategy use. In this study, the intervention led to a decrease in selfreported metacognitive strategy use (interpreted by the authors as an increase in metacognitive awareness) as measured by the MCA-I (with an effect size of $d=.10$ for the difference between the two groups at posttest), but no changes were observed in actual use of metacognitive strategies in the IMMEX environment. Regardless of the direction of the results and the interpretation of this (a decrease in metacognitive strategies versus an increase in metacognitive awareness), the inconsistency between the self-report questionnaire and the use of metacognitive strategies in the IMMEX environment points to an incongruence between students' self-report and the trace data. As an explanation for this incongruence, the authors propose that the MCA-I might put a greater emphasis on reflection, rather than metacognitive skill application. However, we propose it could also be due to a greater sensitivity of the MCA-I to changes from pretest to posttest, or a lower validity of this instrument with students reporting socially desirable answers as a result of having been exposed to the intervention. Interestingly though, the intervention did lead to an increase in students' problem-solving ability, suggesting that the increase in MCA-I scores might have tapped into an actual change in students' strategies.

Finally, Wang (2015) used a multimethod approach to investigate the general and task-specific aspects of metacognition in different topics in chemistry problem solving (molecular polarity and thermodynamics). Self-reported metacognitive skill was measured with the Inventory of Metacognitive Self-Regulation (IMSR; Howard, McGee, Shia, \& Hong, 2000). Concurrent metacognitive skill was measured using a think-aloud protocol. Furthermore, confidence judgments and calibration accuracy values were obtained. Results indicated a significant association between self-report questionnaire scores and concurrent metacognitive skill use as measured by the think-aloud protocol (with a correlation coefficient of $r=.36$ for the thermodynamics task, and $r=.49$ for the molecular polarity task). For the task on molecular polarity, both the self-report questionnaire and the think-aloud protocols showed a significant correlation with performance ( $r=.39$ and $r=.55$, respectively). For the thermodynamics task, only the think-aloud protocols showed a significant correlation with performance (with a correlation coefficient of $r=.40$ ). The author concludes that the self-report questionnaire assesses a context-independent, general and common aspect of metacognition, while think-aloud methodology assesses context-specific metacognition.

Nguyen and Ikeda (2015) developed and evaluated an electronic portfolio system to support SRL in students in the context of two university courses with ICT topics. They used the MSLQ to measure self-reported SRL strategies and examined traces in the ePortfolio 
environment to assess students' actual use of strategies. Results indicated differences from pretest to posttest and between experimental groups for MSLQ scores, congruent with overall increases in SRL strategies observed in the trace data, which could be interpreted as calibration of self-reported study strategies.

Table 1. Quality assessment of the studies included in the review

\begin{tabular}{|c|c|c|c|c|c|c|c|c|c|c|c|}
\hline Reference & 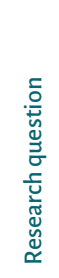 & 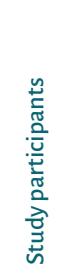 & 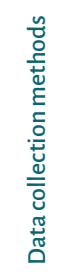 & 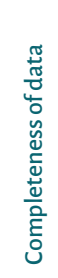 & 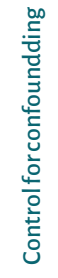 & 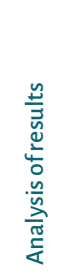 & 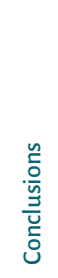 & 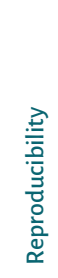 & 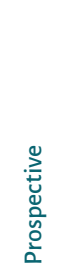 & 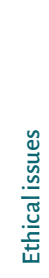 & 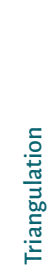 \\
\hline Adesope et al. (2015) & + & + & $+/-$ & + & + & + & + & + & + & + & + \\
\hline Bernacki et al. (2012) & + & + & + & + & + & + & + & + & + & $+/-$ & + \\
\hline Cleary et al. (2015) & + & + & + & + & + & + & + & + & + & + & + \\
\hline Cooper et al. (2008) & + & $+1-$ & + & $+/-$ & + & + & + & + & + & + & + \\
\hline De Backer et al. (2012) & + & + & + & + & $+/-$ & $+/-$ & + & + & + & $+/-$ & + \\
\hline Hadwin et al. (2004) & $+1-$ & + & + & + & - & + & + & + & + & $+1-$ & + \\
\hline Hadwin et al. (2007) & + & + & + & + & + & + & + & + & + & $+/-$ & + \\
\hline $\begin{array}{l}\text { Jamieson-Noel \& Winne } \\
\text { (2003) }\end{array}$ & + & + & + & + & + & + & + & + & + & $+1-$ & + \\
\hline Nguyen \& Ikeda (2015) & + & + & $+1-$ & + & - & $+/-$ & + & + & + & $+1-$ & + \\
\hline Sandi-Urena et al. (2011) & + & + & + & + & + & + & + & + & + & + & + \\
\hline Susac et al. (2014) & + & + & + & + & + & + & + & + & + & $+1-$ & + \\
\hline Wang (2015) & + & + & + & + & + & + & + & + & + & $+/-$ & + \\
\hline $\begin{array}{l}\text { Winne \& Jamieson-Noel } \\
(2002)\end{array}$ & + & + & + & + & + & + & + & + & + & $+1-$ & + \\
\hline Zhou \& Winne (2012) & + & + & + & + & + & + & + & + & + & $+1-$ & + \\
\hline
\end{tabular}


Table 2. Schematic overview of studies comparing specific self-regulatory strategies, with + indicating high calibration, - indicating low calibration, and +/indicating mixed results

\begin{tabular}{|c|c|c|c|c|c|}
\hline Reference & Online & Offline & Type of task & Calibration? & $\begin{array}{l}\text { Achievement } \\
\text { predicted by? }\end{array}$ \\
\hline Adesope et al. (2015) & gStudy & $\begin{array}{l}\text { MSLQ, Coal } \\
\text { Orientation } \\
\text { Questionnaire } \\
\text { (GOQ) }\end{array}$ & Text processing & $+/-$ & n.a. \\
\hline Bernacki et al.(2012) & nStudy & Previous studies & $\begin{array}{l}\text { Text } \\
\text { comprehension }\end{array}$ & $+1-$ & $\begin{array}{l}\text { Online/ } \\
\text { offline }\end{array}$ \\
\hline Cleary et al. (2015) & $\begin{array}{l}\text { Self-report } \\
\text { micro-analytic } \\
\text { questions }\end{array}$ & MSLQ & Exam preparation & - & Online \\
\hline De Backer et al. (2012) & Think-aloud & $\begin{array}{l}\text { Metacognitive } \\
\text { Awareness } \\
\text { Inventory (MAI) }\end{array}$ & $\begin{array}{l}\text { Critical thinking, } \\
\text { problem solving, } \\
\text { negotiating, } \\
\text { decision making }\end{array}$ & - & n.a. \\
\hline Hadwin et al. (2004) & CoNotes2 & $\begin{array}{l}\text { Weekly } \\
\text { self-report } \\
\text { reflections }\end{array}$ & $\begin{array}{l}\text { Text recall and } \\
\text { comprehension }\end{array}$ & - & $\begin{array}{l}\text { Online/ } \\
\text { offline }\end{array}$ \\
\hline Hadwin et al. (2007) & gStudy & MSLQ & $\begin{array}{l}\text { Text processing for } \\
\text { final exam }\end{array}$ & - & n.a. \\
\hline $\begin{array}{l}\text { Jamieson-Noel and } \\
\text { Winne (2003) }\end{array}$ & PrepMate & $\begin{array}{l}\text { Study tactics } \\
\text { questionnaire } \\
\text { (researcher- } \\
\text { developed), } \\
\text { estimates of } \\
\text { achievement }\end{array}$ & $\begin{array}{l}\text { Text processing } \\
\text { (all levels } \\
\text { of Bloom's } \\
\text { taxonomy) }\end{array}$ & - & $\begin{array}{l}\text { Online/ } \\
\text { offline }\end{array}$ \\
\hline Susac et al. (2014) & $\begin{array}{l}\text { Eye-tracking } \\
\text { (number of } \\
\text { fixations) }\end{array}$ & $\begin{array}{l}\text { Self-report } \\
\text { questionnaire } \\
\text { (researcher- } \\
\text { developed) }\end{array}$ & $\begin{array}{l}\text { Rearranging } \\
\text { algebraic } \\
\text { equations }\end{array}$ & - & $\begin{array}{l}\text { Online } \\
\text { (offline } \\
\text { not } \\
\text { measured) }\end{array}$ \\
\hline $\begin{array}{l}\text { Winne and Jamieson- } \\
\text { Noel (2002) }\end{array}$ & PrepMate & $\begin{array}{l}\text { Study tactics } \\
\text { questionnaire } \\
\text { (researcher- } \\
\text { developed), } \\
\text { estimates of } \\
\text { achievement }\end{array}$ & $\begin{array}{l}\text { Text processing } \\
\text { (all levels } \\
\text { of Bloom's } \\
\text { taxonomy) }\end{array}$ & - & n.a. \\
\hline Zhou and Winne (2012) & gStudy & $\begin{array}{l}\text { Achievement } \\
\text { Goal } \\
\text { Questionnaire } \\
\text { (ACQ) }\end{array}$ & $\begin{array}{l}\text { Text recall and } \\
\text { comprehension }\end{array}$ & - & Online \\
\hline
\end{tabular}


Table 3. Schematic overview of studies comparing global strategy use, with + indicating high calibration, - indicating low calibration, and +/-indicating mixed results

\begin{tabular}{|c|c|c|c|c|c|}
\hline Reference & Online & Offline & Type of task & Calibration? & $\begin{array}{l}\text { Achievement } \\
\text { predicted by? }\end{array}$ \\
\hline $\begin{array}{l}\text { Cooper et al. } \\
(2008)\end{array}$ & IMMEX & $\begin{array}{l}\text { Prospective self-report } \\
\text { (Metacognitive Activities } \\
\text { Inventory; MCAI) }\end{array}$ & $\begin{array}{l}\text { Chemistry } \\
\text { problem- } \\
\text { solving }\end{array}$ & + & Online/offline \\
\hline $\begin{array}{l}\text { Nguyen and } \\
\text { Ikeda (2015) }\end{array}$ & Trace data & MSLQ & $\begin{array}{l}\text { University } \\
\text { courses }\end{array}$ & + & n.a. \\
\hline $\begin{array}{l}\text { Sandi-Urena } \\
\text { et al. (2011) }\end{array}$ & IMMEX & $\begin{array}{l}\text { Prospective self-report } \\
\text { (Metacognitive Activities } \\
\text { Inventory; MCAI) }\end{array}$ & $\begin{array}{l}\text { Chemistry } \\
\text { problem- } \\
\text { solving }\end{array}$ & - & Offline \\
\hline Wang (2015) & Think-aloud & $\begin{array}{l}\text { Inventory of Metacognitive Self- } \\
\text { Regulation } \\
\text { (IMSR), confidence judgments }\end{array}$ & $\begin{array}{l}\text { Chemistry } \\
\text { problem- } \\
\text { solving }\end{array}$ & + & Online/Offline \\
\hline
\end{tabular}

Taken together, these studies (Cooper et al., 2008; Nguyen \& Ikeda, 2015; Sandi-Urena et al., 2011; Wang, 2015) indicate that when studies examine the global level of self-regulation, students are relatively well able to report on their use of self-regulatory strategies. This is in contrast with the results from the studies comparing specific self-regulatory strategies, where low calibration is found between the two types of measurement. There appears to be individual value of self-reports of global self-regulation when predicting academic achievement. Selfreports of strategy use can predict achievement, over and above the predictive value of the trace data that were used in the studies. These differential results indicate that different types of measurement (self-report versus online measures) are appropriate for different types of research questions or interventions, a point further elaborated upon in the Discussion.

\section{Discussion}

In this review, we compared offline self-report questionnaires with online behavioral instruments to assess self-regulated learning. Granularity was found to be an important construct when it comes to the comparison between offline self-reports and online measurements, influencing the level of convergence between students' self-reports and behavioral indicators of SRL. Studies that indicate high calibration are mainly those with a focus on students' global use of self-regulatory strategies (coarse grained). Studies that focus on 
calibration of concrete self-regulatory strategies (fine grained) generally indicate a low degree of calibration. Apparently, students are able to report on overall degree, increase or decrease of their use of self-regulatory strategies in general, indicating calibration when SRL is measured at this coarse grain size. However, they have difficulty pinpointing the exact strategies they use when SRL is measured at a fine grain size. Depending on the researcher's specific research question or problem statement this may or may not be a problem. For example, when creating an intervention to increase students' global metacognitive awareness, it might be sufficient to measure this with a self-report questionnaire. Furthermore, in order for interventions to be effective, it is important to also take into account the students' perceptions about their own self-regulatory abilities (Perry \& Rahim, 2011). Self-report can play an important role in this regard. However, when focusing on the development of specific self-regulatory strategies, for example in the context of an intervention to develop deep learning strategies in students, the use of more online measures of SRL (e.g. trace data) might be warranted. If a link should be made to learning outcomes, trace data have been found to be a more powerful predictor.

However, as with any form of measurement, it is important that the online measurements represent a valid way of assessing SRL. When using online measures of SRL, the operationalization of strategies is an important consideration. Both computerized log data (Winne, 2010) and measures such as eye-tracking (Kok \& Jarodzka, 2017) are meaningless without the use of a sound underlying theoretical model. It is important to realize that behavioral measures may obscure mental operations, which could in fact be captured by selfreport. For example, Winne and Jamieson-Noel (2002) defined students' planning of a method as scrolling through the text before performing any of the other traced learning strategies. They found that method planning was one of the strategies in which students were especially poorly calibrated. While they used a very plausible operationalization, it is also very well possible this planning occurred entirely in students' heads. In fact, a notable exception to the general finding that traces have a higher predictive value for achievement than self-reports is the study by Jamieson-Noel and Winne (2003), in which traces of SRL intensity did not predict achievement, while self-report of SRL intensity did. Clusters of traces reflecting the different phases in Winne and Hadwin's (1998) SRL model also did not predict achievement, while selfreports of monitoring did. This might be due to the fact that in this analysis, traces were again clustered to reflect global scales. In fact, when zooming in on individual strategies, some traces did predict achievement. Also, the study included no traces for monitoring, making it impossible to find a traced effect of this scale on students' achievement. In order for research on self-regulated learning and calibration to advance further, there is a need for agreement on an overarching framework of SRL strategies and how to measure them in electronic learning environments or other behavioral measures. In order for this to be possible, a firm theoretical grounding is important. Measures of SRL should be closely aligned to their underlying models, which in the reported studies is often not the case. 
The distinction between measurement of global SRL versus specific strategies could also explain why the behavioral measures of SRL (traces, think-aloud protocols, micro-analytic questions and eye-tracking data) tend to be better predictors of academic achievement than students' self-reports. It is conceivable that achievement can be predicted by some strategies (the 'good' ones) but not by others, precluding the predictive value of measures of 'global'selfregulation, as these tend to aggregate students' responses over multiple occasions and combine multiple different strategies into a few subscales. For example, it has been found that deep strategies such as elaboration and organization are more effective than more shallow strategies such as rehearsal (Pintrich, Smith, Garcia, \& McKeachie, 1993), and even within these categories, some strategies are likely to be more effective than others. For example, when studying materials focusing on connections between constructs it might be helpful to use organization strategies, while strategies related to elaboration might be more appropriate for grasping global theories and systems. Furthermore, different strategies may be more effective and/or better calibrated at different phases of learning (Greene \& Azevedo, 2007). Methods that aggregate such strategies are likely to obscure potential effects on achievement. Future research should focus on clearly delineating the predictive effect of individual strategies on specific learning tasks in higher education, in order to further inform interventions to enhance SRL in students.

In recent years, researchers have also emphasized the social aspects involved in SRL (e.g., Hadwin, Järvelä, \& Miller, 2011; Hadwin \& Oshige, 2011; Järvelä \& Hadwin, 2013). Rather than treating the social context as one of the components in the SRL process, these researchers place shared knowledge construction at the center of learning (Hadwin et al., 2011). This perspective has implications for the way in which SRL should be measured. Specifically, measurements should be used that are able to capture this reciprocity (Hadwin, Oshige, Gress, \& Winne, 2010), without ignoring the temporal and sequential aspects of the interactions (Molenaar \& Järvelä, 2014). The trace data measurements outlined in this review can play an important role in such research (Hadwin et al., 2010). When properly designed, they can offer an efficient, highly detailed alternative to traditional classroom observations. Related to this point, future research could also examine to what extent the accuracy of students' self-reports of strategy changes in an isolated individual versus a social context.

Some weaknesses should be noted. An interesting finding that emerged from the review is that the level of convergence between students' self-reports and behavioral indications of SRL depends on the granularity of measurement. When comparing specific self-regulatory strategies, students seem unable to self-report on their strategy use. Conversely, when comparing global self-regulation, a higher level of convergence is found. However, only few studies have set out to compare the use of self-report questionnaires to more online forms of measurement. The number of studies that have focused on global self-regulation, as opposed to specific strategy use, has been particularly small. Sample sizes are sometimes small and many 
of the studies have been conducted by the same groups of researchers. These considerations led us to conduct a narrative, rather than a systematic review. Consequently, the field could be further advanced by more research by different groups of researchers in different populations of students, in order to replicate the results found in this review. In the future, these studies could be synthesized into a more systematic review or meta-analysis of the literature, providing clearer insight into the individual value of both self-reports and behavioral indicators of SRL. Finally, we have focused this review on SRL strategies in students in higher education. It can be expected that there will be differences in SRL and calibration between different age groups. It would be interesting to make this comparison for other age groups as well.

Furthermore, the studies included in this review suffer from another weakness inherent in the use of self-report. Specifically, without an external criterion of self-regulation, it is difficult to establish whether self-regulation has occurred in the first place. We have attempted to mitigate this problem in this review by only including studies that made a comparison with an online form of measurement, but since online measurements also require considerable operationalization and interpretation, we can never be entirely sure about the nature of the constructs being compared. This issue highlights the importance of properly triangulating measures in research on self-regulated learning.

Finally, the studies described in this review employed several different task types (problem solving, text comprehension, etc.). To our knowledge, research has not focused on how the overlap between students' self-report versus online measures of their self-regulation might differ according to task type, which is surprising given the fact the literature does indicate differences in self-regulation according to the context (McCardle \& Hadwin, 2015; Winne \& Hadwin, 1998; Bråten \& Samuelstuen, 2007). It fell beyond the scope of this review to go into a detailed comparison according to task type, but this could be a fruitful area for further research.

The main conclusion that can be drawn from this review is that self-report questionnaires have their own value in educational research and remediation, in the sense that they might give a relatively accurate insight into students' global level of metacognition, serving as a starting point for more precise interventions. Furthermore, when students' perceptions of their selfregulation are the focus, self-reports can be instrumental in providing this insight (Perry \& Rahim 2011). What matters is that researchers and educationalists think carefully about the research questions or problems they wish to address, being aware of the affordances and limitations of different measurement methods, and align their measurements to the issues at hand. Although these conclusions and implications are not highly specific, this observation provides us with important information about the state-of-the-art of research in this field. As Winne (2018) states: "Because expressions of metacognition in SRL are complex, research upon which to base practice may appear piecemeal, failing to paint a whole picture" (p. 45). We hope that this review can be a first step in the direction of a more complete picture. 


\section{References}

Adesope, O. O., Zhou, M. M., \& Nesbit, J. C. (2015). Achievement goal orientations and self-reported study strategies as predictors ofonlinestudyingactivities. Journal ofEducational Computing Research, 53(3), 436-458, doi:10.1177/0735633115603989 Arbesman, S. (2013). The half-life offacts. Why everything we know has an expiration date. New York: Penguin Group.

Azevedo, R. (2009). Theoretical, conceptual, methodological, and instructional issues in research on metacognition and selfregulated learning: A discussion. Metacognition and Learning, 4, 87-95. doi:10.1007/s11409-009-9035-7

Bernacki, M. L., Byrnes, J. P., \& Cromley, J. C. (2012). The effects of achievement goals and self-regulated learning behaviors on reading comprehension in technology-enhanced learning environments. Contemporary Educational Psychology, 37(2), 148161, doi:10.1016/j.cedpsych.2011.12.001

Bloom, B. S., Engelhart, M. D., Furst, E. J., Hill, W. H., \& Krathwohl, D. R. (1956). Taxonomy of educational objectives. Handbook 1. Cognitive domain. New York: McKay.

Bråten, I., \& Samuelstuen, M. S. (2007). Measuring strategic processing: Comparing task-specific self-reports to traces. Metacognition and Learning, 2, 1-20. doi:10.1007/s11409-007-9004-y

Buckley, S., Coleman, J., Davison, I., Khan, K. S., Zamora, J., Malick, S., ... \& Sayers, J. (2009). The educational effects of portfolios on undergraduate student learning: a Best Evidence Medical Education (BEME) systematic review. BEME Cuide No. 11. Medical Teacher, 31(4), 282-298. doi:10.1080/01421590902889897

Cleary, T. J., Callan, G. L., Malatesta, J., \& Adams, T. (2015). Examining the level of convergence among self-regulated learning microanalytic processes, achievement, and a self-report questionnaire. Journal of Psychoeducational Assessment, 33(5), 439450, doi:10.1177/0734282915594739

Cooper, M. M., \& Sandi-Urena, S. (2009). Design and validation of an instrument to assess metacognitive skillfulness in chemistry problem solving. Journal of Chemical Education, 86(2), 240-245. doi:10.1021/edo86p240

Cooper, M. M., Sandi-Urena, S., \& Stevens, R. (2008). Reliable multi method assessment of metacognition use in chemistry problem solving. Chemistry Education Research and Practice, 9, 18-24, doi:10.1039/b801287n

De Backer, L., Van Keer, H., \& Valcke, M. (2012). Exploring the potential impact of reciprocal peer tutoring on higher education students' metacognitive knowledge and regulation. Instructional Science, 40, 559-588. doi:10.1007/s11251-011-9190-5

Elliot, A. J., \& McGregor, H. A. (2001). A $2 \times 2$ achievement goal framework. Journal of Personality and Social Psychology, 80(3), 501-519. doi:10.1037/0022-3514.80.3.501

Elliot, A. J., \& Murayama, K. (2008). On the measurement of achievement goals: Critique, illustration, and application. Journal ofEducational Psychology, 100(3), 613-628. doi:10.1037/0022-0663.100.3.613

Ericsson, K. A. (2006). Protocol analysis and expert thought: Concurrent verbalizations of thinking during experts performance on representative tasks. In K. A. Ericsson, N. Charness, P. J. Feltovich, \& R. R. Hoffman (Eds.), The Cambridge handbook of expertise and expert performance (p. 223-242). Cambridge: Cambridge University Press.

Greene, J. A., \& Azevedo, R. (2007). A theoretical review of Winne and Hadwin's model of self-regulated learning: new perspectives and directions. Review of Educational Research, 77(3), 334-372. doi:10.3102/003465430303953

Hadwin, A. F., Boutara, L., Knoetzke, T., \& Thompson, S. (2004). Cross-case study of self-regulated learning as a series of events. Educational Research and Evaluation, 10(4-6), 365-417, doi:10.1080/13803610512331383499

Hadwin, A. F., Järvelä, S., \& Miller, M. (2011). Self-regulated, co-regulated, and socially shared regulation of learning. In B. J. Zimmerman, \& D. H. Schunk (Eds.), Handbook of self-regulation oflearning and performance (pp. 83-106). New York, NY: Routledge.

Hadwin, A. F., Nesbit, ]. C., Jamieson-Noel, D., Code, J., \& Winne, P. H. (2007). Examining trace data to explore self-regulated learning. Metacognition and Learning, 2, 107-124. doi:10.1007/s11409-007-9016-7

Hadwin, A. F., \& Oshige, M. (2011). Self-regulation, coregulation, and socially shared regulation: Exploring perspectives of social in self-regulated learning theory. Teachers College Record, 113(2), 240-264.

Hadwin, A. F., Oshige, M., Gress, C. L., \& Winne, P. H. (2010). Innovative ways for using gStudy to orchestrate and research social aspects of self-regulated learning. Computers in Human Behavior, 26(5), 794-805. doi:10.1016/j.chb.2007.06.007 
Howard, B. C., McCee, S., Shia, R., \& Hong, N. S. (2000). Metacognitive self-regulation and problem-solving: Expanding the theory base through factor analysis. Paper presented at the American Educational Research Association, New Orleans, LA.

Jamieson-Noel, D., \& Winne, P. H. (2003). Comparing self-reports to traces of studying behavior as representations of students'studying and achievement. Zeitschrift Für Pädagogische Psychologie, 17(3-4), 159-171. doi:10.1024//1010-0652.17.34.159

Järvelä, S., \& Hadwin, A. F. (2013). New frontiers: Regulating learning in CSCL. Educational Psychologist, 48(1), 25-39. doi:10.108 o/00461520.2012.748006

Kok, E. M., \&]arodzka, H. (2017). Beforeyourvery eyes: The value and limitations of eye tracking in medical education. Medical Education, 51(1), 114-122. doi:10.1111/medu.13066

McCardle, L., \& Hadwin, A. F. (2015). Using multiple, contextualized data sources to measure learners' perceptions of their self-regulated learning. Metacognition and Learning, 10(1), 43-75, doi:10.1007/s11409-014-9132-0

Molenaar, I., \& ]ärvelä, S. (2014). Sequential and temporal characteristics of self and socially regulated learning. Metacognition and Learning, 9, 75-85. doi:10.1007/s11409-014-9114-2

Moos, D. C., \& Azevedo, R. (2008). Exploring the fluctuation of motivation and use of self-regulatory processes during learning with hypermedia. Instructional Science, 36, 203-231. doi:10.1007/s11251-007-9028-3

Nesbit, J. C., Zhou, M., Mahasneh, R., \& Yeung, P. (2008). The Goal Orientation Questionnaire (COQ). Burnaby, BC: Simon Fraser University.

Nguyen, L. T., \& Ikeda, M. (2015). The effects of ePortfolio-based learning model on student self-regulated learning. Active Learning in Higher Education, 16(3), 197-209, doi:10.1177/1469787415589532

Perry, N. E. (1998). Young children's self-regulated learning and contexts that support it. Journal of Educational Psychology, 90 (4), 715-729. doi:10.1037/0022-0663.90.4.715

Perry, N. E., \& Rahim, A. (2011). Studying self-regulated learning in classrooms. In B. J. Zimmerman, \& D. H. Schunk (Eds.), Handbook of self-regulation of learning and performance (pp. 122-136). New York, NY: Routledge.

Perry, N. E., \& Winne, P. H. (2006). Learning from learning kits: gStudy traces of students' self-regulated engagements with computerized content. Educational Psychology Review, 18, 211-228. doi:10.1007/s10648-006-9014-3

Pigott, T. D. (2012). Advances in meta-analysis. New York, NY: Springer Science \& Business Media.

Pintrich, P. R. (2004). A conceptual framework for assessing motivation and self-regulated learning in college students. Educational Psychology Review, 16(4), 385-407. doi:10.1007/s10648-004-0006-x

Pintrich, P. R., Smith, D. A. F., Garcia, T., \& McKeachie, W. J. (1991). A manual for the use of the Motivated Strategies for Learning Questionnaire (MSLQ). Ann Arbor: National Center for Research to Improve Postsecondary Teaching and Learning, University of Michigan.

Pintrich, P. R., Smith, D. A. F., Garcia, T., \&McKeachie, W.J. (1993). Reliabilityand predictivevalidity ofthe Motivated Strategiesfor Learning Questionnaire (MSLQ). Educational and Psychological Measurement, 53, 801-813. doi:10.1177/0013164493053003024

Sandi-Urena, S., Cooper, M. M., \& Stevens, R. H. (2011). Enhancement of metacognition use and awareness by means of a collaborative intervention. International Journal of Science Education, 33(3), 323-340, doi:10.1080/09500690903452922.

Schellings, G. (2011). Applying learning strategy questionnaires: problems and possibilities. Metacognition and Learning, 6(2), 91-109. doi: 10.1007/s11409-011-9069-5

Schellings, G., \& Van Hout-Wolters, B. (2011). Measuring strategy use with self-report instruments: theoretical and empirical considerations. Metacognition and Learning, 6, 83-90. doi:10.1007/s11409-011-9081-9

Schellings, G. L. M., Van Hout-Wolters, B. H. A. M., Veenman, M. V. J., \& Meijer, J. (2013). Assessing metacognitive activities: the in-depth comparison of a task-specific questionnaire with think-aloud protocols. European Journal of Psychology of Education, 28, 963-990. doi:10.1007/s10212-012-0149-y

Schneider, W. (2008). The development of metacognitive knowledge in children and adolescents: Major trends and implications for education. Mind, Brain, and Education, 2(3), 114-121. doi:10.1111/j.1751-228X.2008.00041.X

Schraw, G., \& Dennison, R. S. (1994). Assessing metacognitive awareness. Contemporary Educational Psychology, 19, 460-475. doi:10.1006/ceps.1994.1033 
Susac, A., Bubic, A., Kaponja, J., Planinic, M., \& Palmovic, M. (2014). Eye movements reveal students strategies in simple equation solving. International Journal of Science and Mathematics Education, 12, 555-577. doi:10.1007/s10763-014-9514-4 Tourangeau, R., Rips, L. J., \& Rasinski, K. (2000). The psychology of survey response. Cambridge: Cambridge University Press. Veenman, M. V. J. (2005). The assessment of metacognitive skills: What can be learned from multi-method designs? In C Artelt, \& B. Moschner (Eds.), Lernstrategien und Metakognition: Implikationen für Forschung und Praxis (pp. 77-99). Münster: Waxmann

Veenman, M. V. J. (2011). Alternative assessment of strategy use with self-report instruments: a discussion. Metacognition and Learning, 6, 205-211. doi:10.1007/s11409-011-9080-x

Veenman, M. V. J., Van Hout-Wolters, B. H. A. M., \& Afflerbach, P. (2006). Metacognition and learning: conceptual and methodological considerations. Metacognition and Learning, 1, 3-14. doi:10.1007/s11409-006-6893-0

Wang, C.-Y. (2015). Exploring general versus task-specific assessments of metacognition in university chemistry students: A multitrait-multimethod analysis. Research in Science Education, 45, 555-579. doi: 10.1007/s11165-014-9436-8

Weinstein, C. E., \& Palmer, D. R. (2002). Learning and study strategies inventory (2nd. ed.). Clearwater, FL: H \& H Publishing.

Winne, P. H. (2010). Improving measurements of self-regulated learning. Educational Psychologist, 45(4), 267-276, doi:10.1080/ 00461520.2010 .517150

Winne, P. H. (2018). Cognition and metacognition within self-regulated learning. In D. H. Schunk, \& J. A. Greene (Eds.), Handbook of self-regulation of learning and performance (pp. 36-48). New York, NY: Routledge.

Winne, P. H., \& Hadwin, A. F. (1998). Studying as self-regulated learning. In D. J. Hacker, J. Dunlosky, \& A. C. Graesser (Eds.) Metacognition in educational theory and practice (pp. 277-304). Mahwah, N]: Lawrence Erlbaum.

Winne, P. H., \& Jamieson-Noel, D. (2002). Exploring students calibration of self reports about study tactics and achievement. Contemporary Educational Psychology, 27(4), 551-572. doi:10.1016/S0361-476X(02)00006-1

Winne, P. H., Jamieson-Noel, D. L., \& Muis, K. (2002). Methodological issues and advances in researching tactics, strategies and self-regulated learning. In P. R. Pintrich, \& M. L. Maehr (Eds.), Advances in Motivation and Achievement: New Directions in Measured and Methods (Vol. 12, pp. 121-155). Greenwich, CT: JAI.

Winne, P. H., Nesbit, J. C., Kumar, V., Hadwin, A. F., Lajoie, S. P., Azevedo, R., \& Perry, N. E. (2006). Supporting self regulatedlearning with gStudy software: The learning kit project. Technology, Instruction, Cognition and Learning, 3, 105-113

Winne, P. H., \& Perry, N. E. (2000). Measuring self-regulated learning. In M. Boekaerts, P. R. Pintrich, \& M. Zeidner (Eds.) Handbook of self-regulation (pp. 531-566). San Diego, CA: Academic Press

Zhou, M., \& Winne, P. H. (2012). Modeling academic achievement by self-reported versus traced goal orientation. Learning and Instruction, 22(6), 413-419. doi:10.1016/j.learninstruc.2012.03.004

Zimmerman, B. J. (2000). Attaining self-regulation: A social-cognitive perspective. In M. Boekaerts, P. R. Pintrich, \& M Zeidner (Eds.), Handbook of self-regulation (pp. 13-39). San Diego, CA: Academic Press.

Zimmerman, B. J. (2008). Investigating self-regulation and motivation: Historical background, methodological developments, and future prospects. American Educational Research Journal, 45(1), 166-183, doi:10.3102/0002831207312909

Zimmerman, B. J., \& Schunk, D. H. (1989). Self-regulated learning and academic achievement: Theory, research, and practice. New York, NY: Springer. 
Chapter 3 


\section{GHAPTER A}

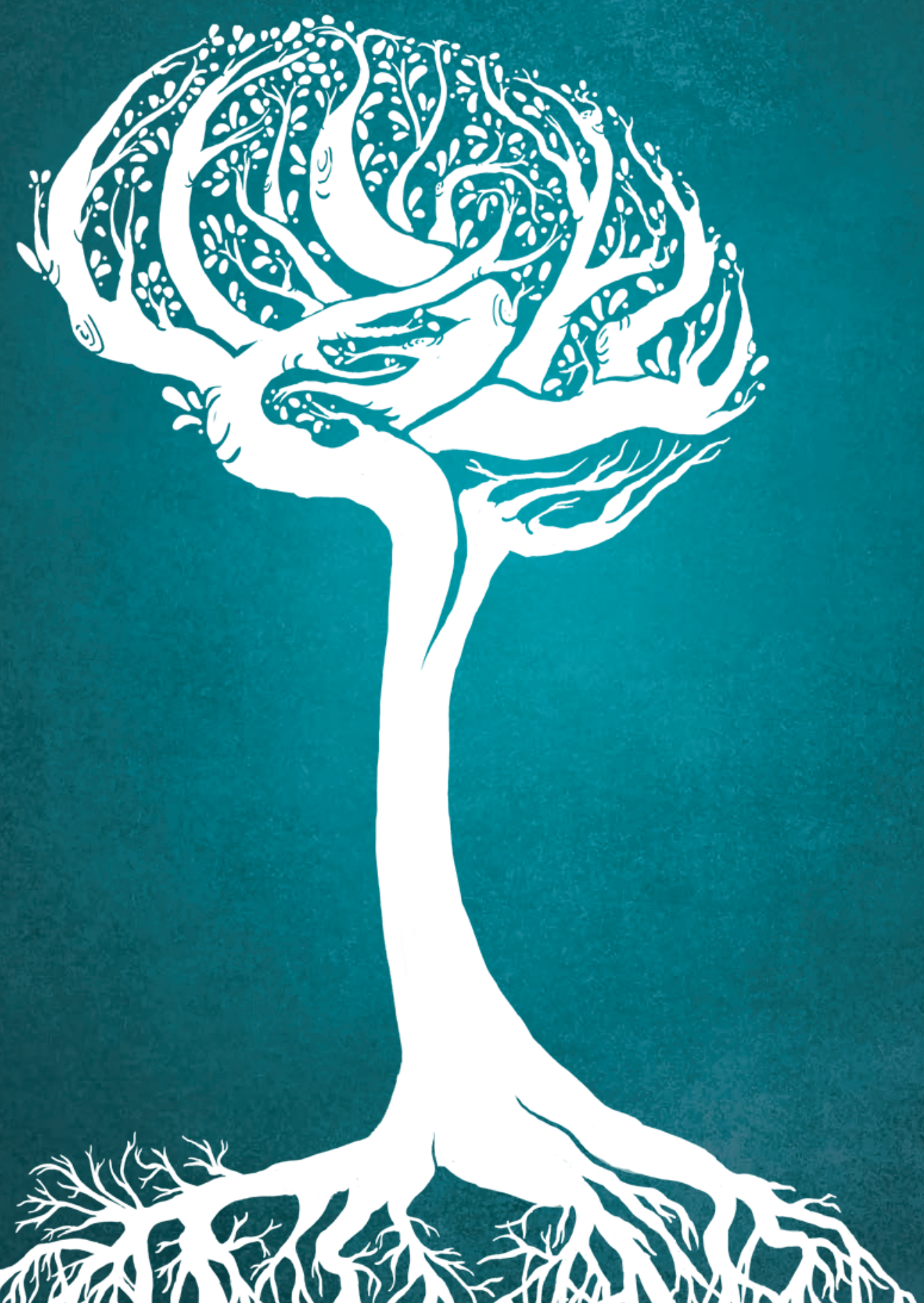




\title{
Improving student expectations of learning in a problem-based environment
}

Rovers, S. F. E., Clarebout, G., Savelberg, H. H. C. M., \& van Merriënboer, J. J. G. (2018).

Computers in Human Behavior, 87, 416-423.

\begin{abstract}
Despite the continuing popularity of problem-based learning (PBL) approaches in higher education worldwide, concerns have been raised regarding a decrease in effectiveness. Unrealistic expectations of students about the nature of learning in a PBL setting may lead to ineffective use of self-regulated learning strategies, in turn leading to suboptimal learning during self-study. In this study, we tested the effects of a workshop aimed at aligning students' perceptions and expectations of their learning environment to those of the university as expressed in faculty training programs.
\end{abstract}

First-year PBL medical students were randomly assigned to either a control condition $(n=26)$ or a contrast (workshop) condition $(n=19)$, designed to enable them to compare and contrast their expectations to those of the university. Results showed no significant differences between conditions in students' reported use of SRL strategies, but indicated a differential development in students' intentions to take responsibility for their own learning, with students in the contrast condition reporting an increase in these intentions as a result of the intervention.

The intervention did not have a differential effect for students with different pretest scores. We discuss how optimization of the PBL environment can inform the design of online, computer-based support tools. 


\section{Introduction}

Problem-based learning (PBL) is a comprehensive educational approach that is based on cognitive theories of learning (Dolmans, Wolfhagen, Van der Vleuten, \&Wijnen, 2001; Moust, Van Berkel, \& Schmidt, 2005). In a problem-based curriculum, students participate in small group tutorials, ideally consisting of 8 to 10 students. In these tutorials, students are presented with a problem or case, that is, a set of phenomena in need of explanation, designed to reflect problems from real-world professional practice. As learning is assumed to be context-specific (Pintrich, 1999), the goal is to enhance learning and transfer to professional practice by aligning the learning context with the future professional context (Könings, Brand-Gruwel, \& Van Merriënboer, 2005). Furthermore, problems from "real" professional practice are assumed to enhance students' intrinsic interest in the subject matter (Schmidt, 1983; Van den Hurk, Wolfhagen, Dolmans, \& Van der Vleuten, 1999a). Based on cognitive theories of learning, it is assumed that the discussions in the tutorial group also activate prior knowledge and promote elaboration, which facilitates learning (Dolmans et al., 2001).

Although many variations of PBL exist, all forms are based on problems as the foundation of learning, to be discussed in small groups in a self-directed, student-centered manner, with the teacher acting as facilitator of the group process rather than as an information transmitter or knowledge expert (Barrows, 1996).

Problem-based learning continues to be an important characteristic of higher education curricula across the world (Davidson, Major, \& Michaelsen, 2014; Moust et al., 2005; Yew \& Coh, 2016). Research indicates that the problem-based approach positively affects students' learning processes, as well as the outcomes of this learning. It has been shown to improve long-term retention of learning content (Strobel \& Van Barneveld, 2009), deep learning and conceptual understanding (Berkson, 1993; Gijbels, Dochy, Van den Bossche, \& Segers, 2005), and skill development (Dochy, Segers, Van den Bossche, \& Gijbels, 2003; Kalaian, Mullan, \& Kasim, 1999; Vernon \& Blake, 1993). Additionally, problem-based learning has been shown to improve students' satisfaction with the curriculum (Colliver, 2000; Czabanowska, Moust, Meijer, Schröder-Bäck, \& Roebertsen, 2012; Newman, 2003). However, researchers have also indicated that at several universities the approach has become less effective over the years (Dolmans et al., 2001; Moust et al., 2005; Woltering, Herrler, Spitzer, \& Spreckelsen, 2009). Students seem to skip important aspects of the problem-solving process, going through the process in a routine manner without attempting to engage in deep learning (Moust et al., 2005).

Theoretically, one would assume that study time and self-regulation are important factors in explaining academic achievement. However, research has shown that time spent on selfstudy is not necessarily related to higher academic achievement (Kamp, Dolmans, Van Berkel, \& Schmidt, 2012; Van den Hurk, Wolfhagen, Dolmans, \& Van der Vleuten, 1998). Therefore, it might be more important to emphasize effective learning during self-study, rather than 
emphasizing the time spent on learning. Self-regulated learning (SRL) plays an important role in this process, and entails both motivational and cognitive processes (Boekaerts, 1997; Pintrich, Wolters, \& Baxter, 2000). SRL has been defined as the "process whereby students activate and sustain cognitions, behaviors and affects, which are systematically oriented toward attainment of their goals" (Schunk \& Zimmerman, 1994, p.309). Because self-study takes place outside of the tutorial group, many details about this process, for example how students study, how they regulate their learning, and how this can be improved, remain unknown. Therefore, it is important to study this aspect of the PBL cycle and how it can be improved. When self-regulation and, by extension, deep study can be improved during this phase, students could acquire a deeper understanding of the content matter, enabling and motivating them to engage with this content more elaborately during the remainder of the process. This could be more successful than forcing them to go through the entire process in a static manner, which will not remediate and could even exacerbate the superficial processing. Rather, according to this reasoning, more effective self-regulation and self-study would naturally enhance processing in the other phases of the PBL process.

Although students have the ability to come up with their own 'relevant' learning issues (i.e., learning issues that were intended by faculty members), these learning issues do notalways guide the amount of time students spend on these topics, or their mastery of these issues, indicating that what students intend to do does not always correspond with what they actually do during self-study (Dolmans, Schmidt, \& Gijselaers, 1995). A reason for this could be that students in a PBL curriculum can feel uncertain about what they should study. As a result, they rely solely on peers and on resources that were suggested or prescribed by their teachers (Dahlgren \& Dahlgren, 2002; Dolmans \& Schmidt, 1994; Kivela \& Kivela, 2005; Lloyd-Jones \& Hak, 2004; Van den Hurk et al., 1999a). In other words, instead of adhering to the self-defined learning issues, independently searching for literature to share with the group, and adopting strategies that facilitate deep learning (e.g. elaboration), students may exclusively use the literature provided by faculty members and use suboptimal learning strategies, such as memorizing.

In order to promote more effective self-study behavior, it could be important to enhance students' use of SRL strategies. PBL is considered to enhance SRL (Loyens, Magda, \& Rikers, 2008). However, students come to university with a set of expectations regarding learning in this new environment, which will influence how they approach this learning (Smith \& Wertlieb, 2005). There is a lack of alignment between the teacher-oriented methods students have become accustomed to in high school and those of university (Raidal \& Volet, 2008; Smith $\&$ Wertlieb, 2005), a problem which could be exacerbated in the context of problem-based learning, in which students are assumed to be active, self-regulated agents (Loyens et al., 2008). As students prefer to work according to their own learning habits (Könings et al., 2005), this incongruence may cause them to fall back on non-problem-based approaches during the selfstudy stage. In other words, students' expectations about their learning environment moderate 
the relationship between PBLand SRL, and creating a more realistic set of expectations could lead to an enhancement of SRL in students by means of two mechanisms. First of all, volition is considered to be an important aspect of SRL (Corno, 2001). When students understand what is expected from them in a PBL curriculum and why, they may be more willing to comply with these expectations and make an effort to self-regulate theirlearning. Second, Wedman's performance pyramid framework (Wedman, 2010) identified expectations as an important factor influencing performance in the workplace (Wedman \& Graham, 1998), a framework which has also been applied in education (Hardy \& Aruguete, 2014). In other words, in order to perform well on a certain process, it is important that individuals understand what is expected of them. As SRL is generally considered to be a teachable process (Schunk \& Zimmerman, 1998), improving these expectations could potentially improve students' SRL performance. Although PBL universities might offer an introduction to students about the method before or at the beginning of the first year, this may not be sufficient for students to completely grasp the concept.

Based on this reasoning, a workshop was developed in which students were queried about their perceptions and expectations regarding their learning environment, enabling them to contrast these to the expectations as formulated by the university in faculty training programs. The current study investigated whether students' expectations and self-regulated learning can be enhanced by aligning their perceptions and expectations about their PBL learning environment to those of the university by means of this workshop. On a basic level, the workshop could lead to more realistic perceptions and expectations in students about their learning environment. As intentions are an important precursor for behavior (Sutton, 1998; Webb \& Sheeran, 2006), this could provide a fruitful basis for the development of more effective SRL strategies, as this understanding could make students more inclined to make an effort to self-regulate their learning. Based on what is known about student learning, an intervention emphasizing active and collaborative learning would be most beneficial (e.g., Bonwell \& Eison, 1991; Johnson, Johnson, \& Smith, 1998). Therefore, we chose a workshop as the form of our intervention, to make sure students were actively engaged in the subject.

Furthermore, educational interventions may have a different effect on students with differing ability levels (Snow, 1991), which has been demonstrated for both cognitive abilities (e.g., Kanfer \& Ackerman, 1989) as well as for metacognitive constructs (e.g., Mclnerney, Mclnerney, \& Marsh, 1997). Experimental and quasi-experimental research in education is indicative of a 'Matthew effect', suggesting a relative as well as an absolute advantage for participants with higher pretest scores on beneficial outcomes related to the intervention (Walberg \& Tsai, 1983). Specifically, the Matthew effect would predict students with high initial abilities to benefit more from educational interventions (e.g., Becker, 2013), as their initial abilities give them a fruitful basis to learn from. Therefore, we further investigated whether the interventional workshop described above would have a larger effect for students with highervalues for SRL and more realistic perceptions and expectations about their learning 
variables at pretest, versus students with lower scores on these variables at pretest.

As described above, PBL includes collaborative problem-solving, face-to-face-discussion and self-study involving SRL. This study focuses on the self-study phase for two reasons. First of all, much attention has already been given to the collaborative, face-to-face-aspects of PBL (e.g., Dolmans et al., 2001; Kamp, Dolmans, Van Berkel, \& Schmidt, 2013; Van Blankenstein, Dolmans, Van der Vleuten, \& Schmidt, 2011). Second, effective learning in the self-study phase can positively influence the other phases of the PBL cycle, giving students the tools to have more fruitful discussions in the collaborative, face-to-face sessions (Azer, 2009).

In summary, the research questions addressed in this study were the following: (1) Can students' SRL strategies be enhanced by means of a workshop aimed at aligning their perceptions and expectations about their learning environment to those of the university, and (2) Do students with different prior levels for SRL and realistic perceptions and expectations benefit differentially from this intervention? Our hypotheses are the following: Students who participated in the workshop will develop more realistic perceptions and expectations about their learning environment than students who did not participate in the workshop (H1a). Students who participated in the workshop will develop more effective SRL strategies than students who did not participate in the workshop $\left(\mathrm{H}_{1} \mathrm{~b}\right)$. Students with more realistic perceptions and expectations about their learning environment at pretest will benefit more from the workshop than students who had less realistic perceptions and expectations ( $\mathrm{H} 2 \mathrm{a})$. Finally, students reporting more effective SRL strategies at pretest will benefit more from the workshop than students reporting less effective SRL strategies $\left(\mathrm{H}_{2} \mathrm{~b}\right)$.

\section{Methods}

\section{Participants, setting and design}

The design used for this study was a pretest-posttest control group design taking place over the duration of a four-week first-year undergraduate Medicine course at a PBL university. It included first-year students from the Medicine undergraduate program.

Initially, 79 students started the pretest. A total of 45 students (Mean age $=19.30, \mathrm{SD}=.81$, 95.6\% female) participated in the intervention and completed all measures, which constituted our final sample. The distribution of gender indicates an overrepresentation of females in the sample, but this was not surprising given the overrepresentation of female students in the program ( $71.2 \%$ female).

Prior to the pretest, students were randomly assigned to either a contrast or a control condition. Three workshops were given, each aiming at 10 participants per workshop. However, due to drop-out the workshops became somewhat smaller, consisting of six, seven and seven participants respectively. Ultimately, 19 students from the contrast condition and 26 students from the control condition completed the posttest. 


\section{Materials}

Two constructs were of interest to the present study: students' perceptions and expectations about their learning environment, and students' use of SRL strategies. We attempted to enhance these constructs by providing students with a workshop enabling them to compare and contrast the expectations they have regarding their learning environment to those of the university. The instruments used to measure these constructs and the workshop that was provided to students are described below.

\section{Perceptions and expectations}

To measure students' perceptions and expectations regarding their learning environment, we used the Perceptions and Expectations about College Questionnaire (PEEK; Weinstein, Palmer, \& Hanson, 1995). This 30-item questionnaire measures students' convictions, thoughts, feelings and expectations about their learning environment at university and consists of three subscales: Academic Expectations, Personal Expectations and Social Expectations. Responses were collected using a 5-point Likert scale ranging from 1 (not at all likely to be part of university experience) to 5 (extremely likely to be part of university experience). Although no psychometric information has previously been published, this questionnaire was used in previous research (Krallman \& Holcomb, 1997) and has been recommended for the measurement of affective (non-cognitive) factors in educational research (Boylan, 2009; Robinson, Burns, \& Gaw, 1996).

For the current study, we only included the two subscales measuring Academic Expectations and Personal Expectations. The subscale measuring Social Expectations assesses students' expectations regarding social relationships with peers, (former) friends and family. It is not related to learning and therefore, it was irrelevant to the current research questions. For this reason, this subscale was not included in the study.

The Academic Expectations subscale measures students' cognitive expectations about the nature of learning and instruction, emphasizing responsibilities of students versus teachers in terms of keeping track of the learning process. Higher scores on this scale indicate students consider themselves less responsible for their own learning progress. For this subscale, item 10 had to be reversed.

The Personal Expectations subscale measures students' intentions to take responsibility for their own progress, with higher scores indicating a greater intention to this responsibility. For this subscale, items 3, 7 and 9 had to be reversed. Please refer to Krallman and Holcomb (1997) for a complete overview of the scales and items. 


\section{Self-regulated learning}

To measure SRL, we used the scales recommended by Wolters, Pintrich, and Karabenick (2003) for measuring academic self-regulation. This questionnaire consists of 103 items measuring the cognitive, affective and behavioral strategies students apply to regulate their learning. Although appeals have been made for more behavioral measures of SRL (e.g., Winne, 2010), previous research has shown that a validated questionnaire can be sensitive enough to detect changes in SRL (Zimmerman, 2008).

Responses to the questionnaire were given on a 7-point Likert scale ranging from 1 (not at all true of me) to 7 (very true of me). The questionnaire consists of three scales: Regulation of Academic Cognition, Regulation of Motivation, and Regulation of Academic Behavior. The Regulation of Academic Cognition scale (Pintrich, Smith, Carcia, \& McKeachie, 1991, 1993) measures the cognitive strategies students use to regulate their learning, and consists of the subscales Rehearsal, Organization, Elaboration and Metacognitive Self-Regulation. The Regulation of Motivation scale (Wolters, 1998; Wolters \& Rosenthal, 2000) measures the affective strategies students use to regulate their learning when they are experiencing motivational problems and consists of the subscales Mastery Self-Talk, Relevance Enhancement, Situational Interest Enhancement, Performance/Relative Ability Self-Talk, Performance/Extrinsic Self-Talk, Self-Consequating, and Environmental Structuring. The Regulation of Academic Behavior scale measures the behavioral strategies used by students to regulate their learning. It consists of the subscales Effort Regulation (Pintrich et al., 1991, 1993), Regulation of Time and Study environment (Pintrich et al., 1991, 1993), General Intention to Seek Needed Help, General Intention to Avoid Needed Help, Perceived Benefits of Help Seeking, Perceived Costs of Help Seeking, Instrumental Help Seeking, Executive Help Seeking, Seeking Help from Formal Source, Seeking Help from Informal Source, and Perceived Teacher Support of Questioning (Karabenick \& Sharma, 1994).

Following recommendations by Wolters et al. (2003), we used the three scales as indicators of self-regulated learning strategies, with the exception that Rehearsal was dropped from the Regulation of Academic cognition scale, as we consider rehearsal to be a surface rather than a deep learning strategy (Biggs, 1987). Furthermore, the subscales Ceneral Intention to Avoid Needed help, Perceived Costs of Help Seeking and Executive Help Seeking were reversed in order to obtain a similar direction of scores for all scales. The reader is referred to Wolters et al. (2003) for a full description of the scales, subscales and items.

\section{Workshop}

In the contrast condition, students participated in a workshop in which their perceptions and expectations regarding their learning environment were contrasted to the expectations as formulated by the university in the PBL faculty training programs. The workshop was led by the first and second author.

In this workshop, students were asked whether they had deliberately chosen to be in a PBL 
curriculum, what their expectations had been prior to starting the program, and the extent to which these prior expectations matched their actual experiences up to that point. The university uses a common script for organizing PBL tutorials, called the Seven-Jump (Moust et al., 2005), in which the following steps are used: (1) term clarification, (2) problem definition, (3) brainstorm, (4) identification of knowledge gaps, (5) formulation of learning issues, (6) selfstudy, and (7) discussion. These steps are based on a constructivist theory of learning, which assumes that understanding is facilitated by students' interacting with their environments, that learning is stimulated by cognitive conflict, and that knowledge is built through students' monitoring of their understanding of the subject matter (Dolmans et al., 2001; Savery \& Duffy, 1995). Students were asked to conduct a brainstorm in which they discussed, for each PBL step individually, their own and their tutor's role and responsibility in conducting this step and keeping track of the learning process. After this brainstorm, a comparison was made between their answers and the official expectations at the PBL university.

This workshop had previously been piloted among a small group of first-year Health Sciences students ( $N=11$ ), a population comparable in terms of faculty, study area and study year. In the pilot workshop, students went through all of the seven PBL steps in the same manner as described in the paragraph above. Results from this pilot study led us to put more emphasis on the defining, brainstorming, self-study and discussion steps of the PBL cycle, in contrast to the steps of clarification, identification of knowledge gaps and formulation of learning issues, as the former steps were found to show a higher discrepancy in terms of students' and university's perceptions and expectations.

\section{Procedure}

Written consent was obtained from all participants prior to data collection. Students were told the study aimed to investigate the factors influencing students' study behavior. Prior to the study, they were not informed that the workshop also aimed at improving this behavior. In the first week of the course, all participants were asked to complete an online questionnaire consisting of the PEEK and the SRL questionnaire. In the week following completion of the questionnaire, participants in the contrast condition participated in the workshop in order to align their perceptions and expectations to those of the university. Participants again completed the online questionnaire regarding their perceptions and expectations and their SRL level in the last week of the course. All participants were debriefed upon completion of the study, informing them about the purpose of the study. In this debriefing, students from the control group were offered the opportunity to take the same workshop after the experiment finished, in order to prevent the students from the workshop condition getting an unfair advantage in their education. Students were offered a small monetary reward for their participation in the study and were entered into a raffle to win an iPad mini. Table 1 shows a summary of the experimental design. 


\section{Data analysis}

A Repeated Measures (RM) ANOVA was used to test whether the workshop led to differences in the development of students' perceptions and expectations and their use of SRL strategies. We chose the RM ANOVA over an ANCOVA, as we are interested in the difference in development on the variables for students over the duration of the block. As students partake in a range of mandatory educational activities as part of their enrolment in the PBL curriculum, it is quite conceivable that their SRL, as well as their perceptions and expectations of the learning environment, change as a function of their participation in the curriculum (Schmidt, Rotgans, \& Yew, 2011; Van den Hurk, Wolfhagen, Dolmans, \& Van der Vleuten, 1999b). Participation in the workshop is expected to change this natural development for students in the contrast condition, leading to a difference in slopes for students in the control condition versus students in the contrast condition. It is therefore necessary to take into account this differential development by including the within-subjects variability in the model (Field, 2009).

The within-subjects variables in this study were students' perceptions and expectations regarding their learning environment and their SRL level at pretest and posttest. Condition (contrast versus control) served as between-subjects variable. We were specifically interested in interaction effects between Session (pretest versus posttest) and Condition, as this would indicate a difference in improvement over time as a function of the intervention. Bonferroni correction was applied to account for analysis of multiple subscales, resulting in a significance value of $p=.05 / 10=.005$.

Furthermore, we were interested in whether effects would be different for students with different pretest scores on the five measures. To answer this question, we specified a regression analysis using the Condition and the pretest variable, as well as the interaction between Condition and the pretest variable as independent variables. The respective posttest variables were used as the dependent variable. If the interaction between Condition and pretest value is significant, this indicates that students with different pretest scores benefit differently from the workshop.

\section{Table 1. Schematic overview of research design}

\begin{tabular}{llll}
\hline & PEEK + SRL & Workshop & PEEK + SRL \\
\hline Control $(n=26)$ & $\times$ & & $\times$ \\
Contrast $(n=19)$ & $\times$ & $\times$ & $\times$ \\
\hline
\end{tabular}




\section{Results}

\section{Reliability}

We used Cronbach's a to determine the reliability of the scales and subscales in the pretest and posttest. Cronbach's a values above .70 were considered to represent adequate reliability (Field, 2009). Due to the exploratory nature of this study and the psychological nature of the constructs measured, Cronbach's a values above .60 were still retained in the study (Field, 2009; Kline, 1999). Table 2 shows an overview of the reliability values found in this study. The SRL scales showed adequate reliability at both pre-and posttest. PEEK subscales showed acceptable to adequate reliability at both pre-and posttest and were therefore retained in the analysis.

Table 2. Internal consistencies (Cronbach's a) for the questionnaire scales

\begin{tabular}{llll}
\hline & & Pretest & Posttest \\
\hline SRL & Regulation of academic cognition & .783 & .806 \\
& Regulation of motivation & .846 & .924 \\
& Regulation of academic behavior & .881 & .870 \\
& & .669 & .759 \\
PEEK & Academic expectations & .656 & .631 \\
\hline
\end{tabular}

\section{Workshop effects}

Table 3 shows descriptive statistics for the expectations and SRL measures included in the study. Results will be discussed according to the hypotheses outlined above.

\section{Hypothesis $7 a / 7 b$}

The Repeated Measures ANOVA revealed no significant interaction effect between Session and Condition for students' academic expectations regarding their learning environment ( $p$ 's $>$.05). However, there was a significant interaction effect between Session and Condition for students' personal expectations, Wilks' lambda $=.82, F(1,43)=9.52, p=.004, \eta_{p}{ }^{2}=.18$, indicating a differential development between conditions in students' intentions to take responsibility for their own learning. Inspection of the mean values indicates that students in the contrast condition improved their personal expectations, while there was no such improvement for students in the control condition. The partial eta squared value indicates a medium to large effect size, signaling that an important portion of the variance in personal expectations was explained by the provision of the workshop to the students in the experimental condition. 


\section{Table 3. Descriptive statistics for the dependent variables}

\begin{tabular}{|c|c|c|c|c|c|c|}
\hline & \multicolumn{2}{|c|}{ Contrast } & \multicolumn{2}{|c|}{ Control } & \multirow[b]{3}{*}{$F$} & \multirow[b]{3}{*}{$p$} \\
\hline & Pretest & Posttest & Pretest & Posttest & & \\
\hline & $M(s d)$ & $M(s d)$ & $M(s d)$ & $M(s d)$ & & \\
\hline $\begin{array}{l}\text { Personal } \\
\text { expectations }\end{array}$ & $3.21(.45)$ & $3.41(.39)$ & $3.37(.54)$ & $3.29(.52)$ & 9.52 & .004 \\
\hline $\begin{array}{l}\text { Academic } \\
\text { expectations }\end{array}$ & $2.85(.34)$ & $2.82(.44)$ & $2.83(.56)$ & $2.71(.58)$ & .78 & .38 \\
\hline Cognition & $4.73(.56)$ & $4.88(.59)$ & $4.89(.62)$ & $5.10(.50)$ & .12 & .73 \\
\hline Motivation/Affect & $4.85(.48)$ & $4.94(.68)$ & $4.97(.59)$ & $5.17(.73)$ & .52 & .47 \\
\hline Behavior & $5.24(.58)$ & $5.17(.58)$ & $4.85(.63)$ & $5.03(.52)$ & 3.36 & .07 \\
\hline
\end{tabular}

Personal and academic expectations were measured on a 5-point Likert scale. Cognition, Motivation/Affect, and Behavior were measured on a 7-point Likert scale (see description under'Materials' above).

The RM ANOVA revealed no significant interaction effects for students' reported use of SRL strategies ( $p$ 's > .05).

\section{Hypotheses $2 a / 2 b$}

To reveal a potential differential effect for students with different pretest scores for the five variables, we performed a regression analysis as described above. The regression weights for the interaction effects between condition and pretest scores were not significant ( $p$ 's > .05), indicating that all students benefited from the intervention in a similar manner. However, given the small standard deviations as indicated in Table 3 , this could be due to a lack of pretest variation among students.

\section{Discussion}

This study tested the effectiveness of an intervention on the development of students' expectations and self-regulated learning strategies in the first-year Medicine undergraduate program at a PBL university. We expected that a better understanding of the university's expectations would make students more willing and able to comply and make an effort to selfregulate their learning (Corno, 2001; Wedman, 2010). Specifically, a PBL curriculum puts high demands on students in terms of initiative and self-regulated learning. Students are expected to proactively take initiative for their own learning, independently search for literature to construct their own knowledge, and make an active, conscious effort to achieve deep knowledge in collaboration with other students. The intervention consisted of a workshop in which students were given the opportunity to compare and contrast the expectations they had of their learning 
environment to the expectations as formulated by the university. It was hypothesized that students who participated in the workshop would develop more realistic expectations than students who did not participate in the workshop ( $\left.\mathrm{H}_{1} \mathrm{a}\right)$. Furthermore, these students were expected to develop more effective SRL strategies ( $\mathrm{H}_{1} \mathrm{~b}$ ). Also, we expected students with more realistic perceptions and expectations about their learning environment at pretest to benefit more from the workshop than students who had less realistic perceptions and expectations at pretest $\left(\mathrm{H}_{2} \mathrm{a}\right)$, and students with more effective SRL strategies at pretest to benefit more from the workshop than students reporting less effective SRL strategies at pretest $\left(\mathrm{H}_{2} b\right)$.

Hypothesis 1a was partly confirmed. We found that the intervention significantly improved students' personal expectations regarding their learning environment, indicating an increase in their motivation and preparedness to monitor and adjust their learning, but contrary to hypothesis $\mathrm{H}_{1} \mathrm{~b}$, this did not lead to any significant changes in their reported use of self-regulated learning strategies. This is, however, an important finding, as this change in expectations could be a first step in the direction of an actual change in self-regulation, given the importance of intentions as a precursor for behavior (Sutton, 1998; Webb \& Sheeran, 2006).

Several implications can be derived from these results. Firstly, this study supports the value of active, collaborative ways of introducing students to the characteristics of learning environments in a PBL curriculum in terms of improving the expectations they have about their learning environment. Furthermore, although the intervention significantly improved students' personal expectations regarding their learning environment, indicating an increase in their motivation and preparedness to monitor and adjust their learning, we did not find significant changes in their reported use of self-regulated learning strategies. It is possible the current intervention was too short to have a lasting effect on students' use of self-regulatory strategies. Therefore, it is recommended that interventions be spread out over a longer period of time in order to have an effect on students' use of SRL strategies.

No support was found for hypotheses $2 \mathrm{a}$ and $2 \mathrm{~b}$. We found no interaction between condition and students' pretest values in terms of perceptions and expectations or SRL strategy use, indicating that all students benefited from the intervention in a similar manner. This lack of interaction between condition and students' pretest levels indicates that all students benefited from the intervention in a similar manner. An explanation for this finding can be found in the relatively small standard deviations associated with the variables, indicating little inter-individual variation in either perceptions and expectations or SRL strategy use. It is possible that an interaction would be found for groups of students with high inter-individual variation on the variables at pretest (Speece, 1990). However, as the students in our sample scored in the middle range of the variables under investigation rather than predominantly in the lower end, this implies that most students will have something to gain from such an intervention. However, as this study was conducted with students who volunteered to participate, it is possible that students with less realistic expectations and lower use of SRL 
strategy use were not included in the study. Future research could target students at the more extreme ends of the spectrum, in order to investigate whether this lack of interaction is replicated, or whether the intervention is in fact more (or less) effective for students with lower (or higher) pretest aptitudes.

Regarding practical implications, a deeper understanding of the factors influencing the effectiveness of the PBL learning environment can help inspire tools to support SRL in such a curriculum. Like many educational programs nowadays, problem-based curricula often have a substantive online component, relying heavily on online learning resources such as BlackBoard. Optimizing the learning environment also opens up possibilities for the optimization of the online tools and resources that are offered to students to support their learning. For example, the online learning environment could incorporate a tool for students to compare and contrast their expectations and perceptions to those of the university, for example, concept mapping techniques with graph comparison (De Souza, Boeres, Cury, De Menezes, \& Carlesso, 2008) or a forum discussion. In this way, students are primed to think about the perceptions and expectations they have and are made aware about the extent to which this does or does not match the university's expectations. Furthermore, as the workshop was not sufficient for students to change their SRL strategies, tools could be incorporated to facilitate this transition. For example, the online learning environment could incorporate a tool that allows students to track their own progress. Examples include a tool that allows them to track how many hours they spend studying, as well as online quizzes to enable them to see how well they understand the material. In this way, students are enabled to translate their intentions to more concrete behavior. Finally, the workshop could be made more efficient by incorporating tools into the online environment that students can use prior to the intervention. When students use an online concept mapping tool to map their expectations prior to the intervention, the workshop time can be more efficiently used, potentially increasing its effectiveness.

Several limitations of this study should be noted. Firstly, our sample was comprised of students who volunteered to participate in the study, a limitation that is further underscored by the high dropout rate. It is quite likely that the students who started and persisted in the study were among the most motivated students in the program. Due to the novelty of this intervention, ethical considerations compelled us to first test it on a sample of students who were completely free in their choice about whether or not to participate. However, it is possible that the intervention's results would have been different when conducted across the entire program. Less motivated students may be more likely to benefit from the intervention. Alternatively, they could be less willing to cooperate, in which case the intervention would have little or no effect on them. Future research could focus on incorporating the intervention into the curriculum, thereby reaching all students who are enrolled in the program to come to a more complete picture of the effects of the intervention.

Furthermore, the use of self-reports for the measurement of SRL has become a topic of 
debate during the past couple of years (Veenman, Van Hout-Wolters, \& Afflerbach, 2006; Winne, 2010), with researchers indicating that students may not be reliable sources when reporting on their own SRL strategy use. However, as research shows that students have a tendency to underrate the occurrence of rare events, while overrating the occurrence of common events (Perry \& Winne, 2006), we feel that our results have probably not been influenced by the use of self-reports. More specifically, as this study dealt with common study events and the workshop likely primed students to focus more on their use of strategies, if anything this would have caused students in the contrast condition to overestimate their strategy use. Therefore, the likelihood of false positives, rather than false negatives, would be increased. However, the use of trace data is likely to give a more fine-grained, detailed picture of students' strategy use, enabling researchers to study students' SRL development throughout a course. Practical issues restrained us from using trace data in this study, but it is certainly recommended for further research and interventions in order to gain a more complete picture of students' development over time.

Third, our study used an active, collaborative workshop as an intervention to stimulate students to compare and contrast the expectations they have about their learning environment to those of the university. We chose this form based on what is known from the literature about student learning (e.g., Bonwell \& Eison, 1991; Johnson et al., 1998). However, sample size did not permit a comparison of this form of intervention to other forms of delivery, such as a traditional lecture. Future research could further inquire into which instructional format is most effective for the current intervention.

Finally, this study did not consider the perceptions and expectations of the tutors regarding students' learning process. As stated earlier, partly in response to students' negative attitudes, tutors often tend to adopt a teacher-oriented approach (Dolmans et al., 2001; Loyens et al., 2008; Moust et al., 2005). When confronted with a highly teacher-oriented tutor, students are not given the space to self-regulate their learning, even if they would be willing to do so. Future research should therefore look into the perceptions and expectations of tutors regarding students' learning environments and the effect this has on students' SRL both in and outside of the tutorial group, as well as focus on longer lasting interventions.

Given the continuing popularity of PBL in medical schools across the world, the importance of interventions to optimize the effectiveness of this educational approach is paramount. In order to successfully educate future professionals, the learning environment of students must be optimized as much as possible. The current study contributes to the literature by investigating an underexplored aspect of the PBL experience, namely the alignment between students' perceptions and expectations of the learning environment in comparison to those formulated by the university. Overall, this study shows the importance of aligning students' perceptions and expectations to the university in an active, collaborative manner, and opens up many interesting possibilities for online tools in learning and teaching. 


\section{References}

Azer, S. A. (2009). Interactions between students and tutor in problem-based learning: The significance of deep learning. The Kaohsiung Journal of Medical Sciences, 25(5), 240-249. doi:10.1016/S1607-551X(09)70068-3

Barrows, H. S. (1996). Problem-based learning in medicine and beyond: A brief overview. In L. Wilkerson \& W. Gijselaers (Eds.), Bringing problem-based learning to higher education: Theory and practice. New directions for teaching and learning series, No. 68 (pp. 3-11). San Francisco, CA: Jossey-Bass.

Becker, L. L. (2013). Self-regulated learning interventions in the introductory accounting course: An empirical study. Issues in Accounting Education, 28(3), 435-460. doi:10.2308/iace-50444

Berkson, L. (1993). Problem-based learning: have the expectations been met? Academic Medicine, 68(10), S79-88. doi:10.1097/00001888-199310000-00053

Biggs, J. B. (1987). Student approaches to learning and studying. Camberwell, Vic.: Australian Council for Educational Research.

Boekaerts, M. (1997). Self-regulated learning: A new concept embraced by researchers, policy makers, educators, teachers and students. Learning and Instruction, 7(2), 161-186. doi:10.1016/S0959-4752(96)00015-1

Bonwell, C. C., \& Eison, J. A. (1991). Active Learning: Creating Excitement in the Classroom. 1991 ASHE-ERIC Higher Education Reports. Washington, D.C.: The George Washington University, School of Education and Human Development.

Boylan, H. R. (2009). Targeted Intervention for Developmental Education Students (T.I.D.E.S.). Journal of Developmental Education, 32(3), 14-23.

Colliver, J. A. (2000). Effectiveness of problem based learning curricula - Research and theory. Academic Medicine, 75(3), 259266.

Corno, L. (2001). Volitional aspects of self-regulated learning. In B.]. Zimmerman \& D.H. Schunk (Eds.), Self-regulated learning and academic achievement: Theoretical perspectives (2nd ed., pp. 179-212). Mahwah, N]: Lawrence Erlbaum.

Czabanowska, K., Moust, J. H. C., Meijer, A. W. M., Schröder-Bäck, P., \& Roebertsen, H. (2012). Problem-based learning revisited, introduction of active and self-directed learning to reduce fatigue among students. Journal of University Teaching ELearning Practice, 9(1), 1-13.

Dahlgren, M. A., \& Dahlgren, M. O. (2002). Portraits of PBL: students' experiences of the characteristics of problembased learning in physiotherapy, computer engineering and psychology. Instructional Science, 30(2), 111-127. doi:10.1023/A:1014819418051

Davidson, N., Major, C. H., \& Michaelsen, L. K. (2014). Small-group learning in higher education-cooperative, collaborative, problem-based, and team-based learning: an introduction by the guest editors. Journal on Excellence in College Teaching, 25(3), 1-6.

De Souza, F., Boeres, M., Cury, D., De Menezes, C., \& Carlesso, G. (2008). An approach to comparison of concept maps represented by graphs. Paper presented at the Third International Conference on Concept Mapping, Tallinn, Estonia \& Helsinki, Finland.

Dochy, F., Segers, M., Van den Bossche, P., \& Gijbels, D. (2003). Effects of problem-based learning: a meta-analysis. Learning and Instruction, 13(5), 533-568. doi:10.1016/s0959-4752(02)00025-7

Dolmans, D. H. J. M., \& Schmidt, H. G. (1994). What drives the student in problem-based learning? Medical Education, 28(5), 372-380. doi:10.1111/j.1365-2923.1994.tbo2547.x

Dolmans, D. H. J. M., Schmidt, H. G., \& Gijselaers, W. H. (1995). The relationship between student-generated learning issues and self-study in problem-based learning. Instructional Science, 22, 251-267. doi:10.1007/BFoo891779

Dolmans, D. H. J. M., Wolfhagen, I. H. A. P., Van der Vleuten, C. P. M., \& Wijnen, W. H. F. W. (2001). Solving problems with group work in problem based learning - hold on to the philosophy. Medical Education, 35(9), 884-889. doi:10.1046/j.13652923.2001.00915.x

Field, A. (2009). Discovering statistics using SPSS. London: Sage publications.

Gijbels, D., Dochy, F., Van den Bossche, P., \& Segers, M. (2005). Effects of problem-based learning: A meta-analysis from the angle of assessment. Review of Educational Research, 75(1), 27-61. doi:10.3102/00346543075001027 
Hardy, P., \& Aruguete, M. (2014). Needs assessment in STEM disciplines: reliability, validity and factor structure of the Student Support Needs Scale (SSNS). Assessment \& Evaluation in Higher Education, 39(5), 553-562. doi:10.1080/02602938.2013.857642 Johnson, D. W., Johnson, R. T., \& Smith, K. A. (1998). Cooperative learning returns to college what evidence is there that it works? Change: The Magazine of Higher Learning, 30(4), 26-35. doi:10.1080/00091389809602629

Kalaian, H. A., Mullan, P. B., \& Kasim, R. M. (1999). What can studies of problem-based learning tell us? Synthesizing and modeling PBL effects on National Board of Medical Examination Performance: Hierarchical Linear Modeling metaanalytic approach. Advances in Health Sciences Education, 4, 209-221. doi:10.1023/A:1009871001258

Kamp, R. J. A, Dolmans, D. H. J. M., Van Berkel, H. J. M., \& Schmidt, H. G. (2012). The relationship between students' small group activities, time spent on self-study, and achievement. Higher Education, 64, 385-397. doi:10.1007/s10734-011-9500-5

Kamp, R. J. A., Dolmans, D. H. J. M., Van Berkel, H. J. M., \& Schmidt, H. G. (2013). The effect of midterm peer feedback on student functioning in problem-based tutorials. Advances in Health Sciences Education, 18(2), 199-213. doi:10.1007/s10459-0129364-1

Kanfer, R., \& Ackerman, P. L. (1989). Motivation and cognitive abilities: An integrative/aptitude-treatment interaction approach to skill acquisition. Journal of Applied Psychology, 74(4), 657-690. doi:10.1037/0021-9010.74.4.657

Karabenick, S. A., \& Sharma, R. (1994). Seeking academic assistance as a strategic learning resource. In P. R. Pintrich, D. R. Brown, \& C. E. Weinstein (Eds.), Student motivation, cognition, and learning: Essays in honor of Wilbert]. McKeachie (pp. 189-211). Hillsdale, N]: Lawrence Erlbaum Associates.

Kivela, J., \& Kivela, R. J. (2005). Student perceptions of an embedded problem-based learning instructional approach in a hospitality undergraduate programme. International Journal of Hospitality Management, 24(3), 437-464. doi:10.1016/j. ijhm.2004.09.007

Kline, P. (1999). The handbook of psychological testing (2nd ed.). London: Routledge.

Könings, K. D., Brand-Cruwel, S., \& Van Merriënboer, J. J. C. (2005). Towards more powerful learning environments through combining the perspectives of designers, teachers, and students. British Journal of Educational Psychology, 75, 645-660. doi:10.1348/000709905X43616

Krallman, D., \& Holcomb, T. (1997). First-year expectations: Pre-and post-orientation. Paper presented at the Annual Meeting of the Association of Institutional Research, Buena Vista, FL.

Lloyd-Jones, G., \& Hak, T. (2004). Self-directed learning and student pragmatism. Advances in Health Sciences Education, 9, 61-73. doi:10.1023/B:AHSE.0000012228.72071.1e

Loyens, S. M. M., Magda, J., \& Rikers, R. M. J. P. (2008). Self-directed learning in problem-based learning and its relationships with self-regulated learning. Educational Psychology Review, 20, 411-427. doi:10.1007/s10648-008-9082-7

Mclnerney, V., Mclnerney, D. M., \& Marsh, H. W. (1997). Effects of metacognitive strategy training within a cooperative group learning context on computer achievement and anxiety: An aptitude-treatment interaction study. Journal of Educational Psychology, 89(4), 686-695. doi:10.1037/0022-0663.89.4.686

Moust, J. H. C., Van Berkel, H. J. M., \& Schmidt, H. C. (2005). Signs of erosion: Reflections on three decades of problem-based learning at Maastricht University. Higher Education, 50, 665-683. doi:10.1007/s10734-004-6371-z

Newman, M. (2003). A pilot systematic review and meta-analysis on the effectiveness of Problem Based Learning. Middlesex University, UK: ITSN Learning and Teaching Support Network.

Perry, N. E., \& Winne, P. H. (2006). Learning from learning kits: gStudy traces of students' self-regulated engagements with computerized content. Educational Psychology Review, 18, 211-228. doi:10.1007/s10648-006-9014-3

Pintrich, P. R. (1999). The role of motivation in promoting and sustaining self-regulated learning. International Journal of Educational Research, 31(6), 459-470. doi:10.1016/S0883-0355(99)00015-4

Pintrich, P. R., Smith, D. A. F., Garcia, T., \& McKeachie, W. J. (1991). A manual for the use of the Motivated Strategies for Learning Questionnaire (MSLQ). Ann Arbor: National Center for Research to Improve Postsecondary Teaching and Learning, University of Michigan.

Pintrich, P. R., Smith, D. A. F., Garcia, T., \&McKeachie, W.J. (1993). Reliabilityand predictivevalidity ofthe Motivated Strategies for 
Learning Questionnaire (MSLQ). Educational and Psychological Measurement, 53, 801-813. doi:10.1177/0013164493053003024

Pintrich, P. R., Wolters, C. A., \& Baxter, C. P. (2000). Assessing metacognition and self-regulated learning. In G. Schraw \& ]. Impara (Eds.), Issues in the measurement of metacognition (pp. 43-97). Lincoln, NE: Buros Institute of Mental Measurements.

Raidal, S. L., \& Volet, S. E. (2008). Preclinical students' predispositions towards social forms of instruction and self-directed learning: a challenge for the development of autonomous and collaborative learners. Higher Education, 57, 577-596. doi:10.1007/s10734-008-9163-Z

Robinson, D. A. C., Burns, C. F., \& Gaw, K. F. (1996). Orientation programs: A foundation for student learning and success. New Directions for Student Services, 75, 55-68. doi:10.1002/ss.37119967507

Savery, J. R., \& Duffy, T. M. (1995). Problem-based learning: An instructional model and its constructivist framework. Educational Technology, 35(5), 31-38.

Schmidt, H. G. (1983). Problem-based learning: rationale and description. Medical Education, 17, 11-16. doi:10.1111/j.1365-2923.1983. tbo1086.x

Schmidt, H. G., Rotgans, ]. I., \& Yew, E. H. (2011). The process of problem-based learning: what works and why. Medical Education, 45(8), 792-806. doi:10.1111/j.1365-2923.2011.04035.X

Schunk, D. H., \&Zimmerman, B. J. (1994). Self-regulation oflearning and performance: Issues and educational applications: Hillsdale, N]: Lawrence Erlbaum Associates, Inc.

Schunk, D. H., \& Zimmerman, B. J. (1998). Self-regulated learning: From teaching to self-reflective practice: New York, NY: Guilford Press.

Smith, J. S., \& Wertlieb, E. C. (2005). Do first-year college students' expectations align with their first-year experiences? NASPA Journal, 42(2), 153-174. doi:10.2202/1949-6605.1470

Snow, R. E. (1991). Aptitude-treatment interaction as a framework for research on individual differences in psychotherapy. Journal of Consulting and Clinical Psychology, 59(2), 205-216. doi:10.1037/0022-006X.59.2.205

Speece, D. L. (1990). Aptitude-treatment interactions: Bad rap or bad idea? The Journal of Special Education, 24(2), 139-149. doi:10.1177/002246699002400203

Strobel, J., \& Van Barneveld, A. (2009). When is PBL more effective? A meta-synthesis of meta-analyses comparing PBL to conventional classrooms. Interdisciplinary Journal of Problem-Based Learning, 3(1). doi:10.7771/1541-5015.1046

Sutton, S. (1998). Predicting and explaining intentions and behavior: How well are we doing? Journal of Applied Social Psychology, 28(15), 1317-1338. doi:10.1111/j.1559-1816.1998.tbo1679.x

Van Blankenstein, F. M., Dolmans, D. H. J. M., Van der Vleuten, C. P. M., \& Schmidt, H. G. (2011). Which cognitive processes support learning during small-group discussion? The role of providing explanations and listening to others. Instructional Science, 39, 189-204. doi:10.1007/s11251-009-9124-7

Van den Hurk, M. M., Wolfhagen, I. H. A. P., Dolmans, D. H. J. M., \&Van der Vleuten, C. P. M. (1998). The relation between time spent on individual study and academic achievement in a problem-based curriculum. Advances in Health Sciences Education, 3, 43-49. doi:10.1023/A:1009732511707

Van den Hurk, M. M., Wolfhagen, I. H. A. P., Dolmans, D. H. J. M., \& Van der Vleuten, C. P. M. (1999a). Student-generated learning issues: A guide for individual study? Education for Health, 12(2), 213-221.

Van den Hurk, M. M., Wolfhagen, I. H. A. P., Dolmans, D. H. J. M., \& Van der Vleuten, C. P. M. (1999b). The impact of studentgenerated learning issues on individual study time and academic achievement. Medical Education, 33(11), 808-814. doi:10.1046/j.1365-2923.1999.00403.x

Veenman, M. V. J., Van Hout-Wolters, B. H. A. M., \& Afflerbach, P. (2006). Metacognition and learning: conceptual and methodological considerations. Metacognition and Learning, 1, 3-14. doi:10.1007/s11409-006-6893-0

Vernon, D. T. A., \& Blake, R. L. (1993). Does problem-based learning work? A meta-analysis of evaluative research. Academic Medicine, 68(7), 550-563. doi:10.1097/00001888-199307000-00015

Walberg, H. J., \& Tsai, S.-L. (1983). Matthew effects in education. American Educational Research Journal, 20(3), 359-373. doi:10.3102/00028312020003359 
Webb, T. L., \& Sheeran, P. (2006). Does changing behavioral intentions engender behavior change? A meta-analysis of the experimental evidence. Psychological Bulletin, 132(2), 249-268. doi:10.1037/0033-2909.132.2.249

Wedman, ]. (2010). The performance pyramid. In R. Watkins \& D. Leigh (Eds.), Handbook of Improving Performance in the Workplace. Vol. 2: Selecting and implementing performance interventions (pp. 51-80). San Francisco, CA: Wiley/Pfeiffer.

Wedman, J., \& Graham, S. W. (1998). Introducing the concept of performance support using the performance pyramid. The Journal of Continuing Higher Education, 46(3), 8-20. doi:10.1080/07377366.1998.10400352

Weinstein, C. E., Palmer, D. R., \& Hanson, C. (1995). Perceptions, expectations, emotions and knowledge about college. Clearwater, FL: H\&H.

Winne, P. H. (2010). Improving measurements of self-regulated learning. Educational Psychologist, 45(4), 267-276. doi:10.1080/ 00461520.2010 .517150

Woltering, V., Herrler, A., Spitzer, K., \& Spreckelsen, C. (2009). Blended learning positively affects students' satisfaction and the role of the tutor in the problem-based learning process: results of a mixed-method evaluation. Advances in Health Sciences Education: Theory and Practice, 14, 725-738. doi:10.1007/s10459-009-9154-6

Wolters, C. A. (1998). Self-regulated learning and college students' regulation of motivation. Journal of Educational Psychology, 90(2), 224-235. doi: 10.1037/0022-0663.90.2.224

Wolters, C. A., Pintrich, P. R., \& Karabenick, S. A. (2003). Assessing academic self-regulated learning. Paper presented at the Indicators of Positive Development: Definitions, Measures, and Prospective Validity, Washington, DC.

Wolters, C. A., \& Rosenthal, H. (2000). The relation between students' motivational beliefs and their use of motivational regulation strategies. International Journal of Educational Research, 33(7-8), 801-820. doi:10.1016/S0883-0355(00)00051-3

Yew, E. H. J., \& Goh, K. (2016). Problem-based learning: an overview of its process and impact on learning. Health Professions Education, 2(2), 75-79. doi:10.1016/j.hpe.2016.01.004

Zimmerman, B. J. (2008). Investigating self-regulation and motivation: historical background, methodological developments, and future prospects. American Educational Research Journal, 45(1), 166-183. doi:10.3102/0002831207312909 


\section{GHAPTER5}

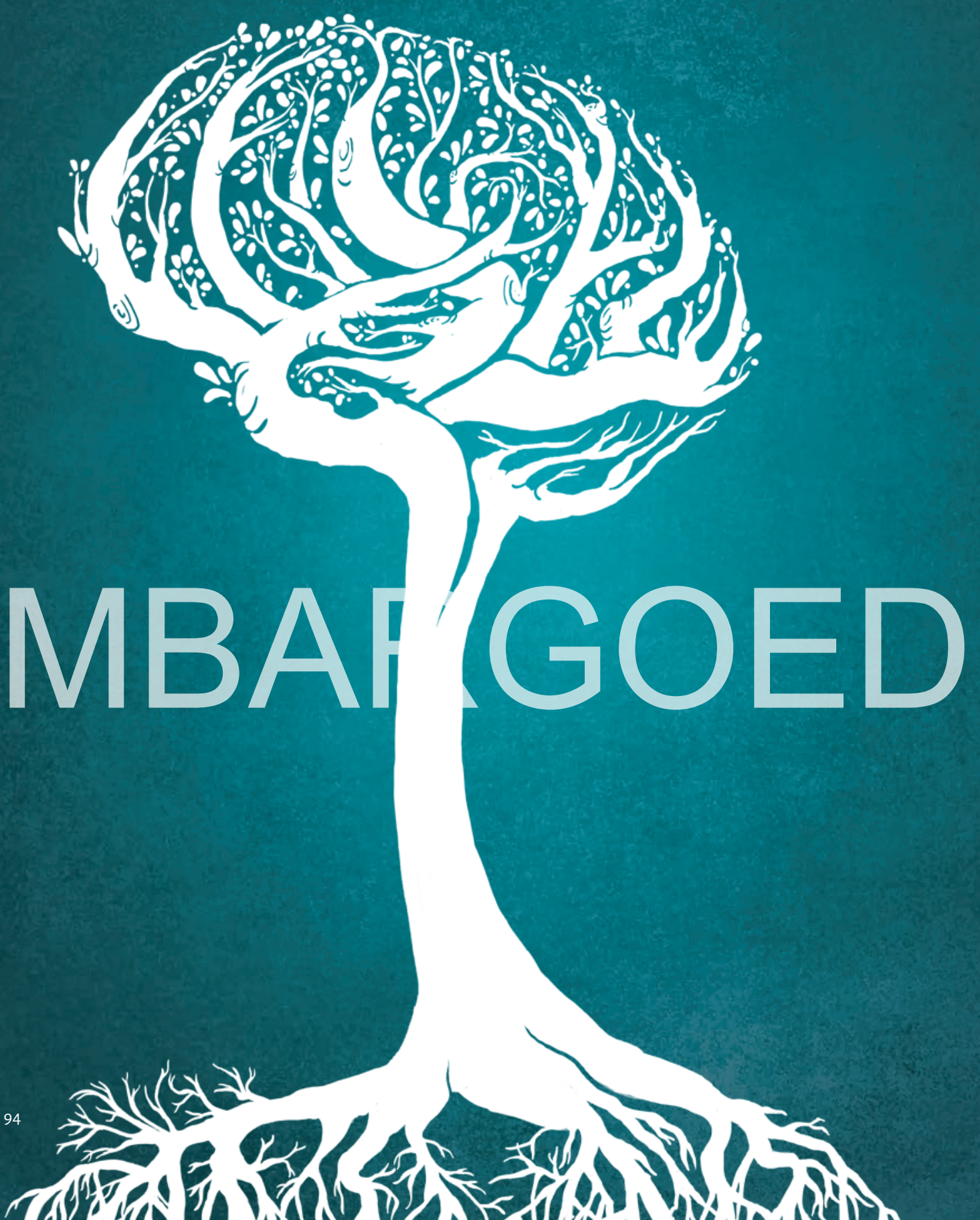





\section{General Discussion}

The central research question guiding this dissertation was as follows: How can we support (bio)medical students' self-regulated learning (SRL) in a problem-based curriculum? In order to answer this question, four studies were conducted.

\section{Research question 1}

In a first study (Chapter 2) we conducted a focus group study aiming at uncovering what effective self-regulation looks like for medical students in a PBL curriculum. Using a purposive sampling technique, medical students' mentors were asked to identify students who they considered to use effective strategies for learning. A model was constructed that describes these effective students' approaches to learning. This model specifies that effective students are guided in their study by a personal learning goal, which can be quantitative or qualitative in nature. Guided by this learning goal, students engage in a constant cycle of active processing of learning content, while simultaneously monitoring their understanding. Furthermore, students maintain a balance between established study habits on the one hand, and a flexibility to adjust when necessary in terms of changes in learning environment, time constraints and assessment demands. Interestingly, students indicated using several strategies that in the literature are commonly considered to be ineffective, but often adapted these in such a way that they became effective within their learning situation. For example, students reported the use of summarization, which is traditionally considered to be an ineffective learning strategy (Dunlosky, Rawson, Marsh, Nathan, \& Willingham, 2013), but made sure that summaries were handwritten in order to be engaged with the subject matter in an active way. This study contributes to the overarching research question by providing a picture of what effective self-regulation looks like for medical students in a PBL curriculum, which could then subsequently serve as a starting point for creating interventions to stimulate effective strategy use in students who are less effective in self-regulating their learning.

\section{Research question 2}

After having established what effective SRL looks like for medical students in a PBL curriculum, a second requirement to creating effective interventions - and establish their effects is to develop an understanding of how to properly measure students' SRL. For the study described in Chapter 3, we carried out a narrative literature review, which zoomed in on the level of convergence ('calibration') between offline self-report questionnaires (taken outside of the learning process, either before or after learning) and online behavioral measures of 
SRL (taken during the learning process itself). The main finding from this review was that calibration depends on the level of granularity at which SRL is measured. Specifically, when measuring SRL on a global level, such as on the level of scales or subscales ('coarse grained'), calibration between students' self-reported strategies and the strategies measured by the online behavioral measurement was generally found to be high. In contrast, when measuring students' SRL on strategy level ('fine grained') calibration was found to be low. As such, researchers and professionals in the field need to be well aware of the questions or issues they are trying to resolve, and choose a (combination of) measurement methods accordingly.

\section{Research question 3}

In Chapter 4 we described the effects of an intervention study aimed at improving students' use of SRL strategies. As described above, results from the first study indicated that effectively self-regulating students engage in a constant cycle of active processing and monitoring their own understanding. In other words, they are taking responsibility for their own learning process by actively monitoring their own progress and adjusting when necessary. Therefore, this sense of own responsibility could be an important foundation for interventions aiming to improve students' SRL. Specifically, as students might experience a mismatch between the teacher-centered approach they have experienced in high school and the self-regulated approach expected from them in university (Raidal \& Volet, 2009), a workshop was created for first-year medical students, which aimed to align their perceptions and expectations about learning in PBL with those set forth by the university. Compared to students in the control condition, who did not receive a workshop, students who participated in the workshop demonstrated a greater development in their intentions to take responsibility for their own learning. However, no differences between groups were found in students' self-reported use of learning strategies.

\section{Research question 4}

Finally, SRL should be developed in (bio)medical students with the aim of encouraging lifelong learning (Skinner et al., 2015), which in turn has been linked to the development of generic academic competencies (Harris, Snell, Talbot, Harden, \& for the International CBME Collaborators, 2010). Chapter 5 reported the effects of a curriculum reform towards competency-based education within a Biomedical Sciences bachelor's program on students' perceived competence development. To this end, we compared a cohort of students who took their bachelor program in the old curriculum, with a cohort of students who started after the reform. Focus groups were organized to acquire a deeper understanding of quantitative results. Results indicated that students from the revised curriculum experienced a greater development of general academic competencies, but tended to have a lower sense of selfefficacy for studying Biomedical Sciences more generally. One of the themes that emerged 
from the focus groups was that students were often unclear about what was meant with the specific general academic competencies. This might provide an explanation for these findings, which at first sight might seem contradicting. Specifically, students may have become more aware of the competencies they were expected to develop, and because of this increased awareness, combined with unclarity about what they were supposed to achieve, they may have become less secure, thus showing a lower self-efficacy for studying Biomedical Sciences in general. Other themes that emerged from the focus groups were the importance of practice for competency development, and the structure of PBL as being conducive to the development of competencies.

\section{Supporting (bio)medical students' SRL in PBL}

Overall, the overarching research question guiding this dissertation was "How can we support (bio)medical students' self-regulated learning (SRL) in a problem-based curriculum?", and this dissertation contributes to answering this question as follows. Students need to be supported in taking active responsibility for their own learning process, which should ideally be measured with a combination of online and offline measurements. Aligning students' perceptions and expectations about their learning environment to those set forth by the university can indeed make students more willing to take responsibility for their own learning, but this does not automatically lead to a change towards the use of more effective learning strategies. Finally, a competency-based curriculum can help students prepare for the final step from SRL to lifelong learning, as this was found to effectively stimulate students' self-perceived general academic competencies.

\section{Theoretical and practical considerations and implications}

The studies in this dissertation show that on a theoretical level, based on a model of effective SRL for medical students in a PBL curriculum, it is possible to stimulate students' intentions to take responsibility for their own learning, and that the curriculum can play an important role in taking a further step to lifelong learning by developing their general academic competencies. However, in Study 3, students' increased willingness to take responsibility for their own learning did not lead to a change towards the use of more effective learning strategies. Apparently, more is required to effectuate such a change.

From the students' perspective, engaging in proper self-regulated, problem-based learning is often accompanied by a substantial amount of uncertainty. Solomon and Finch (1998) conducted a qualitative study among physiotherapy students in the problem-based learning context of McMaster University in Canada that indicated that students in the PBL curriculum experienced several unique stressors. Specifically, students were unsure regarding 
what they should study and the depth they were supposed to reach. They were afraid of missing important information and being unable to find appropriate literature. Many students indicated that they did not believe they could be successful in the PBL curriculum.

To make matters worse, the stages of learning model (Howell, 1982) stipulates that as students progress through their learning trajectory, they will go from an initial 'unconscious incompetence' stage (not knowing what they don't know) to the second 'conscious incompetence' stage, where what they have learned up until that point makes them aware of all the things they do not yet know. This consciousness, coupled with the insecurities described above about what to study and how to find it, could further students' desire to rely on the teacher to tell them what to do. This was reflected in the results from the fourth study, in which students from the revised, competency-oriented curriculum reported a higher selfperceived level of general academic competencies, but reported a lower degree of self-efficacy in their ability to study Biomedical Sciences.

Furthermore, an important principle in education is that student learning is motivated by what will be assessed (McLachlan, 2006; Muijtjens, Hoogenboom, Verwijnen, \& Van der Vleuten, 1998). Indeed, in a study by Wormald, Schoeman, Somasunderam, and Penn (2009), an increase in the weighting associated with Anatomy in the overall assessment plan led to an increase in students' motivation to study this particular topic. If students' goal is to pass the test, short-term tests (such as the typical course exams at Maastricht University) will lead to short-term learning strategies. Therefore, if we truly wish to promote long-term development of self-regulation of the students in our PBL curriculum, students need to be required to fulfil long-term goals. In health professions education, the use of 'progress testing' is an important answer to this issue (Schuwirth \& Van der Vleuten, 2012; Tio et al., 2016). The rise of programmatic assessment (Schuwirth \& Van der Vleuten, 2011; Van der Vleuten et al., 2012; Van der Vleuten \& Schuwirth, 2005) and its broader implementation throughout PBL curricula could also further benefit students' SRL development.

From the teachers' perspective, creating truly self-regulated students in the PBL program would also require a substantial shift in mindset. One of the reasons suggested for students' lack of self-regulation in PBL, is uncertainty on the part of the teachers. Specifically, teachers might be unsure about whether students will be able to cover the required subject matter on their own (Dolmans, Wolfhagen, Van der Vleuten, \& Wijnen, 2001; Loyens, Magda, \& Rikers, 2008; Moust, Van Berkel, \& Schmidt, 2005). In order to mediate their own fears, these teachers might react by prescribing learning issues and associated literature (Dolmans et al., 2001; Loyens et al., 2008; Moust et al., 2005), and instead of challenging students with thoughtprovoking questions, they provide them with mini-lectures in order to reassure themselves that all the 'content has been covered' (Moust et al., 2005). In other words, the teachers recede to a more teacher-centered approach to teaching out of fear of losing control of students' learning processes. 
In order to enable teachers to let go of this control of students' learning, changes in the organization would also be required. As outlined by Teelken (2018), higher education institutions in the Netherlands are characterized by a managerial style of evaluation, in which emphasis is placed on performance criteria to evaluate teachers' performance and (anonymous) student evaluations play an important role, which can have consequences for the teachers involved. Often, these evaluations do not reflect the actual educational quality of their teaching, which is much more difficult to measure (Teelken, 2018). As described above, the PBL learning environment can create substantial anxiety in students (Solomon \& Finch, 1998), which might cause them to give negative evaluations to the courses that actually aim to stimulate their SRL. In turn, fear of negative evaluations (Morton, Vesco, Williams, \& Awender, 1997) might make teachers within the PBL curriculum less willing to actually make an appeal on and stimulate students' SRL. As such, in order to give teachers the opportunity to truly develop students' SRL, changes need to occur in the manner of evaluation. Teelken (2018) offers several alternatives that can improve the usefulness of the evaluations. For instance, participants in her study suggested the use of peer review among teachers. Furthermore, oral evaluations could make it possible to delve deeper into the more meaningful aspects of educational quality (Teelken, 2018).

It should also be noted, however, that teachers' unwillingness to relinquish control is not entirely unjustified. In order to be trusted to create their own learning goals and find their own literature sources, students need appropriate information literacy skills. Often, these skills are insufficiently developed in university students (Gross \& Latham, 2012). Moreover, instruction on information literacy is often not fully integrated in university curricula (Derakhshan \& Singh, 2011), and Maastricht University is no exception. As such, another change that should be implemented, before the organizational change described above, is the integrated adoption of information literacy education in all courses throughout the whole curriculum.

At the same time, teachers themselves might be unsure about how to properly support students in self-regulating their learning. Teachers can experience difficulties in assuming their role as facilitator (Neville, 1999; Savery, 2006), and might prefer a directive teaching style themselves (Neville, 1999). Being able to support students' self-regulation may not come naturally to teachers, and they may require support in this area (Moos \& Ringdal, 2012). As such, how to support the development of students' SRL should be an explicit part of faculty development (Moos \& Ringdal, 2012; Panadero, 2017).

A final note concerns the distinction between self-regulated learning on the one hand, and self-directed learning (SDL) on the other. In educational literature more generally, as well as in literature on PBL more specifically, these two terms are often used interchangeably, and definitions are often not clear (Loyens et al., 2008; Saks \& Leijen, 2014). As pointed out by Schunk (2008) in a paper focusing even more specifically on the difference between self-regulation and self-regulated learning, unclear definitions pose a substantial problem: "How we define 
processes influences the measures we use to assess them and how we interpret our research results. It is little wonder that research results often are inconsistent when investigators have used different definitions and measures" (Schunk, 2008, p.464). As pointed out by Loyens et al. (2008), SDL encompasses a broader range of processes than SRL. Specifically, SDL encompasses the independent pursuit of learning by students across different courses and programs, in which they are free to choose their own tasks and topics, and how to proceed. In contrast, SRL encompasses independent learning within a specific learning task, which may also have been defined by somebody other than the student, e.g,. by a teacher (Jossberger, Brand-Cruwel, Boshuizen, \& Van de Wiel, 2010; Loyens et al., 2008). As such, Loyens et al. (2008) posit that $\mathrm{SRL}$ can be considered to be part of SDL, but not the other way around. Furthermore, we also argue that SRL is a first step, which should eventually lead to SDL, which in turn can lead to the development of lifelong learning skills. Hopefully, the studies presented in this dissertation provide a step in the right direction of fostering this development.

\section{Methodological considerations and limitations}

In addition to the theoretical and practical considerations described above, some methodological considerations should also be noted, which led to a number of limitations associated with this dissertation. Two categories will be discussed: the role of context in SRL research and practice, and the role of different methods of measurement.

Firstly, researchers are becoming increasingly aware of the importance of context when investigating and measuring SRL (e.g., Bråten \& Samuelstuen, 2007; Hadwin, Winne, Stockley, Nesbit, \& Woszczyna, 2001; McCardle \& Hadwin, 2015). This may refer to different types of educational activities (Bråten \& Samuelstuen, 2007; Hadwin et al., 2001), where students use different strategies when studying for, for instance, an exam versus preparing for the tutorial group discussion within the same course. Or it may refer to different courses (Vanderstoep, Pintrich, \& Fagerlin, 1996), where students will employ different learning strategies in, for instance, an anatomy course versus a course on ethics. With the advent of online forms of learning, these contextual considerations now also extend to differences between faceto-face and online or blended forms of learning (Dabbagh \& Kitsantas, 2004; Li, Baker, \& Warschauer, 2020). In this dissertation, we focused on the specific context of (bio)medical education in the PBL face-to-face learning environment of Maastricht University. Future research should elucidate whether the results reported in this dissertation can be generalized to other contexts and settings.

Secondly, much has been written about the different methods available for the measurement of SRL, and the challenges and affordances associated with each (e.g., Winne, 2010). In fact, Study 2 in this dissertation was devoted to the comparison of different forms of measurement. The conclusion from this study was that each form has its own value, and that 
researchers and practitioners should keep in mind the research question or problem they wish to address, in order to align their measurement methods to the situation at hand. Due to the face-to-face educational setting which we were dealing with in the PBL context of Maastricht University, it was difficult to obtain objective, behavioral measures that would not interfere with the learning process. Although conducting the studies in the context of students' real learning adds ecological validity to the research, the lack of more objective measures of SRL is a methodological limitation of this dissertation. There is a scarcity of studies that directly compare online behavioral measures of SRL with offline self-report measures (Karabenick \& Zusho, 2015; Winne, 2010). Such studies should be conducted to advance the field of SRL, and to see if the results outlined in this dissertation hold true when different, more fine-grained measurement methods are used.

\section{Conclusion}

The central research question that guided the studies in this dissertation was: How can we support (bio)medical students' SRL in a PBL curriculum? Based on a model of effective selfregulation in $\mathrm{PBL}$ medical education, in which students who are driven by a personal learning goal engage in a constant process of active processing and monitoring of understanding while maintaining a balance between habits and flexibility, SRL can best be examined with a deliberate set of measures driven by the research question or problem at hand. An intervention aimed at aligning students' perceptions and expectations regarding their learning environment to those set forth by the university, was found to increase students' intentions to take responsibility for their own learning process, but did not have an effect on their self-reported use of learning strategies. When looking at the level of the whole curriculum, a curriculum redesign within the Biomedical Sciences bachelor program focused at students' general academic competencies indeed had a positive effect on students' perceived development of these competencies, but had a negative effect on their general self-efficacy for studying Biomedical Sciences. Future research should be conducted to assess the generalizability of our results to other populations, settings and contexts, using a wider variety of measurement methods.

Studies show that students often experience difficulties in using appropriate learning strategies, and employ easy-to-use but ineffective strategies instead (Kornell \& Bjork, 2007). As ineffective strategy use can negatively impact students' test performance and long-term retention (e.g., Rawson, Dunlosky, \& Sciartelli, 2013), properly supporting students in their knowledge about and use of effective learning strategies is paramount. This dissertation contributes to the literature by addressing students' self-regulation from a comprehensive overview: Starting from a model of effective self-regulation in PBL medical education, we progressed through studying different forms of measurement, to supporting students both 
from an individualized approach, as well as from the perspective of the curriculum.

If SRL skills education is not given an explicit place in the curriculum and is instead left to individual teachers, this will lead to uncertainty in both students and teachers and suboptimal SRL skills development. In order to prevent this undesirable situation, structural changes are required in the organizational and educational aspects of the curriculum. 


\section{References}

Bråten, I., \& Samuelstuen, M. S. (2007). Measuring strategic processing: Comparing task-specific self-reports to traces. Metacognition and Learning, 2(1), 1-20. doi:10.1007/s11409-007-9004-y

Dabbagh, N., \& Kitsantas, A. (2004). Supporting self-regulation in student-centered web-based learning environments. International Journal on E-learning, 3(1), 40-47.

Derakhshan, M., \& Singh, D. (2011). Integration of information literacy into the curriculum: a meta-synthesis. Library Review, 60(3), 218-229. doi:10.1108/00242531111117272

Dolmans, D. H. J. M., Wolfhagen, I. H. A. P., Van der Vleuten, C. P. M., \& Wijnen, W. H. F. W. (2001). Solving problems with group work in problem based learning - hold on to the philosophy. Medical Education, 35(9), 884-889. doi:10.1046/j.13652923.2001.00915.x

Dunlosky, J., Rawson, K. A., Marsh, E. J., Nathan, M. J., \& Willingham, D. T. (2013). Improving students' learning with effective learning techniques: Promising directions from cognitive and educational psychology. Psychological Science in the Public Interest, 14(1), 4-58. doi:10.1177/1529100612453266

Gross, M., \& Latham, D. (2012). What's skill got to do with it?: Information literacy skills and self-views of ability among first-year college students. Journal of the American Society for Information Science and Technology, 63(3), 574-583. doi:10.1002/ asi. 21681

Hadwin, A. F., Winne, P. H., Stockley, D. B., Nesbit, J. C., \& Woszczyna, C. (2001). Context moderates students' self-reports about how they study. Journal of Educational Psychology, 93(3), 477-487. doi:10.1037/0022-0663.93.3.477

Harris, P., Snell, L., Talbot, M., Harden, R. M., \& for the International CBME Collaborators. (2010). Competency-based medical education: implications for undergraduate programs. Medical Teacher, 32(8), 646-650. doi:10.3109/0142159X.2010.500703

Howell, W. S. (1982). The empathic communicator. Belmont, CA: Wadsworth Publishing Company.

Jossberger, H., Brand-Gruwel, S., Boshuizen, H., \& Van de Wiel, M. (2010). The challenge of self-directed and self-regulated learning in vocational education: A theoretical analysis and synthesis of requirements. Journal of Vocational Education and Training, 62(4), 415-440. doi:10.1080/13636820.2010.523479

Karabenick, S. A., \& Zusho, A. (2015). Examining approaches to research on self-regulated learning: conceptual and methodological considerations. Metacognition and Learning, 10, 151-163. doi:10.1007/s11409-015-9137-3

Kornell, N., \& Bjork, R. A. (2007). The promise and perils of self-regulated study. Psychonomic Bulletin \& Review, 14(2), 219-224. doi:10.3758/BF03194055

Li, Q., Baker, R., \& Warschauer, M. (2020). Using clickstream data to measure, understand, and support self-regulated learning in online courses. The Internet and Higher Education, 45, 1-13. doi:10.1016/j.iheduc.2020.100727

Loyens, S. M. M., Magda, J., \& Rikers, R. M. J. P. (2008). Self-directed learning in problem-based learning and its relationships with self-regulated learning. Educational Psychology Review, 20, 411-427. doi:10.1007/s10648-008-9082-7

McCardle, L., \& Hadwin, A. F. (2015). Using multiple, contextualized data sources to measure learners' perceptions of their self-regulated learning. Metacognition and Learning, 10(1), 43-75. doi:10.1007/s11409-014-9132-0

McLachlan, J. C. (2006). The relationship between assessment and learning. Medical Education, 40(8), 716-717. doi:10.1111/j.13652929.2006.02518.x

Moos, D. C., \& Ringdal, A. (2012). Self-regulated learning in the classroom: A literature review on the teacher's role. Education Research International, 2012, 1-15. doi:10.1155/2012/423284

Morton, L. L., Vesco, R., Williams, N. H., \& Awender, M. A. (1997). Student teacher anxieties related to class management, pedagogy, evaluation, and staff relations. British Journal of Educational Psychology, 67(1), 69-89. doi:10.1111/j.2044-8279.1997. tbo1228.x

Moust, J. H. C., Van Berkel, H. J. M., \& Schmidt, H. G. (2005). Signs of erosion: Reflections on three decades of problem-based learning at Maastricht University. Higher Education, 50, 665-683. doi:10.1007/s10734-004-6371-z

Muijtjens, A. M. M., Hoogenboom, R. J. I., Verwijnen, G. M., \& Van der Vleuten, C. P. M. (1998). Relative or absolute 
standards in assessing medical knowledge using progress tests. Advances in Health Sciences Education, 3, 81-87. doi:10.1023/A:1009728423412

Neville, A. J. (1999). The problem-based learning tutor: Teacher? Facilitator? Evaluator? Medical Teacher, 21(4), 393-401. doi: $10.1080 / 01421599979338$

Panadero, E. (2017). A review of self-regulated learning: six models and four directions for research. Frontiers in Psychology, 8 , 1-13. doi:10.3389/fpsyg.2017.00422

Raidal, S. L., \& Volet, S. E. (2009). Preclinical students' predispositions towards social forms of instruction and self-directed learning: a challenge for the development of autonomous and collaborative learners. Higher Education, 57, 577-596. doi:10.1007/s10734-008-9163-z

Rawson, K. A., Dunlosky, J., \& Sciartelli, S. M. (2013). The power of successive relearning: Improving performance on course exams and long-term retention. Educational Psychology Review, 25, 523-548. doi:10.1007/s10648-013-9240-4

Saks, K., \& Leijen, $\ddot{A}$. (2014). Distinguishing self-directed and self-regulated learning and measuring them in the e-learning context. Procedia-Social and Behavioral Sciences, 112, 190-198. doi:10.1016/j.sbspro.2014.01.1155

Savery, J. R. (2006). Overview of problem-based learning: definitions and distinctions. Interdisciplinary Journal of Problem-Based Learning, 1(1), 9-20. doi:10.7771/1541-5015.1002

Schunk, D. H. (2008). Metacognition, self-regulation, and self-regulated learning: Research recommendations. Educational Psychology Review, 20, 463-467. doi:10.1007/s10648-008-9086-3

Schuwirth, L. W. T., \& Van der Vleuten, C. P. M. (2011). Programmatic assessment: from assessment of learning to assessment for learning. Medical Teacher, 33(6), 478-485. doi:10.3109/0142159X.2011.565828

Schuwirth, L. W. T., \& Van der Vleuten, C. P. M. (2012). The use of progress testing. Perspectives on Medical Education, 1, 24-30. doi:10.1007/s40037-012-0007-2

Skinner, D. E., Saylors, C. P., Boone, E. L., Rye, K. J., Berry, K. S., \& Kennedy, R. L. (2015). Becoming lifelong learners: A study in self-regulated learning. Journal of Allied Health, 44(3), 177-182.

Solomon, P., \& Finch, E. (1998). A qualitative study identifying stressors associated with adapting to problem-based learning Teaching and Learning in Medicine, 10(2), 58-64. doi:10.1207/S15328015TLM1002_1

Teelken, C. (2018). Teaching assessment and perceived quality of teaching: a longitudinal study among academics in three European countries. European Journal of Higher Education, 8(4), 382-399. doi:10.1080/21568235.2018.1490661

Tio, R. A., Schutte, B., Meiboom, A. A., Greidanus, J., Dubois, E. A., Bremers, A. J., \& the Dutch Working Group of the Interuniversity Progress Test of Medicine. (2016). The progress test of medicine: the Dutch experience. Perspectives on Medical Education, 5(1), 51-55. doi:10.1007/s40037-015-0237-1

Van derVleuten, C. P. M., Schuwirth, L. W. T., Driessen, E. W., Dijkstra, J., Tigelaar, D., Baartman, L. K. J., \& Van Tartwijk, J. (2012). A model for programmatic assessment fit for purpose. Medical Teacher, 34(3), 205-214. doi:10.3109/0142159X.2012.652239

Van der Vleuten, C. P. M., \& Schuwirth, L. W. T. (2005). Assessing professional competence: from methods to programmes. Medical Education, 39(3), 309-317. doi:10.1111/j.1365-2929.2005.02094.X

Vanderstoep, S. W., Pintrich, P. R., \& Fagerlin, A. (1996). Disciplinary differences in self-regulated learning in college students. Contemporary Educational Psychology, 21(4), 345-362. doi:10.1006/ceps.1996.0026

Winne, P. H. (2010). Improving measurements of self-regulated learning. Educational Psychologist, 45(4), 267-276. doi:10.1080/ 00461520.2010 .517150

Wormald, B. W., Schoeman, S., Somasunderam, A., \& Penn, M. (2009). Assessment drives learning: an unavoidable truth? Anatomical Sciences Education, 2(5), 199-204. doi:10.1002/ase.102 


\section{SUMMARIES}

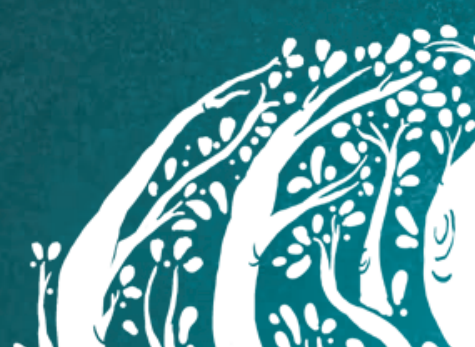

की

6 :

कi

(1)

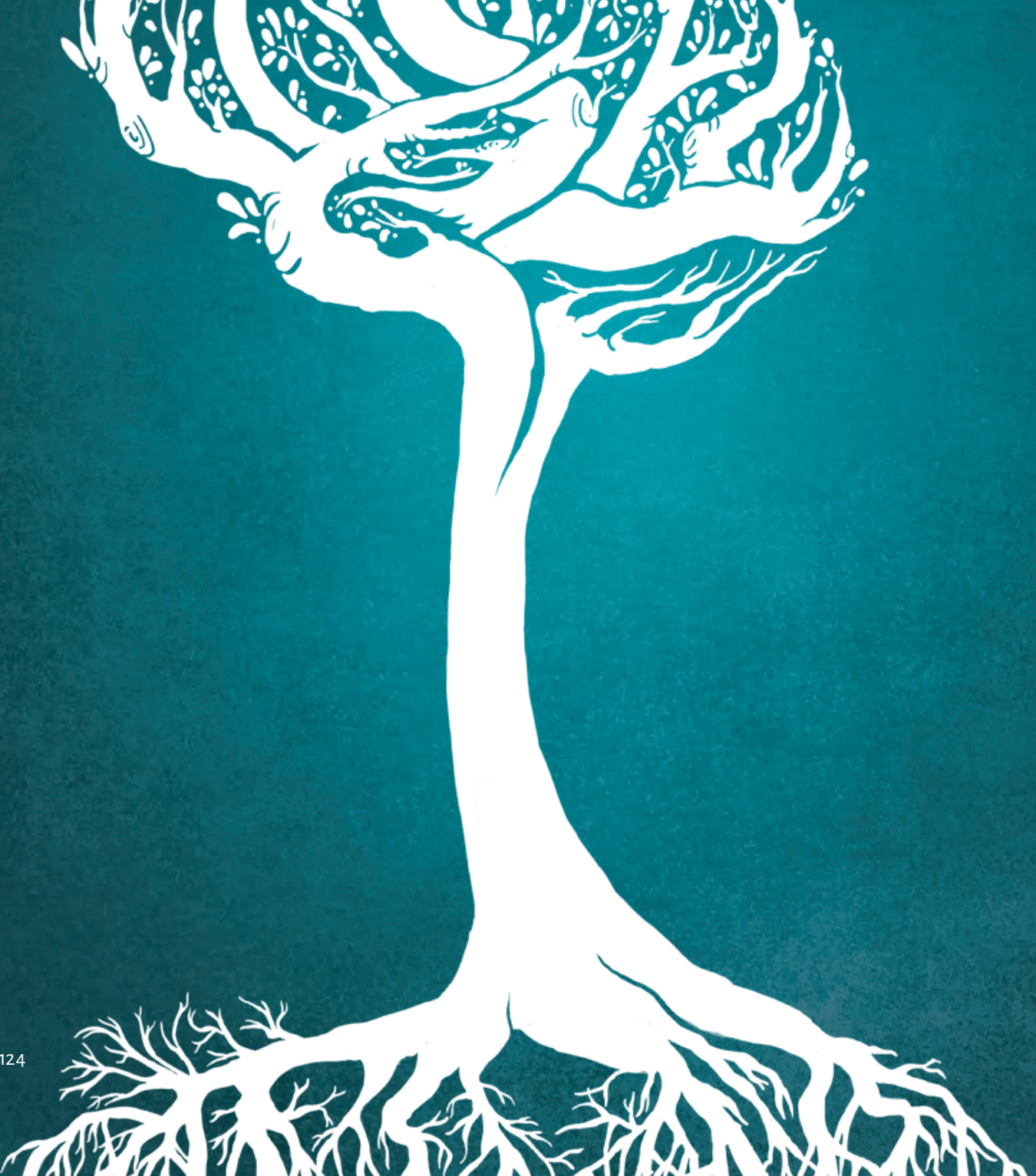




\section{English summary}

This dissertation described four studies conducted to investigate how self-regulated learning (SRL) can be supported in (bio)medical students in a problem-based learning (PBL) curriculum. In the General Introduction (Chapter 1) we describe current issues and considerations around the field of SRL in PBL. After providing a short description of PBL, the PBL process, and its underlying mechanisms and effects, we describe issues experienced by teachers and students in the PBL approach, particularly in the self-study phase. Rather than using effortful strategies that have long-term benefits for learning, students often find themselves employing easy-touse, surface-level learning strategies with only short-term benefits. As such, students need to be motivated to more effectively self-regulate their learning, becoming aware of the benefits of desirable difficulties and incorporating these into the learning process.

In order to investigate how students can best be supported in becoming more effective self-regulated learners, four studies were conducted, which are reported on in Chapters 2-5. The research questions guiding these respective studies were the following:

1. How do highly effective self-regulating students in a PBL curriculum approach their learning? How do they incorporate desirable difficulties into this process? (Chapter 2)

2. How do offline self-report questionnaires compare to online forms of measurement in terms of calibration of students' self-report of strategy use, versus their actual strategy use? Does the degree of calibration vary as a function of the granularity at which SRL is measured? (Chapter 3)

3. Can students' SRL strategies be enhanced by means of a workshop aimed at aligning their perceptions and expectations about their learning environment to those of the university? Do students with different prior levels of SRL and realistic perceptions and expectations benefit differentially from this intervention? (Chapter 4)

4. What are the effects of a curriculum reform toward competency-based education within the Biomedical Sciences bachelor program on students' self-perceived competency development? (Chapter 5)

For the study described in Chapter 2, a mixed-methods study was conducted investigating how highly effective self-regulating students approach their learning. After initially filling out a learning strategy questionnaire, focus groups were conducted in which students were asked in what way they use these learning strategies during the learning process. After four months, students were invited back for a second session for follow-up. Based on the focus groups, a model was created. According to this model, effective self-regulating students start from a 
personal learning goal, which can have a quantitative or qualitative character. Driven by this learning goal, students engage in a continuous process of active processing of content on the one hand, and monitoring of their understanding on the other, all the while maintaining a balance between established study habits and a flexibility to adjust these. Students demonstrated varying levels of metacognitive knowledge regarding which strategies they used and how they had acquired them, and indicated the use of several learning strategies which are often described as ineffective. However, they use these strategies in an active manner, such that the strategies would help them adjust to their particular learning situation.

Chapter 3 describes the results of a narrative literature review, conducted to gain insight into how different measures of SRL compare to one another. We distinguished between online measures, which are taken during student learning, and offline measures, which are taken outside of the learning process (i.e., before or after learning), and looked at the level of calibration (i.e., the degree of overlap) between the measurements. For this study, we searched the literature for peer-reviewed, English articles describing original research on SRL conducted in higher education, which used and/or compared both offline self-report questionnaires, as well as online, often behavioral measures of SRL. The studies which were included in the review, were grouped according to the level at which they measured SRL: studies focusing on specific learning strategies on the one hand, and studies focusing on a more global (overall) level of SRL on the other. This distinction is referred to as the level of granularity (i.e., the 'grain size') at which SRL is measured. Results indicate that the level of calibration depends on the level of granularity at which SRL is measured. When looking at SRL at the strategy level (i.e., a high level of granularity), calibration was found to be low. However, when SRL is measured at a more global level (i.e., a low level of granularity), studies generally indicate a high level of calibration. This implies that both forms of measurement have their own value in research and education, and that the appropriate (combination of) measurement(s) depends on the question or problem at hand.

In Chapter 4, we describe the results of an intervention study which provided students with a workshop aimed at supporting students' development of SRL. This workshop started from the idea that first-year students might experience a mismatch between the teacher-centered working habits they have become used to in high school, versus the self-regulated attitude that is expected from them in a (problem-based) university setting. During this workshop, students were asked to reflect on the seven steps of the PBL cycle, and who is responsible for their learning process in each of these steps. First-year medical students were randomly assigned to either an experimental condition in which they received this workshop, or a control condition in which no workshop was provided. During a pretest and a posttest, students filled out questionnaires regarding their learning strategies, their 'academic expectations' about learning in university, referring to who they think is responsible for their learning, and their 'personal expectations' about learning in university, referring to their intentions to take 
responsibility for their own learning. Results indicated a greater development of students' intentions to take responsibility for their learning for students in the workshop condition, compared to students from the control condition. However, no differences were found in their academic expectations or self-reported use of learning strategies. Furthermore, the workshop did not differentially benefit students with different pretest scores for any of the learning strategies or expectations subscales.

In the final study (Chapter 5), we studied the effects of a curriculum reform in the Maastricht University Biomedical Sciences bachelor program toward competency-based education, which has been implicated for the development of students' lifelong learning skills. For this purpose, two cohorts of students were compared: the first cohort starting their bachelor program before the curriculum reform, thereby taking their entire bachelor program in the old curriculum, and a second cohort starting their program after the new curriculum had been introduced. At the end of each of the three years of the program, students were asked to fill out surveys regarding their self-perceived development of general academic competencies, and their self-efficacy for studying Biomedical Sciences. Focus groups were organized in order to obtain deeper insight into results from the surveys. Results indicated that although the curriculum reform had a positive effect on students' self-perceived development of the general academic competencies that were targeted in the curriculum reform, they also showed a trend towards lower self-efficacy for studying Biomedical Sciences, which disappeared in the final year of the bachelor program. Findings from the focus group provided some elucidations for these seemingly contrasting findings, as students from the revised curriculum indicated that it was often not clear to them what was meant by the specific competencies. In this way, being confronted with the competencies they had to attain at the end of the bachelor program, coupled with a sense of unclarity regarding what this meant for their learning, might have made students more aware of all the gaps in their knowledge, and created some anxiety regarding their self-efficacy.

Chapter 6 provides an overarching discussion about the studies in this dissertation, describing theoretical and practical considerations and implications, as well as the methodological considerations and limitations associated with the studies. As a whole, it is important that action is taken in order to relieve uncertainty in both students and teachers. In order to support teachers in this regard, changes would be required in the evaluation of courses, and faculty development should take place for teachers to become more adept in supporting students' SRL. Furthermore, students need to be supported in their information literacy skills by integrating information literacy education into the curriculum. The overall conclusion drawn from this section is that SRL skills education needs to take an integrated place in the curriculum, in order to decrease uncertainty experienced by students and teachers alike. Furthermore, several organizational and educational changes would need to be introduced into the university system, in order to optimally support teachers and students in this process. 


\section{Nederlandse samenvatting}

Dit proefschrift beschrijft een reeks onderzoeken die zijn uitgevoerd om te bestuderen hoe zelfregulatie van (bio)medisch studenten in een probleemgestuurd onderwijs (PCO) curriculum het beste ondersteund kan worden. Het proefschrift begint met een algemene introductie (Hoofdstuk 1), waarin de huidige stand van zaken wordt beschreven rondom onderzoek naar zelfregulatie binnen PGO. Er wordt een korte beschrijving gegeven van PGO, het PCO proces, almede de onderliggende mechanismen en het onderzoek naar de effecten van dit onderwijssysteem. Veel studenten en docenten ervaren problemen met zelfregulatie binnen het PCO systeem, met name in de zelfstudiefase. Om te leren en kennis te onthouden voor de lange termijn, is het van belang dat studenten effectieve leerstrategieën gebruiken die doorgaans veel moeite kosten. In plaats daarvan zijn studenten echter vaak geneigd tot het gebruik van strategieën die weinig moeite kosten en makkelijk aanvoelen. Deze strategieën zijn echter enkel effectief voor de korte termijn, en helpen studenten niet om de informatie op te slaan in het lange-termijn geheugen en de stof op een dieper niveau te begrijpen. Studenten moeten dus gemotiveerd worden om effectievere leerstrategieën toe te passen, die weliswaar meer moeite kosten, maar uiteindelijk een hoger rendement zullen opleveren. Deze staan in de literatuur bekend als zogeheten 'desirable difficulties'.

Er zijn vier studies uitgevoerd om te onderzoeken hoe studenten het beste kunnen worden ondersteund in het toepassen van deze effectievere vorm van zelfregulatie. Deze onderzoeken worden beschreven in hoofdstukken 2-5. De onderzoeksvragen behorende bij deze onderzoeken waren respectievelijk:

1. Hoe reguleren hoog-effectief zelfregulerende studenten hun leerproces? Hoe integreren zij 'desirable difficulties' in dit proces? (Hoofdstuk 2)

2. Hoe verhouden verschillende soorten meetinstrumenten voor zelfregulatie zich tot elkaar, als het gaat om de overlap tussen de leerstrategieën die studenten zelf rapporteren te gebruiken, versus de strategieën die zij werkelijk blijken te gebruiken? Varieert deze mate van overlap op basis van het niveau van specificiteit waarop zelfregulatie wordt gemeten? (Hoofdstuk 3 )

3. Kan de zelfregulatie van studenten worden verbeterd aan de hand van een workshop die zich richt op het afstemmen van de percepties en verwachtingen die studenten hebben aangaande hun leeromgeving, op de verwachtingen die de universiteit van studenten heeft? Varieert de effectiviteit van deze interventie op basis van het basisniveau van studenten betreffende hun zelfregulatie en percepties en verwachtingen? (Hoofdstuk 4) 
4. Wat zijn de effecten van een curriculumhervorming in de richting van competentiegericht onderwijs binnen het Biomedische Wetenschappen bachelorprogramma op de zelf ervaren competentieontwikkeling van studenten? (Hoofdstuk 5)

Voor het onderzoek dat wordt beschreven in Hoofdstuk 2, is gebruik gemaakt van zowel kwantitatieve als kwalitatieve methoden om te onderzoeken hoe goede zelf-reguleerders hun leerproces benaderen. In eerste instantie werd studenten gevraagd een vragenlijst in te vullen over hun gebruik van leerstrategieën. Hierna werden focusgroepen georganiseerd, waarin aan studenten werd gevraagd op welke manier zij deze strategieën inzetten tijdens hun leerproces. Na vier maanden werd deze eerste focusgroep opgevolgd met een tweede sessie. Aan de hand van de focusgroepen werd een model gemaakt. Dit model stelt dat effectief zelfregulerende studenten beginnen met een persoonlijk leerdoel, dat kwantitatief of kwalitatief van aard kan zijn. Aan de hand van dit leerdoel bevinden studenten zich in een continu proces van actieve verwerking van de leerstof en het monitoren van hun begrip hiervan, terwijl zij een balans aanhouden tussen vaste studiegewoonten enerzijds, en flexibiliteit om zich te kunnen aanpassen aan veranderende leeromstandigheden anderzijds. Studenten vertoonden hierbij wisselende niveaus van metacognitieve kennis aangaande welke strategieën zij gebruikten en waarom, en gaven vaak aan leerstrategieën te gebruiken die in de literatuur traditioneel gezien als ineffectief worden beschouwd. Zij gebruikten deze strategieën echter op een actieve manier, zodat deze hen hielpen zich aan te passen aan hun specifieke leersituatie.

Hoofdstuk 3 beschrijft de resultaten van een narratieve literatuurstudie, uitgevoerd om inzicht te verkrijgen in hoe verschillende meetmethoden van zelfregulatie zich tot elkaar verhouden. Hierbij werd een onderscheid gemaakt tussen online meetmethoden, die worden afgenomen tijdens het leerproces, en offline meetmethoden, die buiten het leerproces worden afgenomen (voor of na het leren). Hierbij onderzochten we de mate van overlap tussen deze meetmethoden. Voor dit onderzoek zochten we naar peer-reviewed, Engelstalige artikelen die origineel onderzoek beschreven naar zelfregulatie binnen het hoger onderwijs, die gebruik makkten van zowel offline zelfrapportage als online meetmethoden. De onderzoeken die in de literatuurstudie werden opgenomen, werden gegroepeerd aan de hand van de mate van specificiteitwaarop zelfregulatie gemeten werd: onderzoeken diezich richten op het meten van specifieke leerstrategieën (dus met een hoge mate van specificiteit) enerzijds, en onderzoeken die zich richten op het meten van een meer globaal niveau van zelfregulatie, gemeten op (sub) schaalniveau (dus met een lage mate van specificiteit) anderzijds. Uit de resultaten bleek dat de mate van overlap afhangt van de mate van specificiteit waarop zelfregulatie gemeten wordt. Wanneer zelfregulatie wordt gemeten met een hoge mate van specificiteit, is de mate van overlap tussen de verschillende metingen laag. Wanneer zelfregulatie echter gemeten wordt op een globaal niveau (met een lage mate van specificiteit), is de overlap voor de meeste 
onderzoeken hoog. Dit impliceert dat beide soorten meetmethoden hun eigen waarde hebben in onderzoek en praktijk, en dat de geschikte (combinatie van) meetmethode(n) afhangt van de (onderzoeks)vraag.

In Hoofdstuk 4 worden de resultaten beschreven van een interventiestudie waarin aan studenten een workshop werd aangeboden, gericht op het ondersteunen van de ontwikkeling van de zelfregulatie van studenten. De gegeven workshop berustte op het idee dat eerstejaars studenten een mismatch kunnen ervaren tussen de docent-gecentreerde aanpak waaraan zij op de middelbare school zijn gewend geraakt, versus de zelfregulerende houding die van hen wordt verwacht in een (probleemgestuurde) universitaire setting. Tijdens de workshop werd studenten gevraagd te reflecteren op de zeven stappen van het PCO proces, en wie verantwoordelijk is voor hun leerproces tijdens elk van deze stappen. Eerstejaars Geneeskundestudenten werden willekeuring toegewezen aan een experimentele conditie waarin zij deze workshop kregen, of een controleconditie waarin geen workshop werd aangeboden. Tijdens een voormeting en een nameting vulden studenten vragenlijsten in over hun leerstrategieën, hun verwachtingen betreffende wie er verantwoordelijk is voor hun leerproces ('academische verwachtingen'), en hun intentie om verantwoordelijkheid te nemen voor hun eigen leerproces ('persoonlijke verwachtingen'). Uit de resultaten bleek dat studenten in de experimentele conditie een hogere ontwikkeling lieten zien in hun intentie om verantwoordelijkheid te nemen voor hun eigen leerproces, vergeleken met studenten uit de controleconditie. Er werden echter geen verschillen gevonden in academische verwachtingen of hun zelfgerapporteerd gebruik van leerstrategieën. Erwerden geen verschillen gevonden in effectiviteit van de workshop op basis van de scores op de voormeting van studenten.

In het laatste onderzoek (Hoofdstuk 5) onderzochten we de effecten van een curriculumhervorming binnen het Biomedische Wetenschappen bachelorprogramma van Maastricht University naar competentiegericht onderwijs, wat als belangrijkwordt gezien voor de ontwikkeling van 'lifelong learning skills'. Hiervoor werden twee cohorten studenten met elkaar vergeleken: het eerste cohort startte hun bachelor programma vóór de invoering van het nieuwe curriculum, en volgde hierdoor het gehele bachelorprogramma in het oude curriculum, en een tweede cohort dat hun studie startte na de invoering van het nieuwe curriculum. Aan het einde van elk van de drie jaren van het bachelorprogramma werd aan studenten gevraagd om vragenlijsten in te vullen betreffende hun zelf ervaren ontwikkeling van de academische competenties beoogd in het nieuwe curriculum, en hun zelfvertrouwen met betrekking tot het studeren van Biomedische Wetenschappen in het algemeen. Verder werden er focusgroepen georganiseerd om dieper inzicht te verkrijgen in de bevindingen uit de vragenlijsten. Uit de resultaten bleek dat hoewel de curriculumherziening een positief effect had op de zelf ervaren ontwikkeling van de academische competenties van studenten, er ook een tendens was in de richting van een lager zelfvertrouwen over het studeren van Biomedische Wetenschappen. Dit verschil verdween in het laatste jaar van het bachelorprogramma. Bevindingen uit de 
focusgroepen gaven inzicht in deze op het oog contrasterende resultaten. Studenten uit het nieuwe curriculum gaven in de focusgroepen namelijk aan dat het voor hen vaak onduidelijk was wat er met de specifieke competenties werd bedoeld. Studenten werden in het nieuwe curriculum dus in hoge mate geconfronteerd met de competenties die zij aan het einde van de bachelor dienden te beheersen, waarbij voor hen tegelijkertijd niet duidelijk was wat dit betekende voor hun leren. Deze combinatie kan ertoe hebben geleid dat studenten zich erg bewust werden van wat zij allemaal nog niet wisten en konden, en hiermee tot onzekerheid over hun capaciteiten.

Hoofdstuk 6 geeft een overkoepelende discussie over de onderzoeken uit dit proefschrift, waarbij theoretische en praktische overwegingen en implicaties worden behandeld, alsmede de methodologische overwegingen en limitaties van de onderzoeken. Er zal actie moeten worden ondernomen om onzekerheid in zowel studenten als docenten te verminderen. Om docenten hierin te ondersteunen, zijn veranderingen nodig in de manier waarop blokken geëvalueerd worden, en docenten moeten ondersteund worden in hoe zij de zelfregulatie van studenten het beste kunnen stimuleren. Verder moeten studenten ondersteund worden in hun informatievaardigheden, door onderwijs hierover te integreren in het curriculum. De algehele conclusie uit deze sectie is dat zelfregulatie-onderwijs moet worden geïntegreerd in het curriculum, om de onzekerheden die worden ervaren door zowel studenten als docenten te verminderen. Verder moeten er verschillende veranderingen worden doorgevoerd op organisatie- en onderwijskundig niveau, om studenten en docenten optimaal te kunnen ondersteunen in dit proces. 
APPENDIX 


\section{Valorization}

Through this dissertation, we have aimed to provide insight into how to support (bio) medical students' self-regulated learning (SRL) in a problem-based learning (PBL) curriculum. Research indicates that students often experience problems regarding the application of effective learning strategies for their studies (Kornell \& Bjork, 2007), which negatively impacts their academic performance and long-term retention of the subject matter (e.g., Rawson, Dunlosky, \& Sciartelli, 2013). As such, students need to be supported in their knowledge and use of effective learning strategies. This support does not only have a positive impact on students themselves, but can also have benefits for different groups of stakeholders such as educational institutes and patients. These benefits are outlined below.

\section{Students}

The most immediate group of beneficiaries consists of (bio)medical students themselves, for whom we have attempted to lay the foundation for the development and use of effective learning strategies. It is important for students to use appropriate strategies in order to optimize their academic performance and to retain their knowledge for their future work as health care professionals.

One of the recommendations following from this dissertation is that students should make explicit the perceptions and expectations they have about learning in (problem-based) higher education, and think critically about how their own expectations do or do not align with the expectations from their educational institute. Where possible, students should actively search for information about this, and adjust their expectations where necessary.

A second recommendation for students that follows from this dissertation, is that students should realize that the use of effective learning strategies costs effort. It is this effort, however, that makes the strategies effective for retaining knowledge for the long term. It might require a shift in mindset for students to realize and accept this reality, and proper support will be required. At Maastricht university, several of our colleagues are working on initiatives to provide this support, such as the Study Smart training provided to students in the first year of their bachelor program, which focuses on students' knowledge about and use of effective strategies and desirable difficulties while learning (Biwer, oude Egbrink, Aalten, \& de Bruin, in press). Interestingly, this initiative reaches further than the (bio)medical programs of the university, and has been implemented in programs such as Psychology and Law, underscoring the applicability of the results from this dissertation to students in other study programs as well. 


\section{Educational institutes}

From universities' perspectives, the results from this dissertation can be used to draw up guidelines for the development of a learning environment that will optimally support students' SRL development. Examples include the development of a curriculum that is conducive to the development of students' general academic competencies (such as competencies related to communication, organization and research), in which expectations about students' role in their own learning process are made explicit.

Further, it is recommended that universities take steps to relieve uncertainty about loss of control of the learning process in both students and teachers, and several suggestions for organizational changes and faculty development followed from this dissertation. These suggestions include changes to be made in the way that courses are evaluated, as well as faculty development aimed at educating teachers on how best to support students' SRL development. Furthermore, education on information literacy for students should be integrated throughout the curriculum.

It is important that universities make an effort to provide a learning environment fit for students' SRL development, in order to avoid an unnecessary financial burden associated with student dropout or study delays (Foo et al., 2018). Furthermore, health professions education programs have a responsibility to deliver competent health care professionals fit for practice (Lindgren \& Karle, 2011), which further underscores the need for enabling students to develop learning strategies that allow long-term retention of (medical) knowledge and skills.

One of the premises in this dissertation was that students' unrealistic expectations about their learning environment, might influence their willingness and ability to engage in SRL. As such, a fruitful basis for SRL could already be created in primary and secondary education, in order to properly preparestudents for learning in tertiary education. As such, recommendations apply not only to higher education institutions, but also extend to primary and secondary education. Specifically, primary and secondary education institutions should already include the development of SRL into their curricula, e.g. by teaching students information literacy skills, and by slowly granting them more control and responsibility over their own learning. In these settings as well, faculty development is required in order to properly support teachers in this role.

In the Netherlands, health professions education does not only take place on a university level. Health professionals (e.g., nurses, paramedics) are trained at the levels of senior vocational education and universities of applied sciences. These settings provide different degrees of autonomy for students to take control of their learning process, and as such afford different opportunities for students to develop their SRL skills. A recommendation for further research would be to investigate how the results found in the current study would be transferrable to education in these settings. 


\section{Lifelong learning and patient care}

As described above, educational institutes are responsible and accountable for delivering competent health care professionals, where the patients' and societal needs are properly addressed (Lindgren \& Karle, 2011). Results from this dissertation indicate that students are motivated by the prospect of becoming a competent health professional. First and perhaps most obviously, patients will benefit from a health professional who has retained his/her medical knowledge throughout the years and has acquired a deep understanding of the medical profession. However, as indicated at several points throughout this dissertation, learning does not stop at the end of the official curriculum, and students need to develop lifelong learning skills in order to keep up with a rapidly changing medical profession (Frankford, Patterson, \& Konrad, 2000; Murdoch-Eaton \& Whittle, 2012; Teunissen \& Dornan, 2008) in order to (continue) to be able to provide safe patient care. As the development of lifelong learning skills depends heavily on students' ability to self-regulate their learning (Skinner et al., 2015), the guidelines provided in this dissertation could provide the foundation for this lifelong learning, and ultimately for continuing safe patient care.

\section{Dissemination of results}

Throughout the course of the project, results from the different studies have been presented at both national and international conferences. Examples include conferences from the 'Nederlandse Vereniging voor Medisch Onderwijs' (Dutch association for medical education, NVMO), the European Association for Research on Learning and Instruction (EARLI), and the American Educational Research Association (AERA). Several of the studies have been published in international, peer-reviewed journals. Over the next period of time, we will direct our efforts towards dissemination of the results from the final study (Chapter 5), both by presentations at conferences and by publication of the results in a peer-reviewed journal.

Furthermore, results and implications from the research are shared with more general audiences, including teachers at various levels of education. In 2018, the Open University of the Netherlands organized a conference in trends in education aimed at teachers and researchers, at which the results from the study described in Chapter 2 were shared and discussed with teaching professionals and students. Finally, as described above, results from this dissertation provided a basis for follow-up initiatives by colleagues, such as the Study Smart initiative by Biwer et al. (in press), which will be implemented and shared by the respective researchers. 


\section{References}

Biwer, F., oude Egbrink, M.C.A., Aalten, P., \& de Bruin, A.B.H. (in press). Fostering effective learning strategies in higher education - a mixed-methods study. Journal of Applied Research in Memory and Cognition.

Foo, J., Ilic, D., Rivers, G., Evans, D. J. R., Walsh, K., Haines, T. P., ... \& Maloney, S. (2018). Using cost-analyses to inform health professions education-The economic cost of pre-clinical failure. Medical Teacher, 4O(12), 1221-1230.

Frankford, D. M., Patterson, M. A., \& Konrad, T. R. (2000). Transforming practice organizations to foster lifelong learning and commitment to medical professionalism. Academic Medicine, 75(7), 708-717.

Kornell, N., \& Bjork, R. A. (2007). The promise and perils of self-regulated study. Psychonomic Bulletin \& Review, 14, 219-224.

Lindgren, S., \& Karle, H. (2011). Social accountability of medical education: aspects on global accreditation. Medical Teacher, 33(8), 667-672.

Murdoch-Eaton, D., \& Whittle, S. (2012). Generic skills in medical education: developing the tools for successful lifelong learning. Medical Education, 46, 120-128.

Rawson, K. A., Dunlosky, J., \& Sciartelli, S. M. (2013). The power of successive relearning: Improving performance on course exams and long-term retention. Educational Psychology Review, 25(4), 523-548.

Skinner, D. E., Saylors, C. P., Boone, E. L., Rye, K. J., Berry, K. S., \& Kennedy, R. L. (2015). Becoming lifelong learners: A study in self-regulated learning. Journal of Allied Health, 44(3), 177-182.

Teunissen, P., \& Dornan, T. (2008). Lifelong learning at work. BM], 336(7645), 667-669 


\section{Acknowledgements}

Toen ik ruim vier jaar geleden aan dit promotietraject begon, had ik nog geen idee van wat me allemaal te wachten zou staan. Er waren hoogtepunten, dieptepunten, en ik heb enorm veel mogen leren van alle mensen met wie ik in deze periode in aanraking ben gekomen. Ik kan dan ook met recht zeggen dat dit proefschrift niet tot stand zou zijn gekomen zonder de hulp en ondersteuning van deze uitzonderlijke groep mensen, en ik maak graag van de gelegenheid gebruik om een aantal van hen in het bijzonder te bedanken. De lijst is ongetwijfeld onvolledig, maar hopelijk een goede weergave van mijn dankbaarheid voor alle steun in de afgelopen vier jaar.

Allereerst natuurlijk mijn promotoren: Anique, Jeroen en Hans. Door de jaren heen heb ik ontzettend veel van jullie mogen leren. Dit team was inhoudsdeskundig én interdisciplinair, wat leidde tot kritische vragen, interessante discussies en de nodige relativering. Wanneer de fut er soms een beetje uit was, kon ik er altijd op rekenen er na ons overleg weer vol energie tegenaan te kunnen.

Anique, jij hebt je iets later als dagelijks begeleider bij het promotieteam gevoegd. In eerste instantie als copromotor en later, na je welverdiende benoeming tot professor, als promotor. Ik heb me vaak verwonderd over hoe je altijd alle ballen in de lucht wist te houden. Hoe druk het soms ook was, ik kon altijd bij je aankloppen. Voor inhoudelijke vragen, of gewoon om even te spuien.

Jeroen, tijdens dit traject heb ik van jou alle ruimte en vrijheid gekregen om het onderzoek vorm te geven en mezelf breder te ontwikkelen. Tegelijkertijd kon ik altijd op je rekenen voor eerlijke, kritische feedback, waarbij je bovendien altijd oog bleef houden voor het grotere geheel. Dit altijd met een onverstoorbare mate van rust en relativeringsvermogen, waar ik meer aan heb gehad dan ik op dit moment in woorden uit kan drukken.

Hans, als biomedicus te midden van onderwijskundigen bood jij een fris perspectief in de discussies. Met een scherpe blik en oog voor detail, zorgde je ervoor dat ik kritisch bleef op het onderzoek en mijn keuzes kon onderbouwen. Deze vaardigheden zullen nog lang van pas komen. 
Geraldine. De eerste anderhalf jaar van mijn promotietraject heb jij als copromotor en dagelijks begeleider een belangrijke basis gelegd voor de rest van het proces. Ook al geloofde ik niet altijd in mezelf, jouw vertrouwen en enthousiasme maakte dat ruimschoots goed. Soms met de nodige Vlaams-Nederlandse spraakverwarring ("Sorry, maar wát moet ik met die kast doen?"), waar Anique dan gelukkig soms als vertaler kon optreden. Je was dapper genoeg om te onderkennen dat je passie niet in de universitaire wereld lag, en bent een lichtend voorbeeld van hoe mooi het kan zijn om je hart te volgen.

Our SRL lab. It has been really great to witness the development of a group of people with similar research interests within our department, and to see our lab gradually grow in size. Our bi-weekly meetings became something to look forward to, both for having in-depth discussions with like-minded researchers, as well as for our off-topic chats about everything and nothing. Felicitas, Luotong, Lucy, Jonas, Karol, Erdem, Héctor and Wisnu, thank you for all your input, constructive criticism, and unwavering enthusiasm.

Sanne S. Vanaf de allereerste dag had ik in jou een bondgenoot gevonden. Zowel voor inhoudelijke als persoonlijke zaken kon ik altijd bij je terecht. Je adviezen zijn soms pijnlijk eerlijk (je maakte zelfal eens de vergelijking met Thor's hamer), maar dat maaktje vriendschap juist zo waardevol. Ook buiten het werk hebben we veel mooie dingen mogen meemaken, en ik hoop dat we dit in de toekomst nog lang mogen voortzetten.

Dat brengt me bij de rest van de kamer: Carolin, Koos, Andrea en Lorette. Meteen vanaf het begin voelde ik me welkom. Met een prettige combinatie van humor en hard werken, was dit voor mij een ideale omgeving.

Zo'n twee jaar later volgde er een verhuizing: de Kamer 2.o. Jolien, Sanne, Derk, Georg, Fatemeh, Guusje and Erdem, thank you for all the conversations, laughter and discussions we had.

A big thanks also to all my fellow PhD students in the department, past and present. Lianne, Juliët, Stephanie, Joy, Serge, HQ, Guy, Tiuri, Emmaline, Maarten, Suzanne, Cindy, Samantha, Anique, Michelle, thank you for making our department such a nice place to work in. From PhD platform meetings to vastelaovend, and everything in between.

Dank ook aan de Taakgroep Onderwijsontwerp en E-Learning: Peter, Maryam, Jeroen Donkers, Daniëlle, Geraldine en Jan. Hoewel er door de jaren heen wat wisselingen hebben plaatsgevonden in de samenstelling (en niet te vergeten de naam), waren jullie altijd een basis om op terug te vallen. Speciale dank ook aan Jan, voor je praktische en mentale steun door de jaren heen. Je was altijd bereid om te helpen met werving, dataverzameling, en voor advies 
over de meest uiteenlopende onderwerpen. "Als het niet gaat zoals het moet, dan moet het maar zoals het gaat".

En dan mijn nieuwe taakgroep: Toetsing. Bedankt voor het vertrouwen dat jullie me hebben gegeven. Ik heb enorm veel zin om deze nieuwe uitdaging aan te gaan. Suzanne, bedankt voor alle ondersteuning en je geduld terwijl ik wegwijs probeer te worden. Marjan, bedankt voor de ruimte die je me hebt gegeven om mijn weg te vinden, en dat je me hebt welkom geheten als kamergenoot. Het is fijn om af en toe wat informeler met iemand van gedachten te kunnen wisselen. Cees, bedankt voor je kritische vragen en inzichten tijdens de taakgroepoverleggen. Jeroen, na al eerder te hebben samengewerkt bij de Taakgroep Onderwijsontwerp en E-Learning, komen we elkaar hier nu weer tegen. Bedankt voor je inzichten in de meer statistische onderdelen van deze functie. Christel en Herman, het is prettig om ervaringen te kunnen uitwisselen tussen de verschillende domeinen. Ik zie uit naar onze verdere samenwerking.

Renée. Jij hebt me wegwijs gemaakt in de wondere wereld van het kwalitatieve onderzoek. Ik had me geen betere introductie kunnen wensen. Naast je inhoudelijke kennis, stond je waar nodig ook klaar met advies, bemoedigende woorden of een luisterend oor.

Voor de analyses van mijn onderzoek heb ik door de jaren heen van verschillende mensen ondersteuning gekregen. Arno, Carlos en Jeroen Donkers hebben hun licht laten schijnen over het kwantitatieve deel, en bij Janneke en Renée kon ik terecht voor kwalitatieve ondersteuning. Jullie expertise was van onschatbare waarde. Bedankt voor jullie geduld en inzicht.

Secretariaat O\&O. Lilian, Nicky, Audrey, Hennie en Ryan, bedankt voor alle ondersteuning door de jaren heen. Jullie begaanheid met de afdeling is hartverwarmend.

My colleagues in the UM Sports spinning team, past and present. Ruud, bedankt dat je me de kans hebt gegeven om bij jullie aan de slag te gaan. Je hebt me de mogelijkheid gegeven om mijn grenzen te verleggen en vaardigheden te ontwikkelen waarvan ik niet eens wist dat ik ze had. Cina, Sophia, Rosa, Elisabeth, Stephanie R., Stephanie C., Nadine, Noortje, Malin, Theresa, Tom, Jos, Armand, Sandra and Anneke, the dedication and enthusiasm in this team are truly inspirational, and I feel very lucky to be a part of it.

My fellow improv people. Oh, the fun we had! Thank you for all the crazy, inspiring, creative evenings. You picked me up when I was at my lowest, going for bike rides in the pouring rain, having ice cream (with sprinkles!), also in the pouring rain, always with zero judgment. Stay awesome! 
Die Abteilung für Pädagogische und Entwicklungspsychologie der Albert-Ludwigs-Universität Freiburg. Alexander and Tino, thank you for giving me the opportunity to do research in your wonderful department, and for your help and support while drafting the proposal and collecting the data. Susanne, thank you for your help with the workshops. The study would not have been the same without you. Nina, Monika, Julius, Lisa, Julia and Katharina, thank you for the warm welcome and hospitality during my stay. You truly made me feel like a part of your group, and I look back on this period with warm feelings. Corinne, vielen Dank für die Hilfe bei den administrativen Aspekten dieser Studie.

Daphne, we zijn beide ver gekomen sinds we samen bij de Albert Heijn achter de kassa zaten. Ik ben blij dat we na al die jaren nog steeds contact hebben. Jouw nuchtere kijk op de wereld laat me dingen vaak nét een beetje anders zien, en onze lunches, brunches, vuurwerkshows en wijnroutes zijn altijd iets om naar uit te kijken.

Chris, door de jaren heen hebben we altijd op elkaar kunnen rekenen. Onze interacties variëren van diepgaande gesprekken tot eindeloze aaneenschakelingen van zinloze gifjes, en ik hoop dat we dit nog lang mogen voortzetten.

Lianne, ik kon bij jou altijd binnenlopen, voor inhoudelijke zaken of om gewoon even te kletsen. Bedankt voor de gezelligheid en goede gesprekken, tijdens de lunch, op de fiets, tijdens congressen, of onder het genot van een goede kop koffie.

Iris, jij bent altijd in voor gezelligheid en een feestje. Hoewel je er inmiddels natuurlijk wat burgerlijkheidspunten hebt bijgekregen, hoop ik dat we in de toekomst nog af en toe samen stoom kunnen afblazen.

Ellen, toen ik aan mijn PhD begon was jij één van mijn grote voorbeelden binnen de universiteit. Inmiddels heb je je plekje gevonden in Utrecht, maar ik ben blij dat we elkaarvan tijd tot tijd nog spreken en hoop dat we dat in de toekomst kunnen voortzetten.

Oma. Je bent een inspiratie voor velen. Met je 95 jaar facebook, whatsapp en wordfeud je er lustig op los. We kunnen altijd bij je terecht, voor van alles en nog wat. Ik ben ontzettend trots op wat je allemaal hebt bereikt, en ben heel blij dat we dit samen mogen meemaken.

Pap, mam en Bas. Het klinkt misschien als een cliché, maar ik zou niet zijn waar ik nu ben zonder jullie. De warmte en liefde uit ons gezin hebben me een basis gegeven waar ik de rest van mijn leven op kan bouwen. En ook al is Maastricht voor jullie niet om de hoek, hebben jullie de afgelopen vier jaar van het meest dichtbij meegemaakt. Lief en lee, door dik en dun. Ik kan jullie niet genoeg bedanken. Susanne, ik ben blij dat jij nu ook deel uitmaakt van deze familie. Ik hoop dat we met z'n zessen nog heel veel mooie jaren tegemoet gaan.

Bruce, Lori, Dustin and Danielle. Thank you for welcoming me as part of your family. I know the distance can be challenging sometimes, but we can feel your love from across the ocean. 
Dixon. When we first met, I had no idea what life had in store for us. Although I still don't know what I did to deserve someone like you, I am very happy to have you in my life. You keep me on my toes and on my feet at the same time, patiently navigating through the chaos that can be in my head sometimes. I love you, and I'm looking forward to many more wonderful years together. 


\section{About the author}

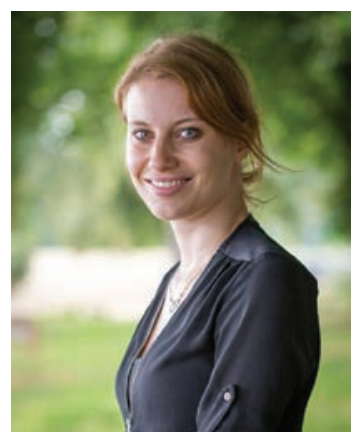

Sanne Francisca Else Rovers was born in Vlaardingen on July $6^{\text {th }}$, 1991. After having become fascinated by the human mind and its development, she decided to study Psychology, and obtained her bachelor's degree from Leiden University in 2013. In 2015, she obtained her research master's degree from Leiden University, specializing in developmental psychology. She started her PhD project at Maastricht University's School of Health Professions Education in November 2015. She is currently working for the Assessment Taskforce of this School. 


\section{SHE dissertation series}

The SHE Dissertation Series publishes dissertations of PhD candidates from the School of Health Professions Education (SHE) who defended their PhD theses at Maastricht University. The most recent ones are listed below.

For more information go to: https://she.mumc.maastrichtuniversity.nl

- Giuliani, M. (19-05-2020) A Critical Review of Global Curriculum Development, Content and Implementation in Oncology

- Schreurs, S. (20-03-2020) Selection for medical school; the quest for validity

- Schumacher, D. (19-03-2020) Resident Sensitive Quality Measures: Defining the Future of Patient-Focused Assessment

- Sehlbach, C. (21-02-2020) To be continued... Supporting physicians' lifelong learning

- Kikukawa, M. (17-12-2019) The situated nature of validity: Exploring the cultural dependency of evaluating clinical teachers in Japan

- Kelly, M. (10-12-2019) Body of knowledge. An interpretive inquiry into touch in medical education

- Klein, D. (06-11-2019) The performance of medical record review as an instrument for measuring and improving patient safety

- Bollen, ]. (01-11-2019) Organ donation after euthanasia: medical, legal and ethical considerations

- Wagner-Menghin, M. (25-09-2019) Self-regulated learning of history-taking: looking for predictive cues

- Wilby, K. (02-07-2019) When numbers become words: Assessors' processing of performance data within OSCES

- Szulewski, A. (20-06-2019) Through the eyes of the physician: Expertise development in resuscitation medicine

- McGill, D. (29-05-2019) Supervisor competence as an assessor of medical trainees; Evaluating the validity and quality of supervisor assessments

- Van Rossum, T. (28-02-2019) Walking the tightrope of training and clinical service; The implementation of time variable medical training

- Amalba, A. (20-12-2018) Influences of problem-based learning combined with community-based education and service as an integral part of the undergraduate curriculum on specialty and rural workplace choices

- Melo, B. (12-12-2018) Simulation Design Matters; Improving Obstetrics Training Outcomes

- Olmos-Vega, F. (07-12-2018) Workplace Learning through Interaction: using socio-cultural theory to study residency training 
- Chew, K. (06-12-2018) Evaluation of a metacognitive mnemonic to mitigate cognitive errors

- Sukhera, J. (29-11-2018) Bias in the Mirror. Exploring Implicit Bias in Health Professions Education

- Mogre, V. (07-11-2018) Nutrition care and its education: medical students' and doctors' perspectives

- Ramani, S. (31-10-2018) Swinging the pendulum from recipes to relationships: enhancing impact of feedback through transformation of institutional culture

- Winslade N. (23-10-2018) Community Pharmacists' quality-of-care metrics. A prescription for improvement

- Eppich, W. (10-10-2018) Learning through Talk: The Role of Discourse in Medical Education

- Wenrich, M. (12-09-2018) Guided Bedside Teaching for Early Learners: Benefits and Impact for Students and Clinical Teachers

- Marei, H. (07-09-2018) Application of Virtual Patients in Undergraduate Dental Education

- Waterval, D. (26-04-2018) Copy but not paste, an exploration of crossborder medical curriculum partnerships

- Smirnova, A. (04-04-2018) Unpacking quality in residency training and health care delivery 


\section{ICO dissertation series}

In the ICO Dissertation Series dissertations are published of graduate students from faculties and institutes on educational research within the ICO Partner Universities: Eindhoven University of Technology, Leiden University, Maastricht University, Open University of the Netherlands, Radboud University Nijmegen, University of Amsterdam, University of Antwerp, University of Chent, University of Croningen, University of Twente, Utrecht University, Vrije Universiteit Amsterdam, and Wageningen University, and formerly Tilburg University (until 2002). The University of Groningen, and the Erasmus University Rotterdam have been 'ICO 'Network partner' in 2010 and 2011. From 2012 onwards, these ICO Network partners are full ICO partners, and from that period their dissertations will be added to this dissertation series.

\section{List update February 4, 2020 (the list will be updated every year in January)}

304. Bouwmans, M.H.C.F. (12-01-2018) The role of VET colleges in stimulating teachers' engagement in team learning. Wageningen: Wageningen University.

305. Jansma, D.]. (25-01-2018) This is wrong, right? The role of moral components in anti-and prosocial behaviour in primary education. Groningen: University of Croningen.

306. Okkinga, M. (O2-02-2018) Teaching reading strategies in classrooms-does it work? Enschede: University of Twente.

307. Thomsen, M. (09-02-2018) Teachers Trust. Measurement, sources and consequences of teacher's interpersonal trust within schools for vocational education and training. Amsterdam: University of Amsterdam.

308. Van der Wurff, I.S.M. (09-02-2018) Fatty acids, Cognition, School Performance and Mental Well-Being in Children and Adolescents. Heerlen: Open University of the Netherlands.

309. Raaijmakers, S.F. (16-02-2018) Improving self-regulated learning: Effects oftraining and feedback on self-assessment and task-selection accuracy. Utrecht: Utrecht University.

310. Zhao, X. (07-03-2018) Classroom assessment in Chinese primary school mathematics education. Utrecht: Utrecht University.

311. Van Rooij, E.C.M. (15-03-2018) Secondary school students' university readiness and their transition to university. Groningen: University of Groningen.

312. Vanlommel, K. (26-03-2018) Opening the black box of teacher judgement: the interplay of rational and intuitive processes. Antwerp: University of Antwerp.

313. Boevé, A.J. (14-05-2018), Implementing Assessment Innovations in Higher Education. Groningen: University of Groningen. 
314. Wijsman, L.A. (30-05-2018) Enhancing Performance and Motivation in Lower Secondary Education. Leiden: Leiden University.

315. Vereijken, M.W.C. (22-05-2018) Student engagement in research in medical education. Leiden: Leiden University.

316. Stollman, S.H.M. (23-05-2018) Differentiated instruction in practice: A teacher perspective. Leiden: Leiden University.

317. Faddar, ]. (11-06-2018) School self-evaluation: self-perception or self-deception? Studies on the validity of school self-evaluation results. Antwerp: University of Antwerp.

318. Ceeraerts, K. (25-06-2018) Dood hout of onaangeboorde expertise? Intergenerationale kennisstromen in schoolteams. Antwerp: University of Antwerp.

319. Day, I.N.Z. (28-06-2018), Intermediate assessment in higher education (Leiden: Leiden University)

320. Huisman, B.A. (12-09-2018) Peer feedback on academic writing. Leiden: Leiden University.

321. Van Berg, M. (17-09-2018) Classroom Formative Assessment. A quest for a practice that enhances students' mathematics performance. Groningen: University of Groningen.

322. Tran, T.T.Q. (19-09-2018) Cultural differences in Vietnam: differences in work-related values between Western and Vietnamese culture and cultural awareness at higher education. Leiden: Leiden University

323. Boelens, R. (27-09-2018) Studying blended learning designs for hands-on adult learners. Chent: Chent University.

324. Van Laer, S. (4-10-2018) Supporting learners in control: investigating self-regulated learning in blended learning environments. Leuven: KU Leuven.

325. Van der Wilt, F.M. (08-10-18) Being rejected. Amsterdam: Vrije Universiteit Amsterdam.

326. Van Riesen, S.A.N. (26-10-2018) Inquiring the effect of the experiment design tool: whose boat does it float? Enschede: University of Twente.

327. Walhout, J.H. (26-10-2018) Learning to organize digital information Heerlen: Open University of the Netherlands.

328. Gresnigt, R. (08-11-2018) Integrated curricula: An approach to strengthen Science \& Technology in primaryeducation. Eindhoven: Eindhoven University of Technology.

329. De Vetten, A.]. (21-11-2018) From sample to population. Amsterdam: Vrije Universiteit Amsterdam.

330. Nederhand M.L. (22-11-2018) Improving Calibration Accuracy Through Performance Feedback. Rotterdam: Erasmus University Rotterdam.

331. Kippers, W.B. (28-11-2018) Formative data use in schools. Unraveling the process. Enschede: University of Twente.

332. Fix, G.M. (20-12-2018) The football stadium as classroom. Exploring a program for at-riskstudents in secondary vocational education. Enschede: University of Twente.

333. Cast, I. (13-12-2018) Team-Based Professional Development - Possibilities and challenges of collaborative curriculum design in higher education. Enschede: University of Twente. 
334. Wijnen, M. (01-02-2019) Introduction of problem-based learning at the Erasmus School of Law: Influences on study processes and outcomes. Rotterdam: Erasmus University Rotterdam

335. Dobbelaer, M.]. (22-02-2019) The quality and qualities of classroom observation systems. Enschede: University of Twente

336. Van der Meulen, A.N. (28-02-2019) Social cognition of children and young adults in context. Amsterdam: Vrije Universiteit Amsterdam

337. Schep, M. (06-03-2019) Guidance for guiding. Professionalization of guides in museums of art and history. Amsterdam: University of Amsterdam

338. Jonker, H.M. (09-04-2019) Teachers' perceptions of the collaborative design and implementation offlexibility in a blended curriculum. Amsterdam: University of Amsterdam

339. Wanders, F. H. K. (03-05-2019). The contribution of schools to societal participation of young adults: The role of teachers, parents, and friends in stimulating societal interest and societal involvement during adolescence. Amsterdam: University of Amsterdam

340. Schrijvers, M.S.T. (03-05-2019) The story, the self, the other. Developing insight into human nature in the literature classroom. Amsterdam: University of Amsterdam

341. Degrande, T. (08-05-2019) To add or to multiply? An investigation of children's preference for additive or multiplicative relations. Leuven: KU Leuven.

342. Filius, R.M. (23-05-2019) Peer feedback to promote deep learning in online education. Unravelling the process. Utrecht: Utrecht University

343. Woldman, N. (24-05-2019) Competence development of temporary agency workers. Wageningen: Wageningen University

344. Donszelman, S. (06-06-2019) Doeltaal-leertaal didactiek, professionalisering en leereffecten. Amsterdam: Vrije Universiteit Amsterdam

345. Van Oeveren, C.D.P. (12-06-2019) ITHAKA gafje de reis. Amsterdam: Vrije Universiteit Amsterdam

346. Agricola, B.T. (21-06-2019) Who's in control? Finding balance in student-teacher interactions. Utrecht: Utrecht University

347. Cuyvers, K. (28-08-2019), Unravelling medical specialists self-regulated learning in the clinical environment. Antwerp: University of Antwerp

348. Vossen, T.E. (04-09-2019) Research and design in STEM education. Leiden: Leiden University

349. Van Kampen, E. (05-09-2019) What's CLILabout bilingual education? Leiden: Leiden University

350. Henderikx, M.A. (06-09-2019) Mind the Gap: Unravelling learner success and behaviour in Massive Open Online Courses. Heerlen: Open University of the Netherlands

351. Liu, M. (13-09-2019) Exploring culture-related values in Chinese student teachers' professional self-understanding and teaching experiences. Utrecht: Utrecht University

352. Sun, X. (13-09-2019) Teacher-student interpersonal relationships in Chinese secondary education classrooms. Utrecht: Utrecht University

353. Wu, Q. (02-10-2019) Making Construct-Irrelevant Variance Relevant: Modelling item position effects and response behaviors on multiple-choice tests. Leuven: KU Leuven 
354. Jansen, R.S. (11-10-2019) Dealing with autonomy: Self-regulated learning in open online education. Utrecht: Utrecht University

355. Van Cinkel, S.O. (23-10-2019) Fostering oral presentation competence in higher education. Wageningen: Wageningen University

356. Van der Zanden, P. (05-11-2019) First-year student success at university: Domains, predictors, and preperation in secondary education. Nijmegen: Radboud University Nijmegen

357. De Bruijn, A.C.M. (14-11-2019) The brain in motion: Effects of different types of physical activity on primary school children's academic achievement and brain activation. Groningen: University of Groningen

358. Hopster-Den Otter, D. (28-11-2019) Formative assessment design: A balancing act. Enschede: University of Twente

359. Harmsen, R. (10-12-2019) Let's talk about stress. Beginning secondary school teachers' stress in the context of induction programmes. Groningen: University of Groningen

360. Post, T. (11-12-2019) Fostering inquiry-based pedagogy in primary school: a longitudinal study into the effects of a two-year school improvement project. Enschede: University of Twente

361. Ackermans, K. (20-12-2019) Designing Video-Enhanced Rubrics to Master Complex Skills. Heerlen: Open University of the Netherlands 


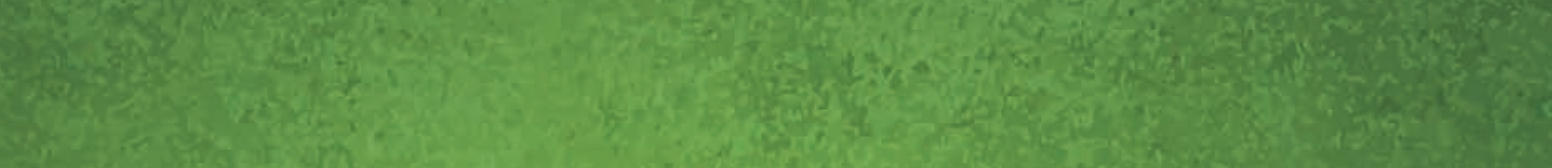

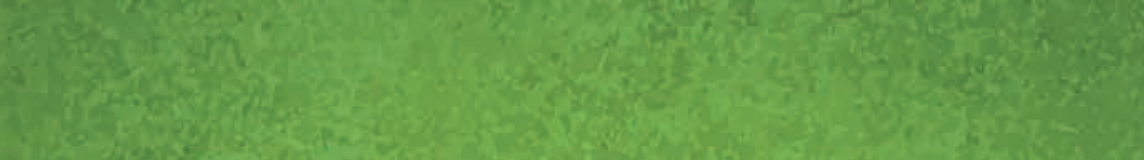

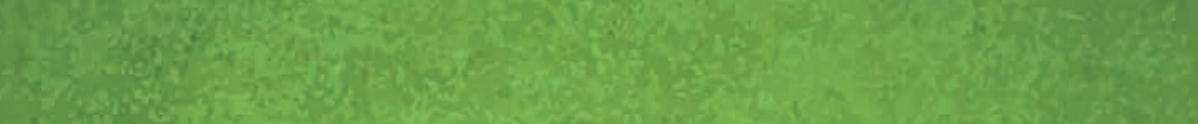

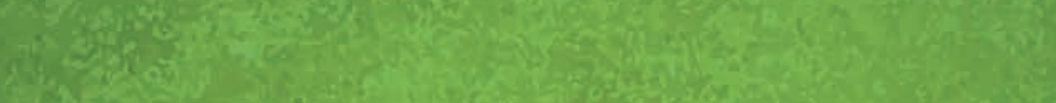
N.

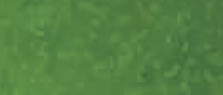

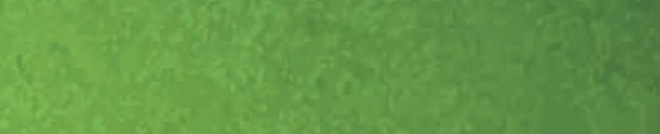

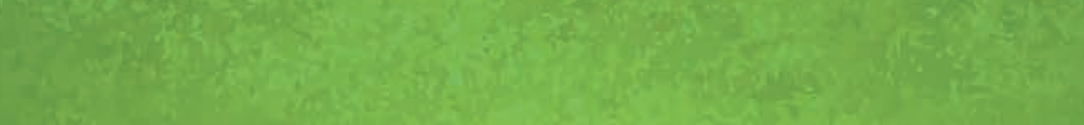

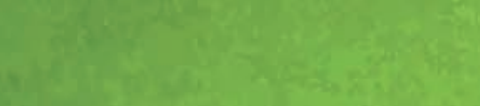

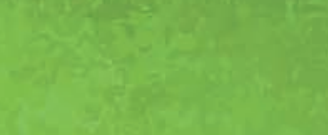


20.

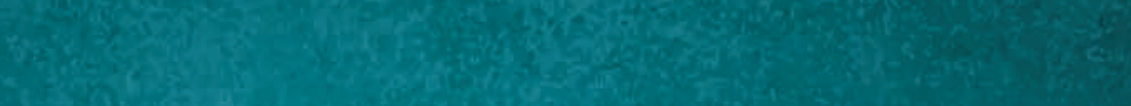

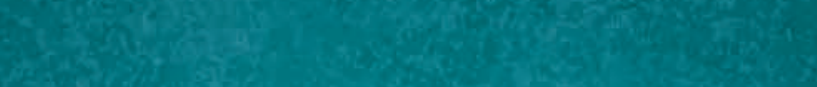

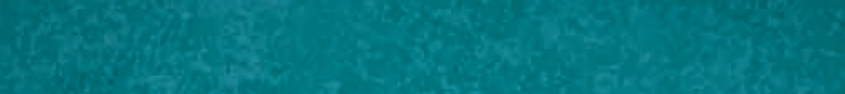

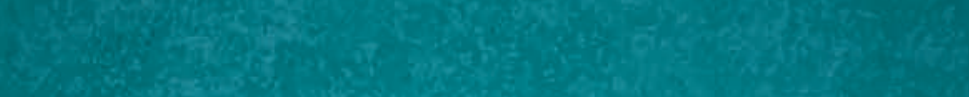

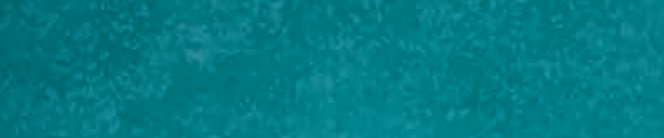

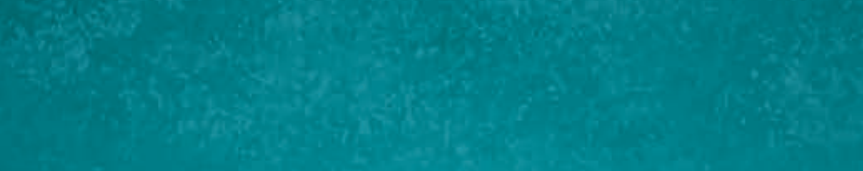

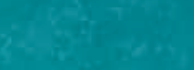

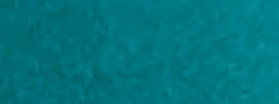

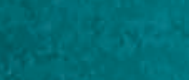

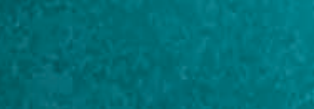

s.

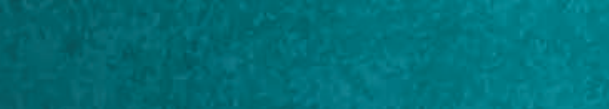

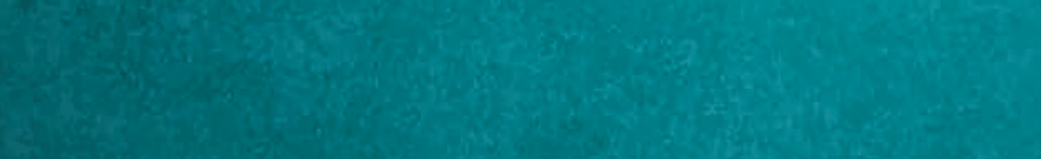

8

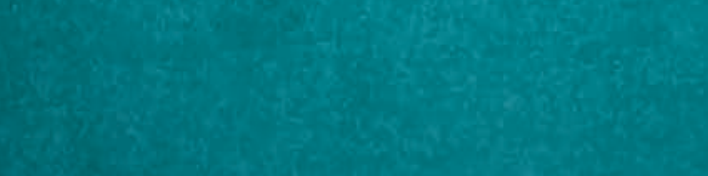

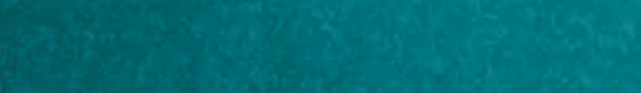

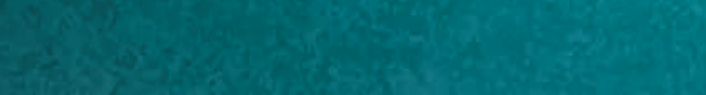

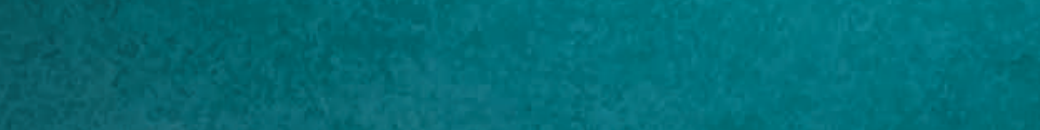
hes a

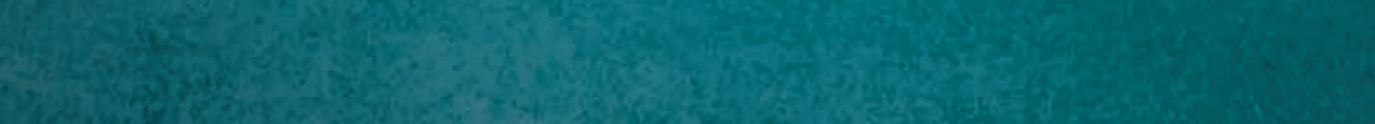

